\title{
QATAR UNIVERSITY
}

COLLEGE OF ARTS AND SCIENCES

DYNAMICS (SEASONAL AND INTRA-DIURNAL) OF AIR-BORNE FUNGAL SPORE POPULATION OF DOHA AREA, QATAR

\section{BY}

RAGHDAA KAMAL FAYAD

A Thesis Submitted to the Faculty of

College of Arts and Sciences

in Partial Fulfillment

of the Requirements

for the Degree of

Master of Science in

Environmental Sciences

June 2016

(c) 2016 Raghdaa Kamal Fayad. All Rights Reserved. 


\section{COMMITTEE PAGE}

The members of the Committee approve the thesis of Rghdaa Kamal Fayad defended on $26 / 5 / 2016$

Dr. Mohammed H. Abu-Dieyeh
Thesis/Dissertation Supervisor
Dr. Roda Fahad Jassim Al-Thani
Committee Member
Dr. Fatima Ammar J Al-Naemi
Committee Member
Prof. Khaled Husein Abu-Elteen
External Examiner

Approved:

Dr. Eiman Mustafawi, Dean, College of Arts and Sciences 


\begin{abstract}
Airborne fungi are considered to cause adverse health impacts on humans, animals and plants. Fungal spores and due to their volume in the atmosphere and small size have an important contribution to the respiratory dysfunctions, allergies and to cause various symptoms range from asthma, allergic rhinitis to bronchitis. The availability and dynamics of airborne fungal spores in the atmosphere are strongly influenced by the meteorological parameters and by other factors such as air pollutants. From 106 settle plate exposures (on alternative days) throughout the period April 2015-March 2016, a total of 1197 mould- and 283 yeast colony-forming units (CFU), twenty one genera and 62 species were retrieved. The highest fungal spore's concentration was recorded in February 2016, whereas the lowest concentration occurred in August 2015. The main constituents of the fungal airspora were attributed to Cladosporium (60.2\%), Aspergillus (10.4\%), Fusarium (9.4\%), Alternaria (8.5\%), and Ganoderma spp. (2.3 \%). Cladosporium showed two peaks in April and February, while Fusarium and Alteranria peaked in July. Aspirgillus had one peak in August. The prevalence of Ganoderma spp. were exclusively detected in February and March.

Temperature was significantly and negatively correlated with the total colony count and fungal species, however no significant correlation was found between relative humidity and both the total colony count and fungal species. Wind speed was significantly and positively correlated with the total colony count and fungal species. However, no significant correlation was detected between wind direction and the incidence of fungal airspora. The correlation between rainfall and either total colony
\end{abstract}


count or fungal species was non-significant. However, Alternaria was significantly and positively correlated with precipitation. Intra-diurnal fluctuations of fungal spores was investigated during the period of $1^{\text {st }}$ of Feb $-31^{\text {st }}$ of March 2016. The highest dispersal of fungal spores favored 18:00 h, whereas at 00:00 h (midnight) the lowest fungal spores release was recorded. The mean daily colony count was negatively correlated with mean daily relative humidity and positively correlated with mean daily temperature. The potentiality of fungal growth on different media on two different culture media, Potato Dextrose Agar (PDA) and Rose Bengal were examined during $1^{\text {st }}$ of Feb - 31 ${ }^{\text {st }}$ of March 2016 using gravimetric method. No significant difference was observed in total number of fungal colonies or species collected with the two media. Nevertheless, certain fungal taxa were highly selective and thus their growth rate was on one media much higher than with another.

The impact of atmospheric $\mathrm{CO}_{2}$ concentration on the abundance and diversity of airborne fungal spores were investigated at two different locations. There were no significant differences in the composition and diversity of the airborne fungal population between the two study sites, though daily concentration of $\mathrm{CO}_{2}$ was higher at the Industrial area site than at Qatar University Campus. Remarkably, the concentrations of Alternaria spp. and Fusarium spp. were significantly higher at Industrial area site in Corresponding to $\mathrm{CO}_{2}$ than at Qatar University site 


\section{Table of Contents}

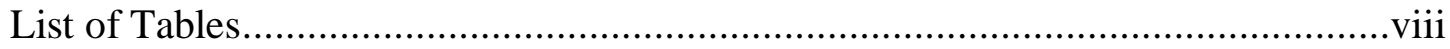

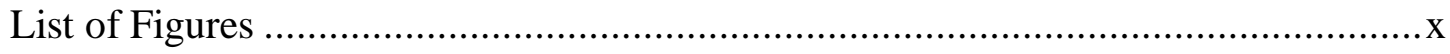

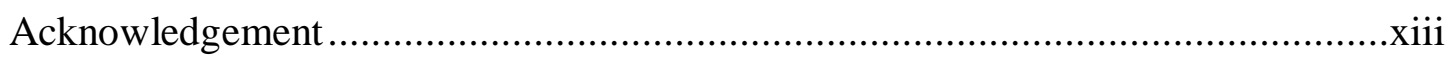

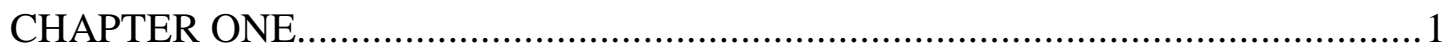

INTRODUCTION

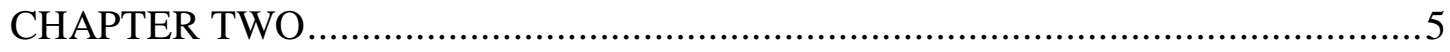

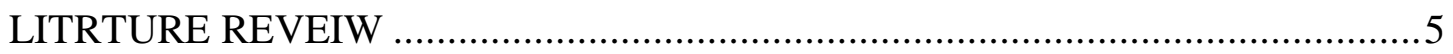

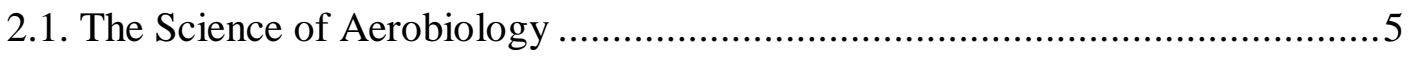

2.2. Airborne fungal spores and allergy ……..................................................

2.3. Factors affecting availability and survivability of airborne fungi: ..................11

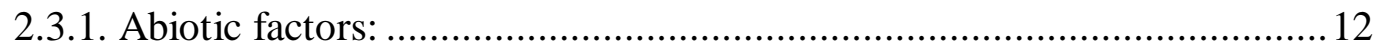

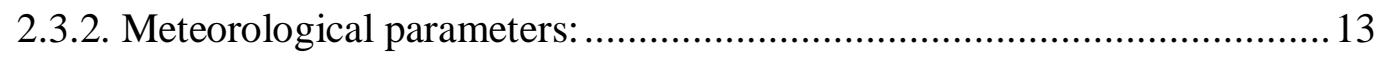

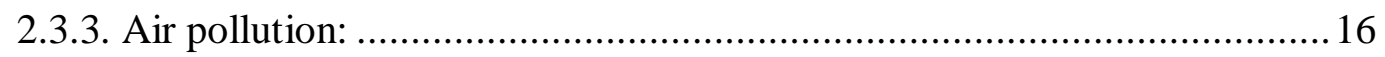

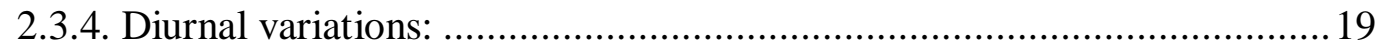

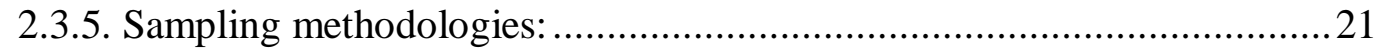

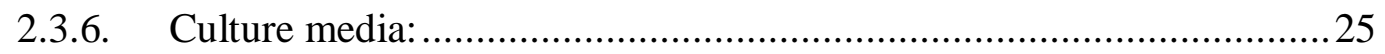

2.4. Worldwide relevant aeromycological studies .............................................2

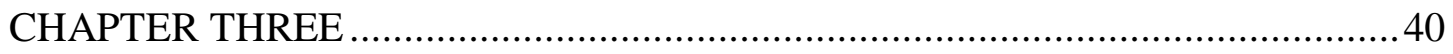


3.1. Study site 40

3.2. Seasonal variations in air-borne fungal populations in Doha city 41

3.3. Intra-diurnal variations in air-borne fungal populations in Doha city

3.4. Effect of culture media used in sampling on species composition and abundance of fungal spore populations

3.5. Effect of urbanization and $\mathrm{CO}_{2}$ concentration on species composition and abundance of fungal spore populations

3.6. Statistical and data analysis 45

CHAPTER FOUR 46

RESULTS .46

4.1. Seasonal variation of fungal spore populations in the atmosphere of Doha ....46

4.2. Diurnal variation of fungal spore populations in the atmosphere of Doha ......58

4.3. Investigating the importance of culture media on recovery of fungal diversity and abundance

4.4. The impact of atmospheric status ( $\mathrm{CO} 2$ concentration) on the dynamics of airborne fungi

CHAPTER FIVE .78

DISCUSSION .78 
5.1. Seasonal variations of fungal spore populations in the atmosphere of Doha...78

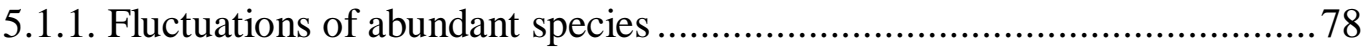

5.1.2. Fungal species fluctuation versus climatic factor .............................. 83

5.2. Diurnal variation of fungal spore populations in the atmosphere of Doha ......90

5.3. Investigating the importance of culture media on recovery of fungal diversity and abundance

CONCLUSIONS \& RECOMENDATIONS

REFERENCES

Appendix B: Samples of pictures for selected fungal spores on slides which photographed under light microscope using the 40X objective lens. 


\section{List of Tables}

Table 1. Total colony count and occurrence of airborne fungi recovered from the air of Doha Qatar. .......................

Table 2. Monthly climatic parameters of Doha during the year of study versus results of correlation analysis.

Table 3. Diurnal variation of fungal species richness and abundance of air-borne fungi in the atmosphere of Doha, Qatar..

Table 4. Diurnal variation of species richness and abundance of air-borne fungi in the atmosphere of Doha, Qatar, in respect to variation in temperature and relative humidity..................

Table 5. Similarity table among different diurnal times in respect to fungal species encountered from 72 exposure samplings in the atmosphere of Doha, Qatar.

Table 6. Total number of colonies and fungal species retrieved from the two culture media during the study period ( $1^{\text {st }}$ of Feb $31^{\text {st }}$ of March 2016) using gravimetric method (a total of

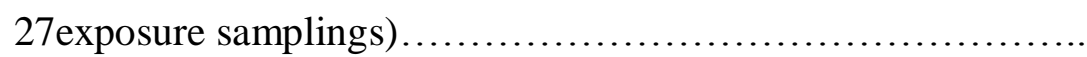


Table 7. Total number of colonies and fungal species retrieved from the two study sites during the study period $\left(1^{\text {st }}\right.$ of Feb $-31^{\text {st }}$ of March 2016) using gravimetric method (a total of 22exposure

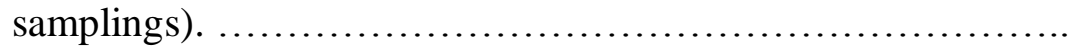




\section{List of Figures}

Figure 1. The composition of fungal constituents (\%) in the atmosphere of Doha City during ( $1^{\text {st }}$ of Apr $2015-31^{\text {st }}$ of March 2016) using gravimetric method (a total of 106 exposure samplings).

Figure 2. Temperature and wind speed (upper graph) versus total colony count and total number of species (lower graph) recovered each month during the year of study $\left(1^{\text {st }}\right.$ of Apr $2015-31^{\text {st }}$ of March 2016) using gravimetric method (a total of 106 exposure samplings). (n)

Figure 3. Seasonal variation of the four most common fungal genera in the atmosphere of Doha during the year of study $\left(1^{\text {st }}\right.$ of Apr $2015-31^{\text {st }}$ of March 2016) using gravimetric method (a total of 106 exposure samplings).

Figure 4. Fungal spore calendar for air-borne fungi in the atmosphere of Doha. The values are based on the average daily colony count of each fungal taxa recovered on PDA culture plates. 
Figure 5. Variations in daily fungal colony counts in respect to changes in mean daily temperature and mean daily relative humidity.

Figure 6. Diurnal variations in total fungal colony counts of the most common species in the atmosphere of Doha during the period $\left(1^{\text {st }}\right.$ of Feb - $31^{\text {st }}$ of March 2016). A total of 72 exposure samplings.

Figure 7. Total number of fungal colonies collected at each sampling event during the study period ( $1^{\text {st }}$ of Feb - $31^{\text {st }}$ of March 2016) in each of the two culture media used.

68

Figure 8. Total number of fungal species collected at each sampling event during the study period ( $1^{\text {st }}$ of Feb - $31^{\text {st }}$ of March 2016) in each of the two culture media used.

Figure 9. Total number of fungal colonies grown from the most common encountered genera during the study period $\left(1^{\text {st }}\right.$ of Feb $-31^{\text {st }}$ of March 2016) in each of the two culture media using gravimetric method (a total of 27exposure samplings) 
Figure 10. Box plot represents the daily concentration of $\mathrm{CO}_{2}$ recorded in each of the two study sites during the period of $\left(1^{\text {st }} \mathrm{Feb}-31 \mathrm{Mar}\right.$ 2016). The dotted lines refer to mean daily count. The blacked circles represent the outlier values. .............................

Figure 11. Fungal taxa that shown significant abundance differences between the two study sites (according to t- test of daily colony count at $P=0.05)$ during the period of $\left(1^{\text {st }} \mathrm{Feb}-31\right.$ Mar 2016) with a total of 22 exposure samplings.

Figure 12. Pie graph to show the main constituents of fungal genera and their relative abundances in the atmosphere of the two study sites during the period of $\left(1^{\text {st }} \mathrm{Feb}-31\right.$ Mar 2016) with a total of 22 exposure samplings 


\section{Acknowledgement}

My deep gratitude goes first to Dr. Mohammed Abu-Dieyeh who expertly guided me through my graduate education and who shared the excitement of one year of discovery. His unwavering enthusiasm for aeromycology kept me constantly engaged with my research. I would like to express my gratitude to my committee members Dr. Fatima Ammar Al-Naemi and Dr. Roda Fahad Jassim M Al-Thani for their kindness and encouraging and scientific advices. My appreciation also extends to the Ms. Abeer Al-Mohannadi, a lab technician, for her kindness and unlimited help. I am grateful for the financial support provided by Academic Research Office at Qatar University. I also want to express my great thanks to The Civil Aviation Authority, Meteorology Department, Qatar and particularly to Mr. Abdulrahman Saleh M Al-Ansari, The Acting Head of Climate Section for providing the necessary weather data. The continuous help and support from the Department Head, Dr. Fatima Al-Naemi and all faculty members are highly appreciated. I am indebted to my family whose values to me only grows with age, I acknowledge my husband, Ibrahim, who supported me at all levels and for his unconditional love, he is my champion. I would like to express my gratitude to my lovely children who rendered their support and help during the period of project work. I also wish to thank my special and stunning friends, Layla, Raja and Reem for sharing hard moments and their encouragements while finishing this thesis.

Most of all, to our Almighty God, for giving His endless blessings, knowledge and strength to make this thesis possible. 


\section{Dedication}

I didicate this woark to my MOM's soul who passed away just two months ago, and during the final step of my thesis work. To whom her prayers still accompany me at every moment of my life, to whom I still hear her voice making prayers and gently asking Allah to empower me, to support me and to be always on my side. May Almighty Allah's blessings grace and mercy be upon her soul. 


\section{CHAPTER ONE}

\section{INTRODUCTION}

Aeromycology is concerning about airborne fungal spores, their release in the air, concentrations, composition and the parameters affecting their dynamics in the atmosphere. As a branch of aerobiology, aeromycological studies help aerobiologists, plant pathologists and allergist by providing baseline knowledge about fungal populations. Airborne fungi are considered to cause adverse health impacts on humans, animals and plants (Harrison et al., 1992; Bush \&Portnoy, 2001; Ren et al., 2001; Shelton et al., 2002). The allergen production by fungi is influenced by their life cycle as the allergens are released into the atmosphere from the spores during spore germination (Reponen, 2011). Fungal spores, due to their volume in the atmosphere and small size, have an important contribution to the respiratory allergies and cause various symptoms range from asthma, allergic rhinitis to bronchitis (Vijay et al.1991, D’amato \&Spieksma 1995, Hasnain et al., 1998). It has been demonstrated that the environmental factors such as meteorological and seasonal climatic factors (Rossi et al., 2005; Klarić \& Pepeljnjak, 2006), the type of vegetation (Pepeljnjak \& Šegvić, 2003), air pollution (Lin \&Li, 2000), and human activities (Mitakakis et al., 2003), affect the variety of air borne fungi. Numerous works on airborne fungal spores have been published worldwide with almost the same objectives to detect the dynamics of the aeromycota in associations with the biotic and abiotic factors of their surrounding environment, among those: India (Chandara \& Chanada, 2000; Jothish \& Nayar, 2004); Australia (Mitakakis \& Guest, 2001); Chile (Ibanez et al., 2001), Poland 
(Stepalska \&Wolek, 2005; Grinn-Gofroń \& Bosiacka 2015) and In China (Wang et al., 2010). Only a limited number of aeromycological studies were conducted in the Middle East compared to other parts of the world, however the similar objectives were introduced. For example; In Palestine (Barkai \& Glazer 1962) in Jordan (Abu-Dieyeh\& Barham 2014), in Egypt (Hameed et al., 2009) in Turkey (Erkara et al.,2008), in Iran( Nourian et al., 2007; Shams-Ghahfarokhi et al., 2014), in Saudi Arabia (Abdel-Hafez, 1984; Hasnain et al., 2005) , in Kuwait (Halawagy, 1989; Khan et al.,1999).Fungal spores are ubiquitous component of the bioaerosols. The availability and survivability of the aeromycota are known to be influenced by their interactions with biotic and abiotic components of the environment such as meteorological factors, geographical location, air pollutions, vegetation cover, and anthropogenic activates. The effects of meteorological factors on the dynamic of airborne fungal spore's populations were intensively reviewed in the literatures. However; other parameters such as the impact of air pollution are not studied as much as meteorological factors.

In Qatar only one study was carried out by Al-Subai (2002) to reflect the airspora of Doha for the whole year (1997-1998). The author concluded that the mycoflora in the air of Doha exhibited a seasonal and diurnal variation in which Cladosporium, Alternaria and Ulocladium were the most abundant genera in the atmosphere of Doha (Al-Subai, 2002). Qatar is a peninsula located in the Arabian Gulf region. Plant coverage is infrequent and scattered due to the shortage in water supplies, mainly varied between herbaceous plants, shrubs and limited number of tree species (Syed \& Abdullah, 2002). The most of Qatari's land are arid desert with a scarce annual precipitation. According to Batanouny (1981), the 
landforms system in Qatar is mainly comprised of the following phytoecogeomorphologies: rocky and conglomerates hamads which occupy the major land in Qatar, rocky ridges where the vegetation in both systems are poor, depressions, wadies and runnels and sabkhas (salt marshes) where the soil is of high salt content and the water table is near the surface (Batanouny, 1981). Doha is the capital of Qatar and the most popular city. Huge anthropogenic changes including urbanization, industrialization, and establishment of housing compounds, shopping centers and high-way roads were occurred in Doha within the last 15 years. Those anthropogenic changes are expected to affect the dynamics and species composition of air-borne fungal spores.

This research project was mainly initiated to update the knowledge about the seasonal and diurnal variations in airborne fungal spores of Doha area and to correlate these variations with meteorological factors. The present study also tackled with other parameters, atmospheric $\mathrm{CO}_{2}$ concentrations and different culture media, which might provide more information about the dynamics of fungal spores in relation to their surroundings. More specifically, this study was conducted to achieve the following objectives:

(1) Provide baseline knowledge about density, diversity and dynamics of airborne fungal spore in the atmosphere of Doha using settle plate exposures. This knowledge is necessary for mycologists, applied ecologists, plant pathologists and other disciplines of biological, environmental and health sciences.

(2) Investigate variations in seasonal and diurnal distribution of airborne fungal spores, abundance, density and diversity and to correlate these variations with meteorological factors. 
(3) Investigate variations in diurnal distribution of airborne fungal spores, abundance, density and diversity during February and March (2016).

(4) Correlate the variations in species composition and abundance of air-borne fungi with atmospheric $\mathrm{CO}_{2}$ concentration in two different areas in Qatar during February and March (2016) in order to investigate the impact of urbanization on air-borne fungal spore population.

(5) Compare results obtained from two different cultural selective media: Potato Dextrose Agar (PDA) and Czapek’s/ Rose-bengal media during February and March 2016. 


\section{CHAPTER TWO}

\section{LITRTURE REVEIW}

\subsection{The Science of Aerobiology}

The science of aerobiology deals with air-borne agents, the processes of aerosolization, the aerosol itself, and to a lesser extent, the exposure and response (Burge, 2002). Biological materials which exist in the atmosphere, or in other wards bioaerosols, are consisting of airborne particles of biological origin including fungi, bacteria, pollen and viruses, as well as their by-products such as endotoxins and mycotoxin, fragments and other fragments or waste products of living organisms like animal allergens (Reponen, 2011). In the atmosphere, the performance of any particle will be depended mainly on its shape, density and size .The numerous types of particles involving in biological aerosol are of different sizes. While pollens might have the largest diameter, anemophilous plants's pollens are of typical diameters ranges from 17 till $58 \mu \mathrm{m}$, and to lesser extent the diameter of fungal spores which ranges from 1to $30 \mu \mathrm{m}$ (Chatterjee \& Hargreave, 1974), viruses are thought to be the smallest in its surrounding, they have a typical diameter of less than $0.3 \mu \mathrm{m}$ (Taylor, 1988). Bacteria are ubiquitous in the atmosphere representing a considerable portion of the bioaerosols. The size of bacterial cells ranges between 0.6 and $2 \mu \mathrm{m}$. Certain infectious bacteria are windblown cells which can affect the man health such as Mycobacterium tuberculosis (Bowers et al., 2011).

In addition to naturally occurring sources of bioaerosols such as, plants, animals and biological decomposition of organic matters, various human activities leads to enriching the ambient atmosphere with biological aerosols . Waste disposal facilities, agricultural 
and food production activities are examples of potential facilities that represent bioaerosol sources of emission (Kummer \& Thiel, 2008). Pollen grains are such an important consistent of outdoor bioaerosol which found to exacerbate allergenic reactions. Pollen grains are produced by many trees, weeds and grasses. Dispersal by wind is the main mechanism of pollens distribution in the air, they absorb moisture from the atmosphere until they are swollen enough to breach and release pollen allergens out to the air (Reponen, 2011). Their concentration in the air is highly dependent on temperature and humidity; higher temperature and lower humidity drive higher pollen grain concentrations. The effect of wind velocity depends on pollen aerodynamic diameter (Jones \& Harrison, 2004). Because of their relative large size, the pollen allergens which are associated with particles of less than $5 \mu \mathrm{m}$ in diameter are able to penetrate lower in the lungs and subsequently causing asthma (Burge, 2002).

Among the most common bioaerosol particles either in outdoor or indoor are fungal spores. Aeromycological studies are mainly dealing with airborne fungal spores providing baseline information to plant pathologists, allergists and aerobiologists. Air-borne fungal spores are of primary importance for the induction of plant diseases and public health hazards in term of allergic reactions to fungal spores. The main source of outdoor fungal aerosols is plant materials (Moubasher, 1993). Fungal diversity has been found to be greatly influenced by the existence of plants and much less by bare sediment (Mohamed \& Martiny, 2011). However, the significant changes with ecology of plants can lead to considerable changes in fungal air spores (Burge, 2002). Soil is another considerable source of fungal spores (Rousk \& Baath, 2011). Physical characteristics of the soil such as $\mathrm{pH}$ and temperature are 
factors shaping the fungal communities and activities which subsequently affecting the release rate of airborne fungal spores(Rousk \& Baath, 2011; Yuste et al., 2011).Human activities can induce changes in airborne fungal spore's sources; global warming and increasing atmospheric $\mathrm{CO}_{2}$ level are examples. The usage of fungi as bio-control agents is also contributing to human-induced sources which might disturb fungal spore's distribution. As an example, spreading Epicoccum nigrum conidia onto sunflowers can control pathogens affecting this specific plant but it might rise the distribution of this significant allergenic fungus in the atmosphere (Pieckenstain et al., 2001). The exposure to fungi is associated with public health hazards because they can cause infections, irritations, allergies and toxic effects (Agrios, 2005; Mohammadi \& Krumbein, 2008).

\subsection{Airborne fungal spores and allergy}

During the past decades, the changes in environment have associated with an increase in prevalence of allergies (Koppelman, 2007). Fungi are abundant in the environment and they have a great ability to grow either as saprophytes colonizing nonliving organic substrate or as pathogens penetrating living tissues, from where they become airborne (Green et al., 2005). The personal exposure to airborne fungal spores and their components is strongly linked to allergic diseases and dysfunction of respiratory

system including allergic rhinitis, bronchopulmonary, and hypersensitivity diseases (Koppelman, 2007) pneumonitis and bronchial asthma (Masoli et al., 2004; Bousquet et 
al., 2008). In general, the admission rate to emergency department because of allergy to airborne fungal spores increases and hospitalization period for respiratory diseases extends as well (Dales et al., 2004; Atkinson et al., 2006).

The common mechanism of fungal airospora distribution in the atmosphere is through asexual conidia or sexual spores which considered significant aerosol particles. Quantities of fungal conidia are generally dependent on the environments of indoor and outdoor, different seasons, weather and climatic conditions, and topographical features. One hundred genera of fungal conidia and more are recently documented as a source of inhalant allergens (Green et al., 2005). Airborne fungal spores can range from zero to higher than one hundred thousand colony forming units ( $\mathrm{CFU}$ ) per cubic meter of air. According to Horner et al., (1995) among the 69,000 fungal species defined, around 80 species have been connected to allergic respiratory illnesses which usually intermediated by $\operatorname{IgE}$ hypersensitivity. Most molds are capable of producing highly allergenic proteins or glycoproteins which can exacerbate the allergic symptoms in atopic hosts (Reponen, 2011). The productions of fungal allergens are widely dependent on fungal species and on the media where they develop and grow. Moreover, life cycle of fungi can affect the allergens production; commonly spores release their allergens into the surrounding environment during germinations (Green et al., 2005)

Spore germination of Alternaria and Aspergillus is found to increase the number of allergens (Green et al., 2005). Green et al., (2003) concluded that allergens were released from 11 fungal species, Alternaria alternata, Cladosporium herbarum, Aspergillus fumigatus, Botrytiscinerea, Epicoccum nigrum, Exserohilum rostratum, Penicillium 
chrysogenum, Stemphylium botryosum, Curvularia lunata, Trichoderma viride, and Bipolaris spicifera. $5.7 \%$ - $92 \%$ of spores of 9 out of 11 fungal species mentioned above liberate their allergens before germination (Green et al., 2003). However, all the germinated spores released allergens from their hyphae after germination and the total quantity of allergens was recognized to be greater after germination than before it, and thus germination is a principal contributor in allergen release mechanism for many allergenic fungi species even though many of non-germinated spores of certain species contributed to allergens release as well, but in small amounts (Green et al., 2003). Mitakakis et al. (2001) conducted a study to examine if the spore germination of Alternaria increases the allergen release, they revealed that a greater allergen elution from spores occurs by germination, yet not all spores release allergens.

As it was demonstrated by skin test, $10 \%$ to $60 \%$ of vulnerable hosts (atopic) represent hypersensitivity to molds (Burge, 2002). The most commonly known allergenic fungi include Penicillium, Aspergillus, Cladosporium, Alternaria,, Curvularia, Bipolaris, Epicoccum, and Candida (Vermani et al., 2011). Most of them can penetrate downwards to lower part of pulmonary airways and cause hypersensitivity reactions. In Qatar, an observational study was carried out to estimate the size of fungal infections at public level (Taj-Aldeen et al., 2015). The data analysis revealed that, 1486 people were affected by severe asthma with fungal sensitization, 1126 patients were diagnosed with allergic bronchopulmonary and 176 individuals complained from chronic pulmonary aspergillosis (Taj-Aldeen et al., 2015). The majority of fungal spores have a size range of 2-10 $\mu \mathrm{m}$ though a significant quantity of fungal components including allergens, glucan and 
mycotoxins occur in a size less than $1 \mu \mathrm{m}$. The size of conidia and fungal spores detect the deposition location in lungs and the severity of allergenic reactions. Conidia and spore size of $5 \mu \mathrm{m}$ and above is linked to direct type of hypersensitivity but with smaller size, about $1 \mu \mathrm{m}$, the hypersensitivity is said to be of delayed type where the conidia and spores are able to penetrate further downward of respiratory tract (Kurup \& Fink, 1993). Additionally, the mode of spore's entrance into respiratory system determines the deposition site in lungs (Burge, 1989; Kurup, 1989; Kurup \& Fink, 1993). The conidial clusters of Aspergillus fumigatus are commonly settled down in the upper airways tract, but with individual conidia, the deposition site are usually in lower airways (Kurup et al, 2000). Approximately $60 \%$ of Calvatia species spores have been found to penetrate lower respiratory tracts into alveoli, due to their relative smaller sizes (Burge, 2002). According to Green et al., (2005), fungal hyphae fragmented conidia and new fungal genera belonging to Ascomycetes, Deuteromycetes, and Myxomycetes are considered as aeroallergen sources and subsequently contribute to inhalant allergens.

In addition to allergens, molds contain other biologically active constituents including (13)-B-D-glucan and mycotoxins. (1-3)-B-D-Glucan is a principle cell wall structure of fungi and other microorganisms, comprising about $60 \%$ of fungal cell wall (Sharpe et al., 2015). (1-3)-B-D-Glucan exposure is related to some of pulmonary diseases such as airways inflammation by which more common with infants and schoolchildren (Jaakkola et al., 2010). Mycotoxins are secondary fungal metabolites in which their production depends on the environmental conditions like temperature and the availability of moisture and nutrients (Reponen, 2011). According to the later author, mycotoxins are common aerosol in 
significantly contaminated agricultural environments. In Saudi Arabia, an aerobiological study was conducted in three sites ( Jizan, Hail and Taif) revealed the presence and prevalence of Ganoderma basidiospores which cause respiratory allergic diseases. Three study sites were included in the investigation. One site (Jizan) had the highest concentration of Ganoderma basidiospores which interestingly correlated to the highest level of asthma prevalence among children through the three study sites (Hasnain et al., 2004).

\subsection{Factors affecting availability and survivability of airborne fungi:}

The air pollutants are well known causes for adverse effects on both the health of human and environment. Biological and non-biological contaminants are together associated with the increase of allergenic symptoms, recurrent visit to emergency room and hospitalization period or even motility. Several studies have examined the potential consequences of nonbiological pollutants, physical components of the environment and meteorological parameters on the dynamics and concentrations of airborne fungal spores (Al-Subai, 2002; Sousa et al., 2008; Abu-Dieyeh et al., 2010; Hameed et al., 2012; Abu-Dieyeh \& Barham, 2014). 


\subsubsection{Abiotic factors:}

The diversity or composition of fungi is thought to be determined by $\mathrm{CO}_{2}$ concentration in the atmosphere (Klamer et al., 2002), soil depth (O’Brien et al., 2005), nitrogen availability (Allison et al., 2007) and salinity (Mohamed \& Martiny, 2011). It was concluded that, fungal biomass in the soil increased due to the treatment with elevated atmospheric $\mathrm{CO}_{2}$; however, the treatment with elevated atmospheric $\mathrm{CO}_{2}$ didn't affect either the fungal community composition or their species richness (Klamer et al., 2002). It is believed that, plants and through the richness in the quality and quantity of resource supply, to significantly affect soil micro biota (Mohamed \& Martiny, 2011). Plant diversity adds to the fungal richness and diversity by providing more organic substrate diversity, increasing habitat complexity, decreasing surface temperature, reducing surface salinity and increasing $\mathrm{O}_{2}$ availability (Zak et al., 2003; van der Heijden et al., 2008; Mohamed \& Martiny, 2011;). In their study, O’Brien et al., 2005 demonstrated that, different soil samples showed compositional variances, while mycorrhizal species were the most abundant fungi in deeper soil profile, saprophytic fungi predominated the upper litter layer (O'Brien et al., 2005). Nitrogen is a basic nutrient required to promote healthy growth of any living organisms. Yet, increased nitrogen deposition due to $\mathrm{N}$ fertilization was reported to decline the fungal taxonomic richness and alters community structure (Allison et al., 2007). Other abiotic factors can influence the composition and diversity of fungal populations. In Jordan, mycorrihzal abundance and distribution was not influenced by soil $\mathrm{pH}$, soil phosphorus, or soil texture, but it was strongly and positively correlated to organic matter and $\mathrm{CaCO}_{3}$ percentages (Mohammad et al., 2003). Salinity is another factor that can 
significantly affect the availability of fungal communities. Sediment fungal composition was found to be influenced by salinity gradient more than plant appearance. In contrast, greater fungal diversity was detected by the presence of plants and much less by salinity, only with intermediate salinity, greater fungal diversity was detected (Mohamed \& Martiny, 2011).In Kuwait, the saline soil yielded 14 species of Aspergillus revealing that the saline soil may provide a suitable habitat for considerable number of fungi and subsequently contribute to the aerial occurrence of the related fungi (Moustafa, 1975).

\subsubsection{Meteorological parameters:}

Bioerosols contribute significantly to atmospheric pollutants in which fungal spores are an important portion of them. Environmental variables such as temperature, relative humidity and wind speed affect fungal spores' concentration in the atmosphere, their growth and reproduction as well. The concentration of airborne fungal spores in the atmosphere is varying daily and seasonally depending on many environmental variables, among them air

pollution, meteorological parameters, human activities and seasonal climatic factors (Lin \& Li, 2000; Mitakakis et al., 2003; Rossi et al., 2005; Abu-Dieyeh \& Barham, 2014). The most important indicators of fungal airspora population in the air are meteorological variables. Temperature and humidity are of highly significant positive effects on the total concentration of fungal population (Aydogdu \& Asan, 2008; Oliveira et al., 2009). 
Temperate and tropical regions were found to accommodate higher concentration of airborne spores, while in desert region the number is much lesser (Lacey, 1981). As an example of the concentration of air-borne fungal spores collected from Amman area (humid Mediterranean climate) was 461779 spores (Shaheen, 1992) compared to 76396 fungal spores collected from Zarqa area, Jordan (Arid Irrano-terranean climate) (AbuDieyeh \& Barham, 2014). The most significant meteorological factor which positively correlated to fungal airspora is the temperature. A positive correlation was found between temperature and airborne fungal spores (Aydogdu \& Asan, 2008), including certain fungal genera Aspergillus (Adhikari et al., 2006), Cladosporium (Quintero et al., 2010) and Alternaria (Reyes et al., 2009). Grinn-Gofroń \& Bosiacka, (2015) demonstrated that and through a 4-years study, Alternaria, Drechslera type and Cladosporium spores were displayed their maximum abundance at higher mean temperature values. Al-Subai, (2002) deduced that, the greatest density of fungal spores was recorded in July and December. Abu-Dieyeh et al., (2010) revealed that, the highest frequency of fungal spores in Zarqa area in Jordan was found to occur during winter and rainy months of the year. According to Oliveira et al., (2009) the maximum concentration of fungal spores was observed during summer and autumn. Supporting previous findings indicated that, during the hot and dry days, the population of the following airborne fungal spores are prevailed: Alternaria, Torula, Cladosporium, Drechslera, while Epicoccum spp. were the highest when the moisture is relatively high (Grinn-Gofroń \& Bosiacka, 2015).

Wind speed showed inconsistent effects on the distribution of airborne fungal spores. Some publications demonstrated that wind velocity can enhance microorganisms' dispersion in 
the atmosphere by detaching them from their attached surfaces (Jones and Harrison, 2004). On other hand, other studies found the wind speed might dilute fungal spore's concentrations in the air (Sabariego et al., 2000; Stennett \& Beggs, 2004). Highest wind speed might bring to higher fungal spores concentration (Al Subai 2002; Jones \& Harrison, 2004). When the wind speed is less than $5 \mathrm{~m} / \mathrm{s}$, the fungal spore's concentration decreased, but when the wind velocity is more than $5 \mathrm{~m} / \mathrm{s}$ the concentration of fungal spores increased (Lin \& $\mathrm{Li}, 2000$ ). On the other hand, wind can act as a dispersal and diluting factor for spores when the wind is high and so decrease the concentration of spores significantly (Quintero et al., 2010). Fluctuations in the wind velocity are significantly associated with changes in spore's concentration and particularly when other meteorological factors are optimum (Sakiyan \&Inceoglu, 2003). The study of Grinn-Gofroń\& Bosiacka (2015) showed that the highest release of Alternaria, Cladosporium and Drechslera type spores occurred when the wind speed is at the lowest value of the mean, while the concentration of Leptosphaeria and Didymella spores increased when the mean of wind speed is the highest. Abu-Dieyeh \& Barham (2014) found the Puccinia spores are positively and significantly correlated with wind speed, while Alternaria, Cladosporium, Drechslera and Ustilago didn't show any significant correlation with the wind velocity.

The study of Pakpour et al., (2015), which conducted for over 20 years period in two North American cities (New York and Toronto) of humid continental climate type, demonstrated that airborne fungal spores are determined by annual variations in climate especially for precipitation and to a lesser extent for temperature. During drier years, a higher fungal spores in the air was reported (Pakpour et al., 2015) 
Rainfall might acts as a vacuum cleaner which clean the air by wet deposition mechanism and thus fungal spores are forced to settle down on the ground or another surfaces (Katial et al., 1997; Polymenakou, 2012).Contrary results were noted by Abu-Dieyeh et al. (2010) who recorded the highest colonies count events post the heaviest precipitation and moderate temperature conditions, in Zarqa area, Jordan (Arid Irrano-terranean climate). Heo et al. (2014) agreed with Abu-Dieyeh et al., (2010), they found the concentration of fungal bioaersols was much higher during rainy season than in non- rainy days. In such studies, the positive correlation between fungal bioaerosol's concentrations and rain was due to the fact that rain helps creating an environment of required moisture level for better fungal vegetation process, and due to the absence or reduction in solar radiation as well.

After all, the effects of meteorological factors on the diversity and concentrations of fungal airspora is a complex relationship between biological and environmental factors. Thus, it is difficult to assess the importance of each meteorological factor separately due to the instantaneous response of fungi to a combination of parameters (Abu-Dieyeh et al., 2010).

\subsubsection{Air pollution:}

The interrelationship between atmospheric pollutants, meteorological factors and airborne fungi are thoroughly investigated in the literature (Adhikari et al., 2006; Sousa et al., 2008).Although the impact of meteorological factors on air quality is considerable and well established, studies concerning the relationship between fungal counts and air pollutants 
are still few (Adhikari et al., 2006). Among those pollutants are: ozone $\left(\mathrm{O}_{3}\right)$, nitrogen dioxide $\left(\mathrm{NO}_{2}\right)$, sulphur dioxide $\left(\mathrm{SO}_{2}\right)$ and particulate matter (PM10). Tropospheric ozone levels have been significantly increasing in the last decades because of uncontrolled anthropogenic emissions (Sousa et al., 2008). Ozone in the troposphere resulted from photochemical reactions involving solar radiation and emitted pollutants from earth surface (Marenco et al., 1994). In contrast to stratospheric ozone, tropospheric ozone has been associated with adverse impact on human health, climate and even on atmospheric composition. A significant positive correlation between $\mathrm{O}_{3}$ and spore concentration of Alternaria and Cladosporium were reported (Adhikari et al., 2006; Grinn-Gofron et al., 2011. The concentration of tropospheric $\mathrm{O}_{3}$ was found to be affected by relative humidity and moreover the highest average level of $\mathrm{O}_{3}$ favors relative humidity of $40 \%$ or lower (Van Weele \& Ma 2000; Elminir, 2005; Grinn-Gofron et al., 2011). Also, higher $\mathrm{O}_{3}$ production was recorded during wormer years when more UV radiation and lower wind velocity are the weather trend (WHO, 2000; Sousa et al., 2008). On the other hand the concentration of fungal spores such as Cladosprium sp. can be significantly affected by high $\mathrm{O}_{3}$ concentration in which high $\mathrm{O}_{3}$ level is capable of killing microorganism by oxidizing their cellular component and cell walls as well (Das et al., 2006; Whangchai et al., 2006). A negative or no significant correlation between $\mathrm{O}_{3}$ and fungal spores in the air was demonstrated by Sousa et al. (2008). Similar results were obtained by Ho et al. (2005), who deduced from a 3 years study period (1994-1996) a negative correlation between $\mathrm{O}_{3}$ and general fungal spores, total fungal spores and in particular with Ganoderma spp. 
$\mathrm{SO}_{2}, \mathrm{NO}_{2}$ and PM10 concentrations in the atmosphere were thought to affect the fungal spore survivability. The concentration of fungal airospora decreased when $\mathrm{SO}_{2}$ increased (Asan et al., 2002). The influence of $\mathrm{SO}_{2}$ and $\mathrm{NO}_{2}$ on Cladosporium and Alternaria spores was rather low or weak (Grinn-Gofron et al., 2011). $\mathrm{NO}_{2}$ and $\mathrm{SO}_{2}$ in the atmosphere are going under chemical reactions and their chemical products are found to be toxic to microorganisms (Won \&Ross, 1969; Harrison and Perry, 1986; Ho etal., 2005; Adhikari et al., 2006; Grinn-Gofron et al., 2011). PM10 presented a positive trend relationship especially with Aspergillus and Alternaria (Adhikari et al., 2006). PM10 can affect the morphology, allergenicity and aerodynamic attributes of bioaerosols (Adhikari et al., 2006, Ormstad et al., 1998). However, Lin \& Li (2000) and Sousa et al., (2008) concluded that there is a non-significant positive correlation between PM10 and Aspergillus or Cladosporium. Because of their chemical composition, PM10 might severely affect fungi's metabolism processes or even adsorb them on their surfaces (Matthias-Maser et al., 1998). It is demonstrated that, the concentration of both airborne bacteria and fungi were lower in heavy haze days than during non- haze days (Gao et al., 2015). With respect to increasing $\mathrm{CO}_{2}$ level, when accompanied with drought it will have a positive effect on soil fungal communities particularly on pathogenic strains such as Fusarium and thus indirect effect on their airborne spores (Curlevski et al., 2014). Klironomos et al. (1997) concluded that the increasing level of atmospheric $\mathrm{CO}_{2}$ can have a recognized effect on airborne fungal vegetation and subsequently on their dispersal rate in the atmosphere and air quality.

In general, many studies demonstrated that, there were no significant correlation between air pollutants and fungal survivability in the air (Ho et al., 2005; Wu et al., 2007; Lin \& Li, 
2000; Sousa et al., 2008). However, the lack of proves is not prove of lack important effect of air pollutants on fungal spores viability in the air.

\subsubsection{Diurnal variations:}

The number of airborne fungal spores varies from season to another, from day to day and from hour to hour. Accordingly, diurnal variations were frequently studied to describe the pattern of fungal airspora throughout the day. Different airspora types showed different diurnal periodicity trends. The following studies are just few examples of what is found in the literature. According to Sreeramulu (1959) who studied the seasonal and diurnal variations affecting the airborne fungal spores in UK, when Ustilago, Helminthosporium, Uredospores, Botrytis, Alternaria, Stemphylium and Periconia spores were at their maximum concentration in the afternoon, their minimum concentrations were used to be in the early morning. Before noon, Erysiphe, Polythrincium and Epicoccum reached their maximum. Between midnight and dawn, Ganoderma, Coniophora and other dark colored basidiospores were the most abundance (Sreeramulu, 1959). In Finland, the circadian periodicity of certain airborne spores was investigated. Cladosporium spores released at their maximum around noon, the concentration of Suillus spores had a minimum concentration at 16:00 h-18:00 h (Helander \& Pessi, 1991). In Ontario-Canada an aerobiological study was conducted to monitor the outdoor air mycoflora throughout 1992. The diurnal pattern of fungal spores varied. The maximum concentration of Cladosporium and Epicoccum showed a midday peak pattern. The maximum concentration of 
Cladosporium occurred at 14:00h while the minimum value occurred at 6:00 h. Epicoccum peaked at around 10:00 and 4:00 and dropped at midnight. No clear diurnal pattern was shown by Aspergillus and Penicillium (Li \& Kendrick, 1995).

Seasonal and diurnal fluctuations of airborne basidiomycete spores group in Mexico City were observed for one year. Basidiospores occurred at their greatest concentration in the early morning, while their lowest concentration was recorded in the afternoon (Calderon et al., 1995). In Qatar, Al-Subai (2002) demonstrated that the diurnal pattern of total fungal spores showed one peak at noon time and the lowest fungal spores distribution was at midnight and Cladosporium showed a regular peak at noon time The positive correlation between mid-day and fungal spores' concentration was reflected by high wind speed, high temperature and low relative humidity while at midnight, lower temperature, lower wind velocity and higher moisture command the trough phenomenon (Al-Subai, 2002). In Zarqa area, Jordan, Abu-Dieyeh et al., (2010) studied diurnal variations of fungal airspora in two different periods of the year, from February to April and from November to January. They found that the total fungal spores presented their maximum distribution pattern at 15:00 hour versus 10:00 hour of collection samples during November and January. Cladosporium, Fusarium and Alternaria spp. favored their spores release at 15:00 hour which might be due to lower relative humidity at early afternoon (Abu-Dieyeh et al., 2010). Unlike those cold months, February and April had no significant differences in terms of diurnal variations (Abu-Dieyeh et al, 2010). Abdel Hameed et al. (2009) conducted a study to evaluate diurnal variations of airborne fungi and bacteria in Helwan, Egypt. They 
revealed that the maximum distribution of fungal airspora was at 20:00 $\mathrm{h}$ during three seasons, except for winter season in which the highest concentration was detected $2 \mathrm{~h}$ earlier than other patterns. Aspergillus showed an outline of doublepeaks, Penicillium and Cladosporium achieved their peak at 20:00 while Alternaria was favoring a midday spore release (Hameed et al., 2009).

Weather conditions throughout the day controlled the fungal spore's distribution pattern, but also the location and human activities can contribute effectively. In Dublin, Ireland, O'Gorman\& Fuller (2008) deduced that there was no significant variations between morning, afternoon and evening counts of total fungal airspora; however they realized that the highest fungal spores concentrations to happen in the summer mornings (June-August), yet the variation was not statistically significant.

As indicated by above mentioned literature intra-diurnal variation in abundance of airspora is not systematic and variable with region, season and weather conditions which mean that the local environment is the most limiting factor in determining the trend of diurnal variation of airspora.

\subsubsection{Sampling methodologies:}

The sampling of airborne fungal spores are commonly conducted using either the gravimetric method (settle plate exposures) or the volumetric method by sucked a known amount of air using spore traps such as Burkard spore trap (Hirst, 1952). 
Gravimetric method is a simple, non-volumetric, passive sampling method collecting spores by settling on the surface of agar-containing plate. The collected samples are simply incubated in an incubator for definite time and temperature degree, and then the recovered fungi are classified based on their macro morphology and micromorphology features. Nonetheless, it is associated with some drawbacks which might affect its validity; for instance: any clustered colonies will not be distinguishable and counted as one, not time discrimination i.e. it is difficult to repeat it several times through the day, the spores which recover on the laboratory substrata are only the viable ones, and thus it cause a bias in the fungal types grow on the agar media (Mostafa \& Kamel, 1976). Spore trap is an active method that use artificial force to control and help spore collection. The vacuum pumps a volume of air of $10 \mathrm{~L} / \mathrm{min}$. rate, airborne particles adhere to a tape covered with a sticky substance; this tape is then removed and divided into 7 segments that are placed on microscopic slides and stained for further investigation (Sabariego et al., 2007). Yet this sampler is an expensive and labour extensive (slides preparation, tape replacement) method. No strong evidence that favors either of the two methods, gravimetric method or spore traps. Abu-Dieyeh \& Barham (2014) mentioned a detailed discussion about the potentiality of the two methodologies after two different studies(Abu-Dieyeh et al. 2010, Abu-Dieyeh \& Barham, 2014) based on two different methodologies on the same area. According to the above authors, Cladosporium was found to be the main constituent of airborne fungal spores using both settle exposure and spore trapping methodologies. Alternaria, Ustilago and Drechslera, in addition to Cladosporium comprise the main percentage of the total tapped fungal spores in the air using spore trapping method. Even 
though; Alteranaria quantity, which detected using spore trapping method, showed similarity to which revealed by settle exposure method in Zarqa, Jordan (Abu-Dieyeh et al. 2010, Abu-Dieyeh \& Barham, 2014), the genera Puccinia, Ustilago and Drechslera are biotrophic fungi, which do not grow on culture media and, consequently, were not reported using the settle exposure method (Abu-Dieyeh \& Barham, 2014). A genus like Fusarium, in comparison to Puccinia, Ustilago and Drechslera, is recognized to be better detected on settle exposure rather than spore trapping (Mitakakis \& Guest 2001), and thus it was introduced as a rare constituent of the total tapped fungal spores in the air of the Zarqa area (Abu-Dieyeh \& Barham, 2014). It was demonstrated that, Aspergillus/Penicillium group represented a small percentage of the total airospora reported by spore trapping method (Abu-Dieyeh \& Barham, 2014). In contrast, they showed higher percentage using the settled exposure method (Abu-Dieyeh et al., 2010). Because of the relative smaller diameter of their spores (1-2 $\mu \mathrm{m})$ (Mitakakis \& Guest 2001) and the disability of Burkard trap to accurately collect particles less than $5 \mu \mathrm{m}$ in aerodynamic diameter (Hirst, 1952), Aspergillus and Penicillium spores are under- estimated using spore trapping method. Unlike, the easily identifiable spores of Alternaria and Epicoccum, for example, it is difficult to visually distinguish between Aspergillus and Penicillium conidia collected using a spore trap (Eduard, 1996). Nevertheless, to conclude better information about aeromycology of an area, both settle exposure and spore trap methodologies are recommended and they are complementary to each other (Abu-Dieyeh \& Barham, 2014). To a lesser extent, Anderson impactor is used as an aeroallergen sampler as well. This sampler is a combination between volumetric and culture methods. Both, the concentration 
and the size of airborne particles are measured. The six stages type consist of filters combined with petri dishes in which the air flows and so the biological aerosol of different diameters settle on the respected stage; later, the estimation of airborne particles is done based on the count of grown colonies (Gillespie et al. 1981; Jensen et al., 1992; Stein, 1999; Wu, 2000; Nesa et al., 2001).

The slide exposure method is a kind of gravity sampling technique where the slides are smeared with a sticky material, and then the slides are exposed to the atmosphere for certain period of time. Later the slides are collected and then carefully stained with a dye and a cover slip is placed, then the slide will be studied to quantify fungal spores under the microscope. This method can help identifying the viable but not culturable fungal spores (Frey \& Durie, 1962; Agarwal et al., 1969)

Frey \& Durie (1962) used the slide exposure method and culture plates to study the availability of fungal spores in the atmosphere of Sydney. The number of colonies isolated with culture plates was higher than the total number of fungal spores counted on slides. The most dominant fungal spores counted on the slides were of Alternaria, Cladosporium and rusts and smuts. While the predominant fungal colonies recovered with culture plate method were of Cladosporium, Alternaria, Epicoccum, Pteospora, Penicitlium, Pullularia genera.

In Delhi,India an aeromycological study was conducted by Agarwal et al. (1969) to assess the prevalence of fungal spores in Metropolitan area and their relationship with allergic cases incidence using two different methods; plate exposure method and slide exposure method. Results detected that Alternaria spp., Cladosporium spp. and spherical spores 
were the predominant using slide exposure method, whereas Cladosporium spp., Alternaria spp., Aspergillus spp., and Fusarium spp. spores were the prevalent when Petri dishes were used (Agarwal et al., 1969).

The Durham sampler is another gravimetric method which technically has the same concept as slide exposure method. Slides, before air exposure, are covered with a sticky jell then placed on the Durham sampler for a certain period of time, then they are collected to identify the fungal spores and pollen grains on the microscope. This method can be used for both culturabel and non-culturable fungal spores; however it is most frequently used to study the prevalence of pollen grains in the atmosphere (Crispen et al., 2010; Erkara et al., 2009). Eskisehir City, Turkey, the relationship between Alternaria and Cladosporium with meteorological conditions was investigated using Durham gravimetric sampler. Cladosporium spores count was as two third as Alternaria spores and their availability was influenced significantly by relative humidity (Erkara et al., 2009).

\subsubsection{Culture media:}

The identifiable growth of viable airborne fungal species on laboratory media is basically controlled by contained nutrients. Thus, the germination and growth of these spores are strongly dependent on the employed media. Burge et al. (1977), used eight different culture media (Modified Mehrlich's medium(MM), Sabouraud dextrose agar (SDA), Malt extract agar (MALT), V8 juice agar (V8), Rose Bengal-streptomycin agar, Casein hydrolysate agar $(\mathrm{CH})$, and Potato dextrose agar (PDA) (with four different Rose Bengal 
concentrations) to compare the fungal spores recoveries. They concluded that, the total growth were similar on SDA, MALT, V8, and PDA, whereas MALT and SDA exhibited the highest occurrences of growth pattern, mostly of all colony types. Epicoccum was excluded by $\mathrm{CH}$ and $\mathrm{MM}$; however, Cladosporium presented high recovery on those media. PDA containing Rose Bengal produced lower total recoveries in comparison with other media (Burge et al., 1977). In Saudi Arabia, Abdel-Hafez (1984) used two different media, glucose- and cellulose-Czapek's agar to study the prevalence of air mycoflora at Taif. The recovery of Aspergillus spores were higher on glucose media than it occurred on cellulose culture, while Alternaria, Cladosporium, Drechslera, Scopulariopsis and Phoma were greatly recovered on both media. Penicillium and Ulocladium were highly selective, while Penicillium showed high growth pattern on glucose, Ulocladium were recovered mainly on cellulose (Abdel-Hafez , 1984).According to Moubasher, (1993) 50\% sucrose Czapek's agar provides the highest total count of fungal recoveries and the widest species spectrum in comparison with glucose and cellulose-Czapek's agar. Mcquilken et al., (1997) proved that not only temperature, $\mathrm{pH}$ and light affect the development on fungal growth, but also the laboratory substrata can drive the developmental process. Both, Potatodextrose agar (PDA) and malt extract agar (MEA) produced the highest rate of conidial germination, pycnidial production and hyphal extension of Coniothyrium minitans. Hyphal extension rate on molasses-yeast agar was more dawdling, other developmental processes rate were similar to those on PDA and MEA (Mcquilken et al., 1997). A single stage / N6 Andersen impactor which was attached with agar plates of different media, MEA and Dichloran Glycerol (DG18) was used to compare the fungal concentration and genera 
recovered on the different culture media. In comparison with MEA, DG18 media supported higher fungal concentrations. Furthermore, the genera of Aspergillus, Penicillium, Fusarium, yeast, and nonsporting fungi yielded significantly higher concentration on DG18 than with MEA (Wu et al., 2000). For the quantification of culturable fungi purpose and assessing the relative efficiencies of different culture media, three culture media were used (CIP10-M, malt extract agar (ME) and dichloran glycerol-18 (DG18). Higher colonies of Aspirgillus spp were acquired on DG18 and ME at25 ${ }^{\circ} \mathrm{C}$, whereas greater CFU values of Scopulariopsis spp. with ME at 37c. Unknown species were obtained with higher values with DG18 at $250 \mathrm{C}$ than on $\mathrm{ME}$ at $25{ }^{\circ} \mathrm{C}$ or at $37{ }^{\circ} \mathrm{C}$.Alternaria spp. was isolated at higher rate with ME and CIP10-M. Only ME media supported the recoveries of Mucorales (Nieguitsila et al., 2011).

\subsection{Worldwide relevant aeromycological studies}

Numerous works on airborne fungal spores and their responses to their surrounding environment and their correlation with respiratory diseases have been established worldwide. In Chicago ,USA Feinberg and his co-authors (1936) surveyed the atmosphere content of air borne fungal spores to determine the diversity and dynamic of fungal population to correlate them with the allergic incidence reacting to mold exposure. They used gravimetric methods to collect their samples for one year (1934-1935). Alternaria, Hormodendrum (Cladosporium), Penicillium, Aspergillus, Rhizopus, Mucor, 
Chaetomium, and Monilia were the predominant spores through the year, yet they were more prevalent in the wormer months. Alternaria and Hormodendrum showed a seasonal trend, in July Alternaria presented much higher prevalence than it showed in May. Moreover, the seasonal variation of Alternaria and Hormodendrum was correlated positively with allergic cases reacting to these molds (Feinberg et al., 1936). Deamer \&Graham (1947) screened the airborne fungal spores in the air of San Francisco for one year (1942-1943) in order to determine the frequency and diversity of mold spores in the atmosphere and to correlate findings with seasonal incidences of respiratory complaints. Both culture and slide methods were used. Hormiodendroni, Penicillium, Macrosporium, Botrytis, Saccharomyces, Candida, Alternaria, Cephalosporium, Monilia, Mucor Spirotrichium, Spicaria and Rhizopus were the predominant spores during the 12 month in San Francisco, but they didn't show any seasonal trend which upset the correlation of mold incidence related to respiratory diseases .

In Britain, Richards (1952) studied the census of airborne fungal spores in the air over Britain using gravimetric methodology. Cladosporium was the predominant in overall areas, and displayed a seasonal pattern between June to September. Other genera such as Penicilliumand Aspergillus were prevalent in the center of London, while Cladosporium, Epicoccum, Botrytis, Alternaria and Pullularia, Pullularia were more abundant in the rural places. Di Menna (1955) conducted a quantitative study between March 1953- April 1954 to evaluate the population of airborne fungal spores in Dunedin- New Zealand; using plate exposure method. Results showed the predominance of Cladosporium with $42.9 \%$, followed by Penicillium with occurrence pattern of $34.2 \%$. Yeast also displayed high 
frequency. In terms of colonies yield, the maximum was during summer, whereas the minimum was during winter. In Hong Kong, Turner, (1966) carried out a study to screen the fungal spores in the atmosphere using gravimetric method. He demonstrated that Cladosporium was the overwhelming predominant genera, followed by Penicillium, Aureobasidium, and Aspergillus respectively. During winter and drier seasons, higher number of colonies was counted. In contrast, in summer and more humid months fewer colonies were obtained (Turner, 1966). In USA and by using volumetric sampler, the influence of weather conditions on the concentrations of atmospheric airspora was examined. It was demonstrated that, wind speed had significant effects on the dispersal rate of spores. Changes in relative humidity levels were found to affect fungal spore release of different fungal phyla. Rainfall affected positively the release and dispersal of Basidiomycetes (Lyon et al., 1984).

In Melbourne, Australia, Mitakakis \& Guest (2001) established a fungal spore calendar. Using volumetric means, they identified twenty nine genera and five spore groups. The most abundant fungal spores were noticed for Cladosporium with $41.7 \%$ of overall fungal spore distribution. In Poland, Grinn-Gofroń \& Bosiacka (2015) conducted a study of four years period to assess the effect of meteorological factors on the airspora composition in the atmosphere. They concluded that, temperature had the greatest impact on fungal airspora composition. The second most significant meteorological factor was the dew point, followed by relative humidity and wind speed respectively (Grinn-Gofron \& Bosiacka 2015). 
A study was conducted for one year, using volumetric sampler, to screen the population of airborne fungi in the atmosphere of Beijing, China and to detect the urbanization effect on their distribution and concentration. Air borne fungal spores varied seasonally; during summer and autumn their concentrations were significantly high, whereas in spring and winter they become lower. Cladosporium spores were the most dominant fungal group, followed by Alternaria, Pencillium and Asperigillus. The area with more vegetation coverage had significantly higher fungal concentrations compared to densely urban and high traffic sites (Fang et al., 2005).

Also in China, the seasonal dynamics of fungal airspora was detected in different open caves using volumetric sampler. Airborne fungal spores showed a seasonal distribution pattern in which greater concentrations were reported in summer and autumn. Cladosporium was the most prevalent spores, followed by Penicillium, Alternaria and Aspergillus. Temperature had the highest impact on the concentrations of ambient fungal spores, but the relative humidity and rain were inversely correlated to them (Wang et al., 2010).

The above mentioned research studies represent just part of heavy literatures conducted to achieve main objectives like: to study the dynamics of fungal populations, to detect correlations between airborne fungal spores and the ambient environment and to construct fungal spore calendars in several countries all over the world.

The significance of almost all aeromycological studies is mainly to provide baseline data about fungal profiles and their fluctuations due to abiotic interactions in order to support preventive measures of respiratory diseases due to fungal allergy. 


\subsection{Middle East Aeromycological Studies}

Aeromycological studies in the Middle East are not established as strong as in other regions; they are still few and dispersed. Abdel-Hafez (1984) studied the prevalence of air mycoflora at Taif region, Saudi Arabia, for one year period, August 1981 to July 1982, using gravimetric method. Two different media, glucose- and cellulose-Czapek's agar, were used in the investigation as well. A total of 25 genera, 58 species and one variety were identified. The colonies number represented great seasonal variations with maximum concentration during winter and minimum in summer season. Moreover; the recovery of Aspergillus Alternaria, Cladosporium, Drechslera, Scopulariopsis and Phoma spores on the two different media was greatly fluctuated (Abdel-Hafez, 1984). More specifically, Hasnain et al., (2005) monitored the seasonal and diurnal fluctuations of airborne basidiospores throughout three coastal discrete sites in Saudi Arabia using volumetric method. One site out of the three represented the maximum concentration of basidiomycetous spores with taking into consideration that smuts spores were the most significant constitute. The findings didn't show any seasonal pattern related to smuts and rusts spore dispersion. Nevertheless, diurnal variations of basidiomycetous spores exhibited a nocturnal pattern in one sit only. Accordingly, not only seasonal and diurnal factors affected the dynamics of air borne basidiospores, but also regional parameter had significant impact (Hasnain et al., 2005).

In Kuwait, Halawagy (1989) monitored seasonal variations of fungal airspora in three different areas in Kuwait during the five years period 1977-1982 using volumetric samplers. 37 genera were introduced with the most common fungal spores of 
Cladosporium Ustilago Alternaria, Drechslera and Chaetomium. Cladosporium was the most abundant among the others. Results showed two peaks of concentrations in spring and autumn while the concentrations decreased significantly twice during summer and winter in all sites. The highest seasonal distribution of airborne molds was observed in 1978, which followed by precipitation and subsequently vegetation growth (Halawagy, 1989). Another aeromycological study was carried out by Khan et al. (1999) in Kuwait using volumetric method for one year to screen allergenic fungi in the outdoor and indoor environment. It was demonstrated that, Asperigillus spp. were the predominant in outdoor environment, while Cladosporium spp. constituted the majority of indoor airspora. In the study, 25 genera were identified as both outdoors and indoors. By comparison, Aspergillus, Alternaria and Fusarium were greatly higher in outdoor environment, whereas Cladosporium, Penicillium, and Bipolar is represented higher prevalence in indoor environment (Khan et al., 1999).

In Qatar, only a single aeromycological study was conducted by Al-Subai (2002) in the period between March 1997 and March 1998 to intensively investigate the effect of seasonal and diurnal variations, and wind velocity on the dynamics of airborne fungal spore's population in the air of Doha. Gravimetric methodology was used for sampling. 35 genera and 73 species were identified. Cladosporium, Alternaria and Ulocladium were the most abundant genera in the atmosphere of Doha. Summer months, May and July, revealed the highest incidence of fungal airspora. Wind was positively correlated to the number of fungal colonies. Once more, Cladosporinm and Alternaria were the predominant concerning diurnal variations effect (Al-Subai, 2002). 
In Palestine, Barkai-Golan (1957) studied the distribution of airborne fungal spores in the atmosphere using plate's exposure method. In Tel-Aviv area, fungal airospora represented seasonal pattern in which their concentration reached the maximum in summer and autumn; while in winter, it was the minimum. In addition to that the author recognized a strong relationship between colonies number and wind velocity, the higher the wind speed, the greater the colonies number. The most frequently fungal spores were Hormodendrum, Penicillium, Aspergillus and Alternaria (Barkai-Golan, 1957). In 1962, Barkai-Golan \& Glazer studied airborne fungal spore concentration at two different areas in Palestine, TelHashomcr and Eilat. By comparison, the concentration of fungal airspora was much higher in Tel-Hashomcr than in Eilat. However, the fungal distribution in both areas represented seasonal variations in which the lower colonies count was recorded during winter and markedly increased during other seasons; moreover, five fungal genera represented the main airspora in both sites: Cladosporium, Alternaria, Prnicillium, Aspergillus, and Stemphylium with Cladosporium as the most dominant genera, followed by Alternaria (Barkai-Golan \& Glazer, 1962). During the years 1993-1995 and in three cities along the Palestine coastal line, the concentration of airborne fungal spores was monitored by Waisel et al., (1997) using volumetric sampler method. They identified fourteen different genera by which Cladosporium and Alternaria were the predominant fungal airspora. Minor monthly variation in atmospheric mold spores was realized among the three cities (Waisel et al., 1997).

In Jordan, Shaheen (1992) carried out an aeromycological study during the years 19871988, for the first time in Amman, to monitor the concentration and distribution of fungal 
aerosol and to initiate a fungal spore calendar for the first time in Jordan. Using volumetric method, the author was able to quantify thirty eight genera related to three classes. Between January and May, ascomycetcs were most frequent; basidiospores were more common during April and August, while deuteromycetcs were highly dominant in October. In terms of fungal genera fluctuation, the maximum incidence of Botrytis airspora was recorded in January, Cladosporium and Alternaria were greatly abundant in October. Furthermore, Cladosporium was found to be the main constitute of airspora in the atmosphere (Shaheen, 1992). About 16 years later, another aeromycological study was conducted by Abu-Dieyeh et al., (2010) from January 2008 to January 2009 to screen the concentration of airborne fungal spore in relation to seasonal variation of Zarqa area, Jordan. They deduced from 170 settle plate exposure that, Cladosporium was the most prevalent airspora, followed by Fusarium, Alternaria, Ulocladium, Penicillium and then Aspergillus. Various airborne fungi peaked in different months. For instance; Cladosporium peaked in October whereas Aspergillus and Penicillium showed a peak in September. Also, diurnal variations were examined during two separated seasons. Cladosporium, Fusarium and Alternaria, favored their release and dispersion into the atmosphere at 15:00 h during winter, however there were no differences in their release time during spring months (Abu-Dieyeh et al., 2010). Another research study was carried out using volumetric methods (spore trapping) by AbuDieyeh\& Barham (2014) to study the seasonal and intradermal variations affecting the concentration of atmospheric mould spora in Zarqa area, Jordan. 41 genera were recorded; yet again Cladosporium was the most abundant fungus among others. The dispersal of fungal airspora was positively correlated with air temperature and rain except for 
Alternaria, and negatively with relative humidity. Regarding the intradermal variations the release and dispersal of fungal spores favored period $20.00-04.00 \mathrm{~h}$ period. Even though, the two previous studies were conducted at the same area and almost during the same time, the authors concluded that the findings of the two methodologies might be complementary rather than comparable (Abu-Dieyeh \& Barham 2014).

Aeromycological studies were more frequently conducted in Egypt rather than other countries, especially during the last century and to a lesser extent in current century. AbdelHafez \& El-Said, (1989) studied the quantity and quality of airborne fungal spores in the air of Wadi Qena, Egypt. To identify 31 genera, 83 species and 2 varieties of fungal airspora, they utilized gravimetric method. The most prevalent fungal genera were Alternaria, Aspergillius, Cladosporium, Curvularia, Drechslera, Epicoccum, Penicillium, Stemphylium and Ulocladium. The total counts of previous airborne fungi showed fluctuated pattern along different seasons. Also they examined the survival ability (osmophilic and halophilic ability) of certain genera based on different media types and nutrients concentrations. Aspergillirs and Eurotium members presented great ability to grow and survive on media of high osmotic potential (Abdel-Hafez \& El-Said, 1989). In Assiut, the seasonal fluctuations of fungal airspora in the atmosphere and sediment dust were investigated for two years (January 1985 -December 1986) (Abdel-Hafez et al., 1993). 32 genera and 89 species were recorded from the air using settle plate-method, whereas 33 genera and 92 species were detected using the dilution plate-method related to sediment dust sample collecting method. The maximum counts of airborne fungi were observed during April and December 1985, while the highest concentrations of fungal 
spores revealed from sediment dust was recorded in February and November 1986. Alternaria, Aspergillits Cochliobolus, Penicillium, Pleospora and Ulocladitrrn were the most common mycoflora genera (Abdel-Hafez et al., 1993). Hameed et al. (2009) aimed from their study to investigate diurnal distribution of air microflora in in Helwan, Egypt during the period from March 2006 to February 2007. They used plate exposure method; they revealed that Aspergillus, Alternaria, Cladosporium and Penicillium were the most predominant genera. During winter season, the highest concentration of fungal airspora took place 2 hours earlier than other seasons. At 10:00 hours and 20:00 hours, Asperigillus showed two peaks. The overall concentration peaks of total fungal airspora regularly occurred at 20:00 hours (Hameed et al., 2009). An aeromycological study was conducted over a period of one year (2008-2009) to evaluate the airborne fungi concentrations and their seasonal fluctuations in indoor and outdoor environment of urban and rural homes in Egypt. Two-stage viable impactor samplers were used to collect samples. The total count of fungi was significantly greater in the rural site than in the urban site. In both, outdoor and indoor the fungal population presented seasonal variations. The highest fungal spore's prevalence was observed during autumn and spring. Similarly, in indoor and outdoor, Alternaria, Aspergillus, Cladosporium, Penicillium and yeasts were the most dominant genera (Awad et al., 2013).Very close to Arab countries, in Turkey, Çolakoglu (1996) monitored the concentration of air borne fungal spores at the Anatolia quarter of Istanbul using volumetric method during the period from January 1994 - December 1994. The most common fungal airspora were Cladosporium, Penicillium, Ustilago, Aspergillus, Alternaria, Botrytis, Leptosphaeria, Rhizopus, Helminthosporium and 
basidiospores.Cladosporium was the most abundant genera with maximum prevalence during windy weathers, then followed by Penicillium. They presented seasonal variations in which their maximum occurrence in summer season (Çolakoglu, 1996). In Eskisehir (Turkey), a study was conducted to identify airborne fungi in three different urban sites using culture method. The most frequent and predominant fungal genera were Alternaria alternata, Cladosporium cladosporioides and Scopulariopsis brevicaulis. The highest density of fungal spores was recorded in September, May and November, while the lowest observed concentration occurred in April, March and June (Asan et al., 2004).

The relationships between Alternaria and Cladosporium with meteorological conditions were investigated in Eskisehir City, Turkey throughout 2005 to 2006. Samples were collected using Durham gravimetric sampler throughout 3 different sites. Cladosporium spores count was as two third as Alternaria spores. For both genera, their ultimate distribution occurred in summer while the lowest was recorded in winter. Precipitation, temperature and wind velocity didn't represent significant impact on the fungal spore's concentration according to the sites; however, relative humidity had a significant effect on the dispersal rate of Cladosporium and Alternariaspores together (Erkara et al., 2009). In Iran, Nourian et al. (2007) carried out a study to monitor fungal airspora in the atmosphere of Zanjan-Iran. To achieve their objective, gravimetric method was used. The most predominant fungal spores in the air were yeast species, Cladosporium, Penicillum, Aspergillus and Alternaria. They presented seasonal variations in their distributions. Colonies count was the greatest in winter while the lowest was during summer season; yet, Cladosporium was the most abundant during all seasons. Negative correlation was detected 
between airborne fungal spores and temperature while they positively linked to relative humidity (Nourian et al., 2007). Also in Iran, the mycoflora in the air of Tehran was screened using gravitational settle plate method. The overall findings determined that the most common fungal spores in the air were of Aspergillus, Cladosporium, Penicillium and Alternaria species. Asperigillus was the predominant airborne fungal spores (ShamsGhahfarokhi et al., 2014).

Obviously, the variations in the concentration, composition and distribution of aeromycoflora of different countries in the Middle East were significantly influenced by the meteorological parameters, geographical and physical features. However, some fungal genera are common between those countries such Cladosporium, Alternaria Aspergillus and Penicillium. In Gulf region, only few aeromycological studies were conducted and many have been done since a long time and they may not reflect the present changes in the airborne fungal populations related to their biotic and abiotic surrounding features in those countries. Qatar is not an exception; the only study about fungal airospora in the air of Doha was conducted since 15 years that make the need for this present study necessary to update the knowledge about the seasonal and diurnal variations in airborne fungal spores of Doha area.

The main objectives of the present study are:

1- Provide baseline knowledge about density, diversity and dynamics of airborne fungal spore in the atmosphere of Doha using settle plate exposures. This knowledge is necessary for mycologists, applied ecologists, plant pathologists and other disciplines of biological, environmental and health sciences. 
2- Investigate variations in seasonal and diurnal distribution of airborne fungal spores, abundance, density and diversity and to correlate these variations with meteorological factors.

3- Investigate variations in diurnal distribution of airborne fungal spores, abundance, density and diversity during February and March (2016).

4- Correlate the variations in species composition and abundance of air-borne fungi with atmospheric $\mathrm{CO}_{2}$ concentration in two different areas in Qatar during February and March (2016) in order to investigate the impact of urbanization on air-borne fungal spore population.

5- Compare results obtained from two different cultural selective media: Potato Dextrose Agar (PDA) and Czapek's/ Rose-bengal media during February and March 2016. 


\section{CHAPTER THREE}

\section{MATERIALS AND METHODS}

\subsection{Study site}

Qatar is a peninsula occupies an area of more than $11,000 \mathrm{Km}^{2}$ and a coastline of $900 \mathrm{~km}$ in length. It lies between latitude $24 \circ 27$ and $26 \circ 10$ and longitude $50 \circ 45$ and $51 \circ 40$. of the Arabian Peninsula and connected to Saudi Arabia in the south, bordered by a very shallow, semi-enclosed sea characterized by hyper-salinity, salinity is ranging between 39 practical salinity unit (psu) and 41 practical salinity unit (psu) at the surface, and is 1-2psu higher at the bottom (Richer,2009). Geographically, it is a flat, rocky and arid desert and in the south sand dunes are the predominant features. As a subtropical desert, Qatar is hot and has a dry weather, the annual rainfall is about $81 \mathrm{~mm}$, and the average highest air temperature is $31^{\circ} \mathrm{C}$ although the maximum temperature can be beyond $47^{\circ} \mathrm{C}$ (Brook et al., 2006). Doha is the capital of the state, located on the eastern Qatari coastal line at $25^{\circ} 17^{\prime} 12^{\prime \prime} \mathrm{N}, 51^{\circ} 32^{\prime} 0^{\prime \prime} \mathrm{E}$. It is the most urbanized and populous city in the state, the number of population within the country until February-2015 is 2,116,400 (Ministry of Development Planning and Statistic's, Qatar 2015). Doha has been flourishing rapidly; it is the commercial and economic center of the state as well.

The present study was carried out at Qatar University which is located on the northern side of the capital Doha at $25.3747^{\circ} \mathrm{N}, 51.4903^{\circ} \mathrm{E}$. The main habitat and associated vegetation in northern part of Qatar is characterized by 'rodat' areas in which compact soils are common. This type of soils are usually support more moisture and organic matters than 
other desert parts. Vegetation type is usually ranges from trees, shrubs to grasses and herbs, commonly Acacia spp., Prosopis juliflora, Ziziphus nummularia and Lycium shawii. Because this area accommodates larger rodats, they have been utilized as farms for growing crops (Norton et al., 2009). Within the campus of University of Qatar, naturally occurring plants are widespread. In addition, many species associated with man-made and maninfluenced sites such as gardens, green houses and roadside are very common.

\subsection{Seasonal variations in air-borne fungal populations in Doha city}

A gravimetric method (settle plate exposure) using a Petri dish was carried out directly on the roof of the building of Qatar University (about $12 \mathrm{~m}$ above ground level). One Petri dish (9 cm diameter) containing Potato Dextrose Agar (PDA) (HiMedia Laboratories Pvt.Ltd, India)was exposed on the roof of the above mentioned building for 15 minutes, which result in more accurate colony counts, at 3:00 pm on each of 3 days a week (alternate days) from the beginning of April 2015 to the end of March 2016. A total exposure of (106) were collected during the year of study. After sampling, the plates were incubated at $25^{\circ} \mathrm{C}$ for 3-5 days. The fungal grown colonies for each species were counted and recorded. For classification, fungal colonies were isolated and purified on Potato Dextrose Agar( PDA) and other selective agars like Malt Extract Agar (MEA) (HiMedia Laboratories Pvt.Ltd, India), then they were incubated for 3-5 days. Identification was based on the macro- and microscopic features following the keys and description given by many authors like: Booth 
(1971), Domsch et al. (1980), Kozakiewicz (1989), Moubasher (1993), Pitt \&Hocking (1997), Barnett \&Hunter (1999), Samson et al. (2002) and Lacey \& West (2007).

Daily meteorological data from Qatar University weather station were supplied by the Weather Record Department, Doha, Qatar. The meteorological data considered are: minimum and maximum daily temperature, minimum and maximum relative humidity, daily rainfall, wind direction and wind speed.

\subsection{Intra-diurnal variations in air-borne fungal populations in Doha city}

February and March months (2016) were chosen to investigate intra-diurnal variations in fungal populations of Doha mainly because these are the months that expect to have the greatest diversity in species composition. One Petri dish (9 cm diameter) containing (PDA) was exposed for $15 \mathrm{~min}$ at 6 hours interval (at 6:00 am; 12:00 pm; 6:00 pm and 12:00 am) during the period of $1^{\text {st }}$ of February and 31 of March 2016. After sampling, the plates were incubated at $25{ }^{\circ} \mathrm{C}$ for 3-5 days. The fungal grown colonies for each species were counted and the total colony counts were recorded. For classification, fungal colonies were isolated and purified on (PDA) and other selective agars like (MEA), and then they were incubated for 3-5 days. Then, the above mentioned books and publications (section 3.2) were used for identification of fungal species.

During the whole period a data logger (OMEGA Engineering, INC., USA) was installed at the site of collection to monitor temperature and relative humidity in hourly time basis. 


\subsection{Effect of culture media used in sampling on species composition and abundance of fungal spore populations}

To differentiate between the potentiality of fungal growth on two different cultural media, two Petri dishes ( $9 \mathrm{~cm}$ diameter) containing (PDA) of the following compositing (Infusion from potato $200 \mathrm{~g} / \mathrm{l}$, dextrose $20 \mathrm{~g} / \mathrm{l}$ and Agar $15 \mathrm{~g} / \mathrm{l}$ )and Czapek's/Rose-Bengal agar with the following ingredients( Mycological peptone $5 \mathrm{~g} / \mathrm{l}$, Dextrose $10 \mathrm{~g} / \mathrm{l}$, Monopotassium phosphate $1 \mathrm{~g} / \mathrm{l}$, Magnesium sulphate $0.5 \mathrm{~g} / \mathrm{l}$, Chloramphenicol $0.1 \mathrm{~g} / \mathrm{l}$, Rose Bengal 0.05

g/l and Agar 15 g/l) (HiMedia Laboratories Pvt.Ltd, India)were exposed to the air for 15 minutes for three days weekly (alternate days) during the period of $1^{\text {st }}$ of February and 31 of March 2016.After sampling, the plates were incubated at $25^{\circ} \mathrm{C}$ for 3-5 days. The fungal grown colonies for each species were counted and the total colony counts were recorded. For classification, fungal colonies were isolated and purified on (PDA) and other selective agars like (MEA), and then they were incubated for 3-5 days. Then, the above mentioned books and publications (section 3.2) were used for identification of fungal species.

\subsection{Effect of urbanization and $\mathrm{CO}_{2}$ concentration on species composition and abundance of fungal spore populations}

Two locations at Doha city were chosen to investigate the impact of urbanization on species composition and abundance of fungal spore populations. Qatar University is one of these locations as relatively far from industrial areas and the other is close to the central industrial 
area of Doha (Industrial Area).Industrial area is a district of Doha, Qatar of coordinate $25^{\circ} 10^{\prime} 3^{\prime \prime} \mathrm{N} 51^{\circ} 26^{\prime} 22^{\prime \prime} \mathrm{E}$. It is mainly occupied with a working population as the main factories such as cement factories, auto repair garage and other industrial business are located there, where from a pre-investigation for three continuous days approved to have more $\mathrm{CO}_{2}$ concentration than Qatar University Campus.

During the period of 1st of February and 31 of March 2016, Petri dishes (9 $\mathrm{cm}$ diameter) containing (PDA) were exposed to the air for 15 minutes for three days weekly (alternate days). In respect to the two locations and during sampling the plates were opened at the same time and for the same exposure period (15 min.). After sampling, the plates were incubated at $25{ }^{\circ} \mathrm{C}$ for $3-5$ days. The fungal grown colonies for each species were counted and the total colony counts were recorded. For classification, fungal colonies were isolated and purified on (PDA) and other selective agars like (MEA), and then they were incubated for 3-5 days. Then, the above mentioned books and publications (section 3.2) were used for identification of fungal species.

During sampling and in each location, a portable $\mathrm{CO}_{2} /$ Temperature/RH data logger (CO2METER.COM, USA) was used to record $\mathrm{CO}_{2}$ concentration, Temperature, and Relative humidity every minute during the collection period (15 min.). The average of the 15 readings was considered for each collection record. 


\subsection{Statistical and data analysis}

Statistical analyses were performed to correlate the mean daily fungal spore concentrations and species composition with the daily data of the meteorological parameter of the same day and for the whole year using Pearson correlation coefficient. Similar correlation analyses were performed for the two months study to investigate the effect of $\mathrm{CO}_{2}$ on species composition and abundance.

Results of different measured parameters from the two different cultural media as well as results from the tow different locations were compared after being subjected to T-test at $\mathrm{P}$ $\leq 0.05$. ANOVA was used to detect the significant differences in species diversity and abundance among the four diurnal periods and then means of variables were separated using Tukey test at $P \leq 0.05$ (SigmaStat 4, Systat Software, Inc).

Jaccard similarity coefficient (Jaccard, 1908) was applied to compare the similarities in species composition (including species identified at specific level and other taxa) among the four diurnal periods as follows: Jaccard similarity coefficient $=(c /(a+b)-c) * 100 . \mathrm{C}=$ number of common species between any two time periods ( $\mathrm{a} \& \mathrm{~b}$ ). 


\section{CHAPTER FOUR}

\section{RESULTS}

\subsection{Seasonal variation of fungal spore populations in the atmosphere of Doha}

From the air of Doha, the total colony count number retrieved from 106 exposure samplings during the year of study ( $1^{\text {st }}$ of Apr $2015-31^{\text {st }}$ of March 2016) using gravimetric method was 283 yeast and 1197 mould colony forming units (CFU). The mould colonies were belong to 21 genera and 62 species (Table 1). Due to difficulties in identification, certain mould colonies were only identified to genus level such as Acremonium, while others were referred to as unknown. The maximum concentration of airborne fungal spores was recorded in February (2016), whereas the minimum occurred in September (2015). The main constituents of the airborne fungi population in the atmosphere of Doha were attributed to the genera: Cladosporium (60.2\%), Aspergillus (10.4\%) Fusarium (9.4\%), Alternaria (8.5 \%), Ganoderma spp.(2.3\%) and Penicillium (2.0\%) (Figure 1). Cladosporium was the most common fungal taxa in the air of Doha compromising around two thirds of the total colony counts and representing with five species. C. cladosporioides was the most dominant species with $70.5 \%$ of the total of the genus Cladosporium, followed by $C$. macrocarpum with $9.2 \%$, and the third common one was $C$. sphaerosprmum with 6.4\%. Cladosporium had double peaks in April (2015) and in February (2016) and a trough in July (2015) (Table 1; Figure 3). Aspergillus sp. was the second predominant fungal genera and represented with ten species (Table 1). Aspergillus achieved the highest concentration in August (2015) and the lowest in January (2016) (Figure 3) A. flavus represented by $46.5 \%$ of the total of the genus Aspergillus, then $A$. 
sydowii with $25.2 \%$ (Table 1; Figure 1). Fusarium was ranked as the third among the most common airborne fungi in Doha. Most of recovered colonies of Fusarium were identified to genus level, however $F$. oxysporum and $F$. clamydosporum were the most abundant and frequently recorded (Table 1). Alternaria represented the fourth most prevalent fungal taxa with seven identified species. The spore's concentration of A. alternata put up with more than the half of the whole genus (61.4\%), followed by A. chlamydospora (12.8\%), then $A$. infectoria (11.9\%) (Table 1; Figure 1). Both Alternaria and Fusarium reached their maximum concentrations in July (2015), the density of Alternaria spores declined in June (2015), while Fusarium colony counts diminished in January (2016) (Figure 3). Interestingly Ganoderma spp. was ranked the fifth among the most predominant fungi in the atmosphere of Doha with $2.4 \%$ abundance, even though they exclusively appeared in February and March (2016) of the whole year (Table 1; Figure 1).

The correlation analyses between weather parameters and the incidence of the main fungal taxa, total daily or monthly colony count and species diversity were represented in Table 2. Both daily and monthly counts of either of Cladosporium or Alternaria spores showed a significant negative correlation $(P \leq 0.05)$ with daily maximum, minimum and mean temperatures. While the correlations of Cladosporium colony count with both daily or monthly relative humidity and rainfall were not significant, the monthly rainfall data showed a highly significant correlation $(P \leq 0.01)$ with Alternaria colony counts. Highly significant $(P \leq 0.01)$ positive correlation was appeared between daily counts of Cladosporium and Alternaria and daily wind speed (Table 2). In contrary, Aspergillus concentration showed a non-significant correlations with any of the studied weather 
parameters (Table 2). Fusarium daily colony counts had only a significant correlation $(P \leq$ 0.01 ) with the daily wind speed data (Table 2). Total daily colony counts of all encountered fungi showed significant negative correlations $(P \leq 0.05)$ with any of the daily temperature parameters. A highly significant positive correlation $(P \leq 0.01)$ was also obtained between the total daily or monthly colony count and daily or monthly wind velocity (Table-2 \& Figure 2) and a non-significant correlation with either daily mean relative humidity or rainfall. However no significant correlations were reported between total colony counts and either of relative humidity or rainfall. Daily temperature parameters possessed highly significant $(P \leq 0.01)$ negative correlations with fungal species diversity of Doha atmosphere while daily wind speed data possessed - highly significant positive correlation $(P \leq 0.01)$ with species diversity (Table $2 \&$ Figure 2$)$. No statistically significant correlations on air-borne fungi had been reported due to wind direction (Table 2). Figure (4) represents the fungal spore calendar for air-borne fungi in the atmosphere of Doha and their seasonal patterns. The highest concentration of fungal colony counts was reported in February (2016), while the lowest was recorded in August (2015). The highest number of fungal species was reported in February (2016), while the lowest was obtained in September (2015). C. cladosporoides prevailed in the atmosphere of Doha in relatively very high concentrations (4.5-16 colonies per exposure) in all months. Ganoderma occurred only in two months of the whole year with concentration (0.8-1.8 colonies per exposure). 
Table 1. Total colony count and occurrence of airborne fungi recovered from the air of Doha during the study period ( $1^{\text {st }}$ of Apr $2015-31^{\text {st }}$ of March 2016) using gravimetric method (a total of 106 exposure samplings).

\begin{tabular}{|c|c|c|c|c|}
\hline Fungal Taxa & $\begin{array}{c}\text { No. of } \\
\text { colonies }\end{array}$ & $\begin{array}{l}{ }^{(a)} \text { Colony } \\
\text { count } \\
(\%)\end{array}$ & $\begin{array}{l}{ }^{(b)} \text { Monthly } \\
\text { occurrence }\end{array}$ & $\begin{array}{c}\text { Month of } \\
\text { occurrence }\end{array}$ \\
\hline Acremonium sp. & 3 & 0.25 & 1 & Dec \\
\hline Acrophialophora & 4 & $\mathbf{0 . 3 3}$ & 1 & Jun \\
\hline Acrophialophora fusispora (S.B. & & & & \\
\hline Saksena) Samson & 4 & 0.33 & 1 & Jun \\
\hline Agaricales sp. & 2 & 0.17 & 1 & Mar \\
\hline Alternaria & 102 & 8.52 & 11 & $\begin{array}{l}\text { Entire year except } \\
\text { June }\end{array}$ \\
\hline Alternaria alternate (FR.) & & & & Entire year except \\
\hline Keissler & 62 & 5.18 & 11 & June \\
\hline $\begin{array}{l}\text { Alternaria brassicicola } \\
\text { (Schwein.) Wiltshire } \\
\text { Alternaria chlamydospora }\end{array}$ & 3 & 0.25 & 1 & Feb \\
\hline $\begin{array}{l}\text { Mouchacca } \\
\text { Alternaria infectoria E.G. }\end{array}$ & 13 & 1.09 & 3 & Dec,Jan,Feb \\
\hline $\begin{array}{l}\text { Simmons } \\
\text { Alternaria phragmospora } \mathrm{V} \text {. }\end{array}$ & 12 & 1.00 & 1 & Mar \\
\hline Emden & 2 & 0.17 & 2 & Feb,Apr \\
\hline $\begin{array}{l}\text { Alternaria porri (Ellis) Cif. } \\
\text { Alternaria tenuissima (Kunze) }\end{array}$ & 4 & 0.33 & 1 & Dec \\
\hline Wilt. & 6 & 0.50 & 2 & May,Jul \\
\hline Aspergillus & 124 & 10.36 & 12 & Entire year \\
\hline Aspergillus flavus Link & 59 & 4.93 & 11 & $\begin{array}{l}\text { Entire year except } \\
\text { Jan }\end{array}$ \\
\hline Aspergillus fumigatus Fresenius & 2 & 0.17 & 1 & Nov \\
\hline $\begin{array}{l}\text { Aspergillus melleus Yukawa } \\
\text { spergillus niger (V. Tiehem) }\end{array}$ & 3 & 0.25 & 1 & Dec \\
\hline $\begin{array}{l}\text { Blochw } \\
\text { Aspergillus sulphereus (Fres.) }\end{array}$ & 9 & 0.75 & 3 & Jul,Aug,Sep \\
\hline $\begin{array}{l}\text { Thom \& Church } \\
\text { Aspergillus sydowii (Bainier \& }\end{array}$ & 2 & 0.17 & 1 & Mar \\
\hline Sartory) Thom \& Church & 32 & 2.67 & 4 & Dec,Jan,Feb,Mar \\
\hline $\begin{array}{l}\text { Aspergillus terreus Thom } \\
\text { Aspergillus versicolor (Vuill.) }\end{array}$ & 3 & 0.25 & 2 & Apr,May \\
\hline $\begin{array}{l}\text { Tiraboschi } \\
\text { Aspergillus carbonarius }\end{array}$ & 3 & 0.25 & 1 & Oct \\
\hline (Bainier) Thom & 4 & 0.33 & 3 & Nov,Jan,Feb \\
\hline Aspergillus japonicas Saito & 2 & 0.17 & 1 & Sep \\
\hline $\begin{array}{l}\text { Aspirgillus ustus (Bain.) Thom \& } \\
\text { Church }\end{array}$ & 5 & 0.42 & 2 & Jul,Feb \\
\hline
\end{tabular}




\section{Blastomyces sp. \\ Cladosporium}

Cladosporium cladosporioides

(Fres) de Vries

Cladosporium herbarum (Pers.)

Link

Cladosporium macrocarpum

Preuss

Cladosporium oxysporum Berk.

\& M.A. Curtis

Cladosporium sp.

Cladosporium sphaerosprmum

Penzig

Cladosporium tenuissimum

Cooke

\section{Cochliobolus}

Cochliobolus australiencsis

(Tsuda \& Ueyama) Alcorn

Cochliobolus hawaiinsis Alcorn (anamorph)

Cochliobolus lunatus Nelson \&

Haasis (anamorph)

Cochliobolus spicifer Nelson (anamorph)

\section{Epicoccum}

Epicoccum nigrum

\section{Fusarium}

Fusarium sp.

Fusarium clamydosporum

Wollenweber \& Reinking

Fusarium dimerum Penzig

Fusarium moriliforme (A.

Braun) Wollenweber

Fusarium oxysporum Schlecht.

\section{Ganoderma spp.}

Geotrichum

Geotrichum candidum Link

Mucor sp.

Myrothecium

Myrothecium verrucaria (Alb. \& Schwein) Ditmar

\section{2}

721

509

80

46

3

18

6

3

4

5

2

2

113

76

10

8

3

16

28

2

2

2

2

2
42.52

0.33

5.51

1.09

6.68

3.84

0.25

1.50

0.17

60.23

68

84

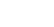

0.50

0.25

0.33

0.42

0.17

0.17

9.44

6.35

0.84

0.67

0.25

1.34

2.34

0.17

0.17

0.17

0.17

0.17

2.01
Dec

Entire year

Entire year

Oct,Dec,Feb

Entire year except Jun,Aug and Sep

Feb,Mar,Apr,May

Apr

Entire year except

Nov

Nov,Feb,Mar

Apr,Jun,Jul,Aug, Sep,Oct,Dec

Jun,Jul,Sep

Aug

Apr

Oct,Dec

May,Jun

May,Jun

Entire year

Jan,Feb,Mar,Apr,

May,Oct,Nov

Nov,dec,Jan,Feb,M

ar

Apr,May,

Dec,Feb,Mar

Oct

Oct,Nov,Dec,Feb,

Mar,Apr,

Feb,Mar

Jun

Jun

Mar

Dec

Dec 


\section{Penicillium}

Penicillium sp.

Penicillium breivicapmactum

Dierckx

Penicillium canescens Sopp

Penicillium citrinum Thom

Penicillium italicum Wehmer

Penicillium steckii K.M.

Zalessky

Phoma

Phoma glomerata (Corda)

Wollenw.

Pleospora
Pleospora tarda Simmons
Rhizopus

Rhizopus oryzae Went \&

Prinsen-Geerligs

Rhizopus stolonifer (Ehrenb.)

Lind

Stachybotrys

Stachybotrys chartarum

(Ehrenb.) Hughes

Stachybotrys elegans (Pidopl.)

W. Gams

Thanatephorus

Thanatephorus cucumeris

(Frank) Donk

\section{Ulocladium}

Ulocladium botrytis Preuss

Ulocladium chartarum (Preuss)

Simmons

\begin{tabular}{c} 
UNKNOWN \\
\hline MOULDS
\end{tabular}

24

\section{3}

2

\section{5}

2

3

6

\section{3}

3

2

2

15

9

0.58

0.58

0.42

0.17

0.25

0.50

0.25

0.25

0.17

0.17

1.25

0.75

0.50

0.75

80.88

19.12

Total No. of Fungal colonies

9
1197
283

\begin{tabular}{|c|c|}
\hline 4 & $\begin{array}{l}\text { Jan,Feb,Mar, } \\
\text { May,Jun }\end{array}$ \\
\hline 1 & Feb \\
\hline 1 & Mar \\
\hline 1 & Feb \\
\hline 1 & May \\
\hline 2 & May,Jun \\
\hline 1 & Jan \\
\hline 1 & Mar \\
\hline 1 & Mar \\
\hline 3 & Apr,May, DEC \\
\hline 3 & Apr,May, DEC \\
\hline 2 & Jan, Mar \\
\hline 1 & Jan \\
\hline 2 & Mar \\
\hline 2 & Dec,Mar \\
\hline 1 & Dec \\
\hline 1 & Mar \\
\hline 1 & Jan \\
\hline 1 & Jan \\
\hline 4 & \\
\hline 2 & Mar,Jul \\
\hline 2 & Mar,May \\
\hline 3 & Jan,Mar,May \\
\hline 12 & Entire year \\
\hline 12 & Entire year \\
\hline
\end{tabular}

1480

(a) calculated as a percentage of the total count of mold colonies recovered from the entire study (i.e a total of 1180 colonies from 106 exposures $=$ days).

(b) number of months of occurrence out of 12 months 


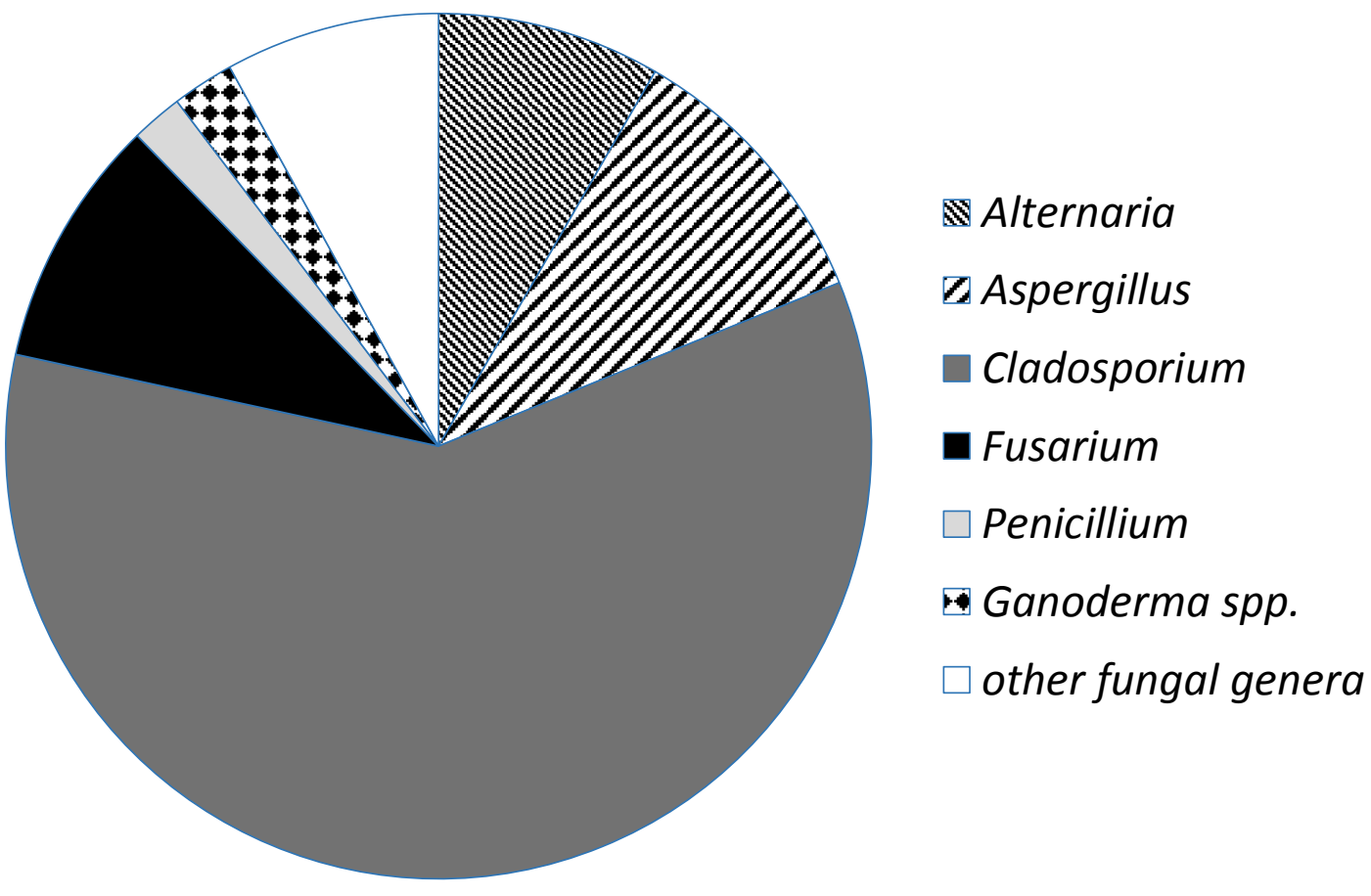

Figure 1. The composition of fungal constituents $(\%)$ in the atmosphere of Doha City during $\left(1^{\text {st }}\right.$ of Apr $2015-31^{\text {st }}$ of March 2016) using gravimetric method (a total of 106 exposure samplings). 
Table 2. Monthly climatic parameters of Doha during the year of study versus results of correlation analysis. The correlation was accomplished based on daily data as well as monthly data and using Pearson correlation coefficient.

\begin{tabular}{|c|c|c|c|c|c|c|c|}
\hline & $\begin{array}{l}\text { Maximum } \\
\text { Temperature } \\
\left({ }^{0} \mathrm{C}\right)\end{array}$ & $\begin{array}{l}\text { Minimum } \\
\text { Temperature } \\
\quad\left({ }^{0} \mathrm{C}\right)\end{array}$ & $\begin{array}{c}\text { Mean } \\
\text { Temperature } \\
\quad\left({ }^{0} \mathrm{C}\right)\end{array}$ & $\begin{array}{c}\text { Mean } \\
\text { Relative } \\
\text { Humidity } \\
(\%)\end{array}$ & $\begin{array}{l}\text { Total } \\
\text { Rainfall } \\
(\mathrm{mm})\end{array}$ & $\begin{array}{l}\text { Mean } \\
\text { Wind } \\
\text { Speed } \\
(\mathrm{m} / \mathrm{s}) \\
\end{array}$ & $\begin{array}{l}\text { Mean } \\
\text { Wind Direction } \\
\text { (degree.) }\end{array}$ \\
\hline Apr 2015 & 35.5 & 23.6 & 29.0 & 27.6 & 0.0 & 4.3 & 255.7=WSW \\
\hline May & 41.0 & 28.7 & 34.4 & 26.0 & 0.0 & 4.2 & $243.3=W S W$ \\
\hline Jun & 42.2 & 29.8 & 35.8 & 31.7 & 0.0 & 4.3 & 297.1=WNW \\
\hline Jul & 40.7 & 32.2 & 36.2 & 45.0 & 0.0 & 3.7 & $230.0=\mathrm{SW}$ \\
\hline Aug & 41.8 & 32.1 & 36.1 & 58.9 & 0.0 & 2.7 & $214.3=\mathrm{SW}$ \\
\hline Sep & 39.9 & 30.0 & 34.3 & 55.8 & 0.0 & 2.5 & $265.0=\mathrm{W}$ \\
\hline Oct & 36.7 & 27.2 & 31.4 & 59.9 & 0.0 & 2.7 & $308.3=\mathrm{NW}$ \\
\hline Nov & 29.4 & 21.3 & 25.0 & 66.7 & 0.0 & 2.4 & $317.8=\mathrm{NW}$ \\
\hline Dec & 23.7 & 15.9 & 19.5 & 69.7 & 0.2 & 3.0 & $292.5=W N W$ \\
\hline Jan 2016 & 22.9 & 14.3 & 18.1 & 66.3 & 0.1 & 3.1 & $256.3=W S W$ \\
\hline Feb & 24.0 & 15.5 & 19.4 & 59.5 & 0.0 & 2.9 & 233.1=SW \\
\hline March & 27.6 & 19.0 & 23.1 & 58.3 & 1.3 & 3.1 & $185.7=S$ \\
\hline \multicolumn{8}{|c|}{ Correlation Coefficients / Daily weather data Vs. Daily data of number of fungal colonies } \\
\hline Cladosporium & $-0.231 *$ & $-0.228 *$ & $-0.237 *$ & -0.0828 & -0.0328 & $0.427 * *$ & 0.175 \\
\hline Alternaria & $-0.243 *$ & $-0.193 *$ & $-0.222 *$ & 0.0125 & -0.0243 & $0.323 * *$ & -0.111 \\
\hline Aspergillus & 0.0135 & 0.0347 & 0.0209 & 0.0459 & -0.0737 & 0.0779 & 0.0909 \\
\hline Fusarium & 0.025 & 0.0906 & 0.0673 & -0.0697 & -0.0276 & $0.329 * *$ & 0.084 \\
\hline $\begin{array}{l}\text { Total daily } \\
\text { colony count }\end{array}$ & $-0.23 *$ & $-0.215^{*}$ & $-0.231 *$ & -0.102 & -0.0519 & $0.484 * *$ & 0.155 \\
\hline $\begin{array}{c}\text { Total daily } \\
\text { number of } \\
\text { species }\end{array}$ & $-0.26 * *$ & $-0.26^{* *}$ & $-0.267 * *$ & -0.0249 & -0.0917 & $0.257 * *$ & 0.143 \\
\hline \multicolumn{8}{|c|}{ Correlation Coefficients / Monthly weather data Vs. Monthly data of total number of colonies } \\
\hline Cladosporium & $-0.625^{*}$ & $-0.703 *$ & $-0.666^{*}$ & 0.14 & 0.108 & 0.129 & 0.267 \\
\hline Alternaria & $-0.203 * *$ & $-0.154 *$ & $-0.18 * *$ & 0.36 & $0.562 * *$ & -0.253 & 0.569 \\
\hline Aspergillus & -0.724 & -0.696 & -0.712 & 0.468 & 0.77 & -0.141 & -0.179 \\
\hline Fusarium & 0.0846 & 0.0595 & 0.0821 & -0.217 & 0.125 & 0.37 & -0.348 \\
\hline $\begin{array}{l}\text { Total monthly } \\
\text { colony count }\end{array}$ & -0.684 & 0.189 & 0.189 & 0.189 & 0.307 & 0.115 & 0.181 \\
\hline $\begin{array}{l}\text { Total monthly } \\
\text { number of } \\
\text { species }\end{array}$ & -0.642 & -0.681 & -0.66 & 0.173 & 0.468 & 0.022 & -0.241 \\
\hline
\end{tabular}

(**) Highly significant correlation at $P \leq 0.01$

(*) Significant correlation at $P \leq 0.05$ 

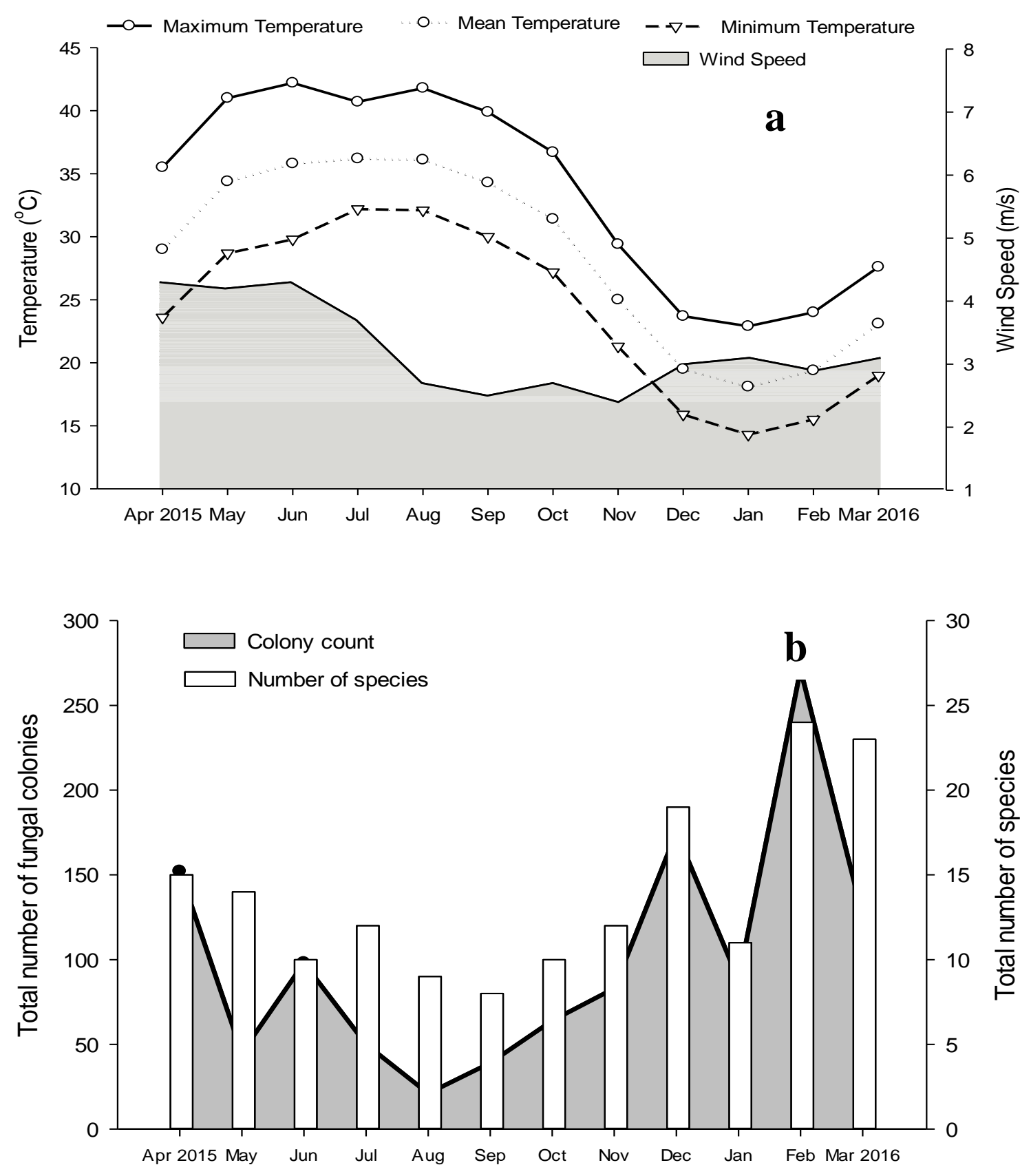

Figure 2. Temperature and wind speed (a) versus total colony count and total number of species (b) recovered each month during the year of study ( $1^{\text {st }}$ of Apr $2015-31^{\text {st }}$ of March 2016) using gravimetric method (a total of 106 exposure samplings). Significant positive correlations were obtained between wind speed and both of colony count and number of species while negative correlations were obtained between any of temperature parameters and both of colony count and species number. 


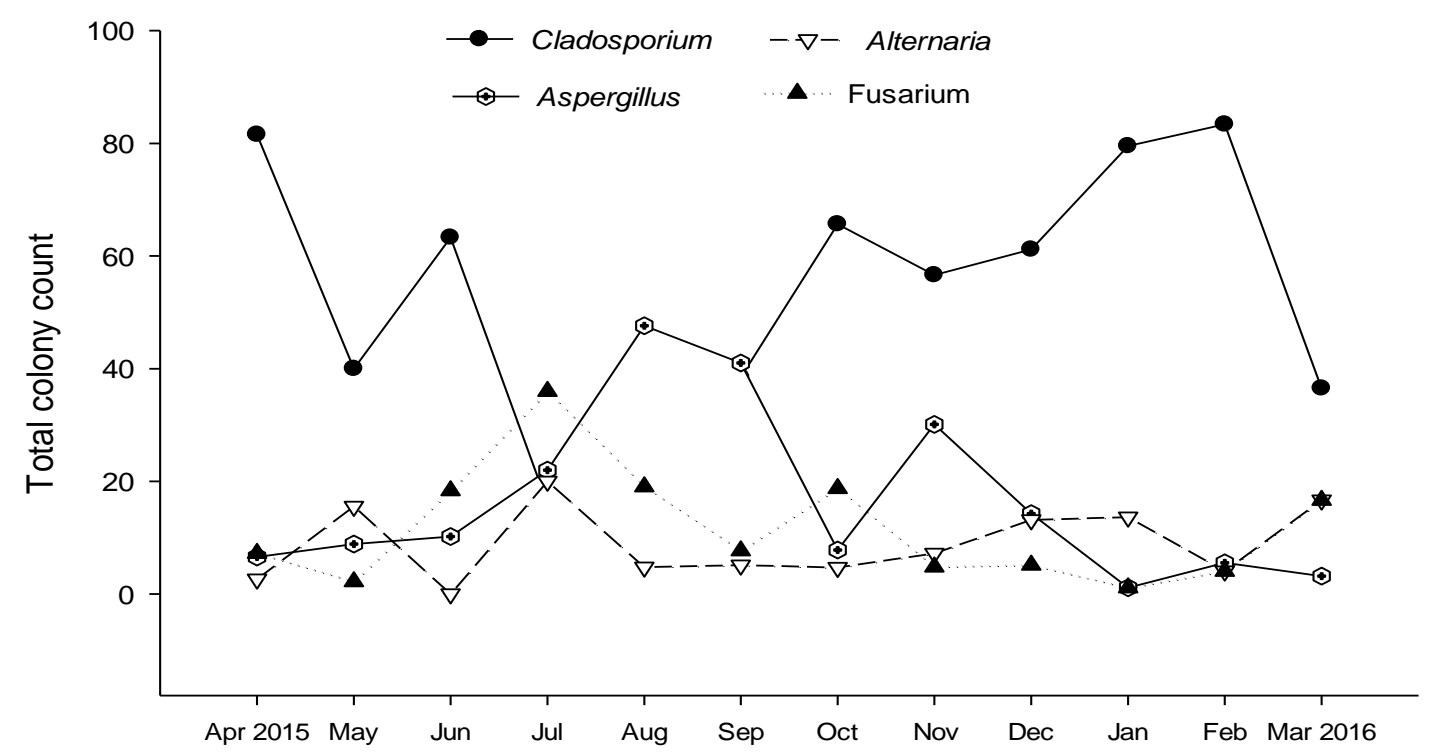

Figure 3. Seasonal variation of the four most common fungal genera in the atmosphere of Doha during the year of study ( $1^{\text {st }}$ of Apr $2015-31^{\text {st }}$ of March 2016) using gravimetric method (a total of 106 exposure samplings). 

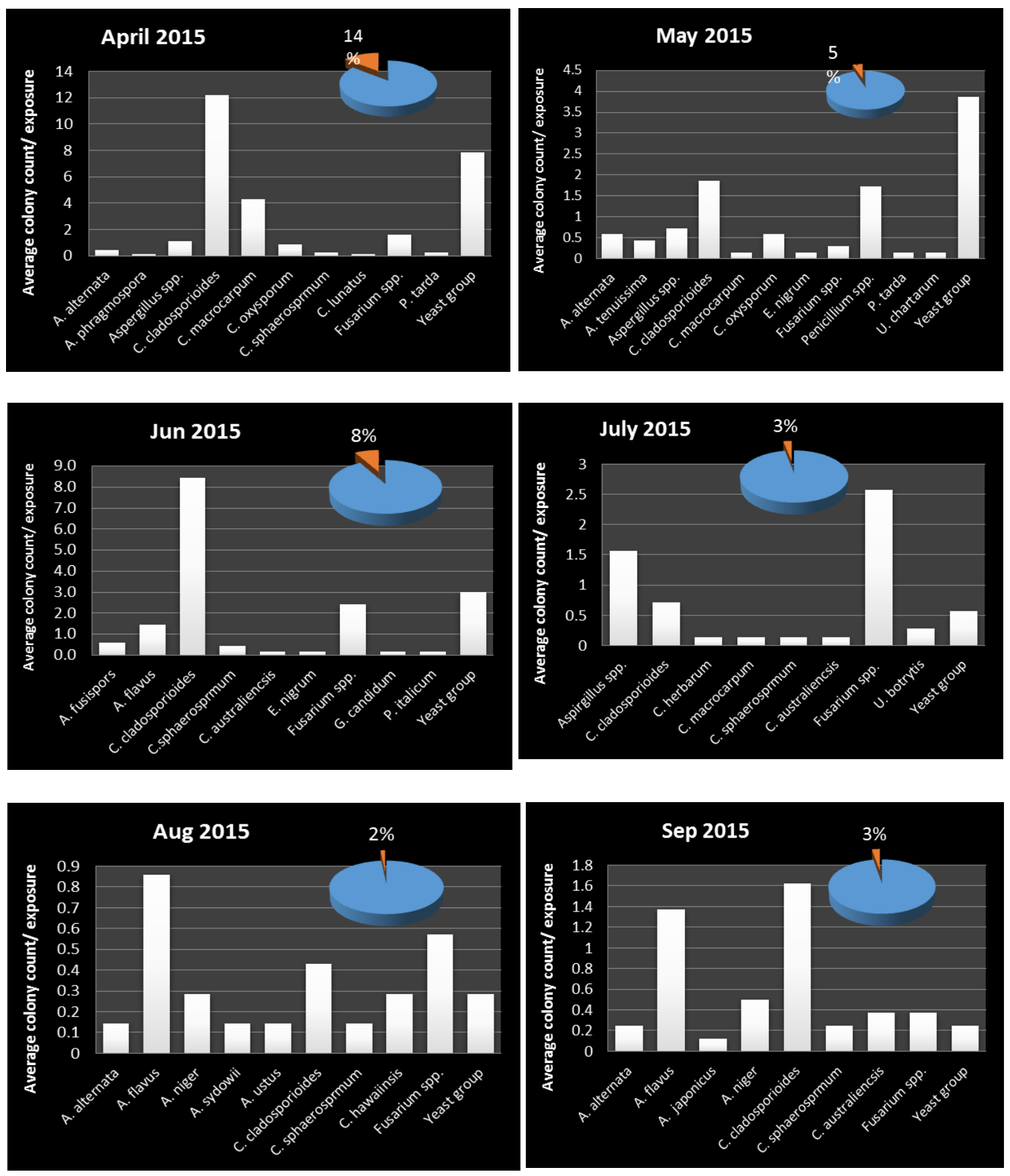

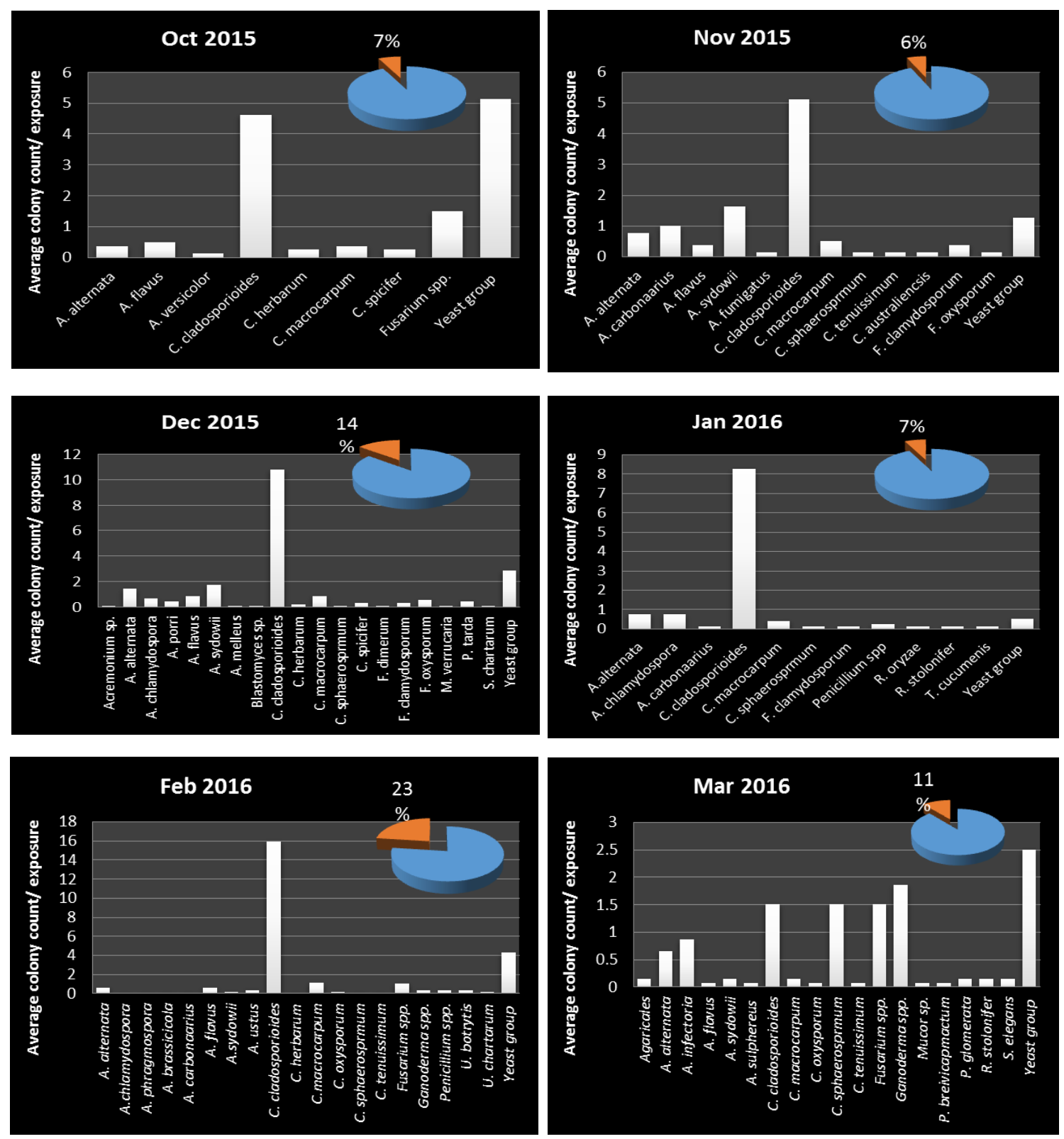

Figure 4. Fungal spore calendar for air-borne fungi in the atmosphere of Doha. The values are based on the average daily colony count of each fungal taxa recovered on PDA culture plates. The Pie graph reflects how much of total fungal colonies (\%) reported in a month compared to the summation of all fungal colony counts reported in the whole year. The highest $\%$ of fungal colonies occurred during February 2016 (23\%), while the lowest occurred in August 2015 (2\%). 


\subsection{Diurnal variation of fungal spore populations in the atmosphere of Doha}

Diurnal variations were studied throughout two months $\left(1^{\text {st }}\right.$ of Feb - $31^{\text {st }}$ of March 2016) with a total of 72 exposure samplings. During the two months of the study, the mean daily maximum temperature ranged from 24.6 to $27.3{ }^{\circ} \mathrm{C}$, the mean daily minimum temperature ranged from 15.0 to $18.7^{\circ} \mathrm{C}$. The daily relative humidity ranged from 39 to $84 \%$. Table (3) shows the diurnal variation of fungal species richness and abundance of air-borne fungi in the atmosphere of Doha. Significant differences at $P \leq 0.05$ in colony count and species diversity were found among the four studied time periods. The highest colony count and species diversity were recovered at 18:00 $\mathrm{h}$ while the least were reported at 00:00 $\mathrm{h}$ (midnight). No significant differences in colony count as well as species diversity occurred between 12:00 and 18:00 $\mathrm{h}$ (Table 4). Jaccard similarity index was used to calculate the similarity coefficient among diversity of fungal species recovered from the four time periods. The highest index value reflects the highest similarity in species composition recovered between the two periods. The highest similarity coefficient was obtained between 00:00h and 06:00h, while the lowest similarity coefficient was detected between 18:00 $\mathrm{h}$ and 12:00 $\mathrm{h}$ (Table 5). The mean daily colony count was negatively correlated ( $P$ $\leq 0.05)$ with mean daily relative humidity and positively correlated $(P \leq 0.05)$ with mean daily temperature (Figure 5). However no significant correlations were found between species diversity and any of weather parameter. Interestingly the mean daily count of the genera Alternaria and Ganoderma were shown significant positive correlation $(P \leq 0.05)$ with the mean daily temperature. The most abundant fungal taxa retrieved throughout the two months at the four time periods were Cladosporium cladosporioides, Alternaria spp., 
Fusarium spp., Ganoderma, Ulocladium botrytis and Aspergillus (Figure 6). Cladosporium cladosporioides represented a mid-day (12:00 h) peak and had a minor peak at 18:00 h, while its concentration significantly declined $(P \leq 0.05)$ at midnight $(00: 00 \mathrm{~h})$ and in the early morning $(06: 00 \mathrm{~h})$. Ganoderma spp. significantly peaked $(P \leq 0.05)$ at 18:00 $\mathrm{h}$ and shown similar abundance among the other three time periods. Alternaria had a significant midday $(12: 00 \mathrm{~h})$ peak pattern, while the colony count significantly declined in the other three periods. No significant differences in Fusarium colony count were reported among the four studied time periods while Aspergillus had a major peak pattern at 18:00 $\mathrm{h}$ and Ulocladium botrytis at midnight (00:00 h) (Figure 6). 
Table 3. Diurnal variation of fungal species richness and abundance of air-borne fungi in the atmosphere of Doha, Qatar. A total of 72 exposure samplings during the period ( $1^{\text {st }}$ of Feb - $31^{\text {st }}$ of March 2016).

\begin{tabular}{|c|c|c|c|c|}
\hline \multirow[b]{2}{*}{ Fungal species } & \multicolumn{4}{|c|}{ Total colony count } \\
\hline & 6:00 AM & $\begin{array}{c}\text { 12:00 } \\
\text { PM }\end{array}$ & $\begin{array}{c}\text { 18:00 } \\
\text { PM }\end{array}$ & $00.00 \mathrm{AM}$ \\
\hline Agaricales & 0 & 0 & 1 & 0 \\
\hline Alternaria alternata & 6 & 17 & 18 & 13 \\
\hline Alternaria chlamydospora & 5 & 2 & 3 & 2 \\
\hline Alternaria phragmospora & 1 & 3 & 0 & 1 \\
\hline Alternaria infectoria & 5 & 1 & 2 & 0 \\
\hline Alternaria tenuissima & 0 & 1 & 0 & 0 \\
\hline Aspergillus sp. & 1 & 1 & 2 & 1 \\
\hline Aspergillus flavus & 1 & 2 & 7 & 4 \\
\hline Aspergillus sydowii & 2 & 0 & 0 & 0 \\
\hline Botrytis sp. & 0 & 1 & 0 & 0 \\
\hline Cladosporium cladosporioides & 23 & 77 & 57 & 11 \\
\hline Cladosporium herbarum & 0 & 0 & 0 & 2 \\
\hline Cladosporium macrocarpum & 3 & 5 & 10 & 0 \\
\hline Cladosporium oxysporum & 5 & 6 & 12 & 4 \\
\hline Cladosporium sphaerosprmum & 5 & 13 & 4 & 4 \\
\hline Cladosporium tenuissimum & 2 & 0 & 4 & 1 \\
\hline Cochliobolus hawaiinsis & 0 & 0 & 0 & 1 \\
\hline Fusarium (genus) & 5 & 7 & 6 & 6 \\
\hline Corynascus sepedonium & 0 & 0 & 2 & 0 \\
\hline Emericella quadrilineata & 0 & 0 & 1 & 0 \\
\hline Fusarium dimerum & 11 & 2 & 6 & 4 \\
\hline Fusarium clamydosporum & 8 & 6 & 2 & 2 \\
\hline Fusarium oxysporum & 9 & 8 & 5 & 4 \\
\hline Fusarium moriliforme & 0 & 2 & 0 & 0 \\
\hline Fusarium tenиissimum & 0 & 0 & 2 & 0 \\
\hline Ganoderma spp & 35 & 35 & 54 & 12 \\
\hline Gilmaniella humicola & 0 & 1 & 0 & 0 \\
\hline Gibberella intricans & 2 & 0 & 1 & 0 \\
\hline Penicillium canescens & 0 & 0 & 3 & 0 \\
\hline Humicola sp. & 0 & 0 & 1 & 0 \\
\hline Penicillium chrysogenum & 0 & 0 & 1 & 0 \\
\hline Penicillium citricum & 3 & 0 & 1 & 0 \\
\hline Penicillium brevicampactum & 4 & 0 & 1 & 0 \\
\hline Penicillium italicum & 0 & 0 & 1 & 0 \\
\hline Phoma sorghina & 1 & 0 & 2 & 0 \\
\hline Rhizopus oryzae & 0 & 1 & 0 & 0 \\
\hline Thanatephorus cucumenis & 0 & 1 & 2 & 0 \\
\hline Trichoderma viride & 5 & 0 & 0 & 0 \\
\hline Ulocladium botrytis & 0 & 3 & 2 & 7 \\
\hline Ulocladium chartarum & 1 & 0 & 1 & 0 \\
\hline Total colony count & 143 & 195 & 214 & 79 \\
\hline Total species & 23 & 23 & 30 & 15 \\
\hline
\end{tabular}


Table 4. Diurnal variation of species richness and abundance of air-borne fungi in the atmosphere of Doha, Qatar, in respect to variation in temperature and relative humidity. Within each column, values with common letters are not significantly different at $P \leq 0.05$ according to Tukey's test. A total of 72 exposure samplings during the period ( $1^{\text {st }}$ of Feb $31^{\text {st }}$ of March 2016).

\begin{tabular}{ccccc}
\hline Sampling time & $\begin{array}{c}\text { Mean Temp } \\
{ }^{\mathbf{0}} \mathbf{C}\end{array}$ & $\begin{array}{c}\text { Mean RH } \\
\%\end{array}$ & $\begin{array}{c}\text { Total colony } \\
\text { count }\end{array}$ & $\begin{array}{c}\text { Total number } \\
\text { of fungal } \\
\text { species }\end{array}$ \\
\hline $6: 00 \mathrm{~h}$ & 18.2 & 70.3 & $143 \mathrm{bc}$ & $23 \mathrm{ab}$ \\
$12: 00 \mathrm{~h}$ & 24.5 & 43 & $195 \mathrm{ab}$ & $23 \mathrm{ab}$ \\
$18: 00 \mathrm{~h}$ & 23.1 & 52.5 & $214 \mathrm{a}$ & $30 \mathrm{a}$ \\
$00: 00 \mathrm{~h}$ & 19.5 & 63.5 & $79 \mathrm{c}$ & $15 \mathrm{~b}$ \\
\hline
\end{tabular}

Table 5 . Similarity table among different diurnal times in respect to fungal species encountered from 72 exposure samplings in the atmosphere of Doha, Qatar during the period ( $1^{\text {st }}$ of Feb - $31^{\text {st }}$ of March 2016).

\begin{tabular}{ccccc}
\hline Time & $\mathbf{0 : 0 0}$ & $\mathbf{6 : 0 0}$ & $\mathbf{1 2 : 0 0}$ & $\mathbf{1 8 : 0 0}$ \\
\hline $\mathbf{0 : 0 0}$ & $100 \%$ & $65 \%$ & $58 \%$ & $41 \%$ \\
$6: 00$ & $65 \%$ & $100 \%$ & $48 \%$ & $56 \%$ \\
$12: 00$ & $58 \%$ & $48 \%$ & $100 \%$ & $39 \%$ \\
$18: 00$ & $41 \%$ & $56 \%$ & $39 \%$ & $100 \%$
\end{tabular}

Jaccard similarity coefficient $=(\mathrm{c} /(\mathrm{a}+\mathrm{b})-\mathrm{c}) * 100 . \mathrm{C}=$ number of common species between any two time periods ( $\mathrm{a} \& \mathrm{~b})$. 


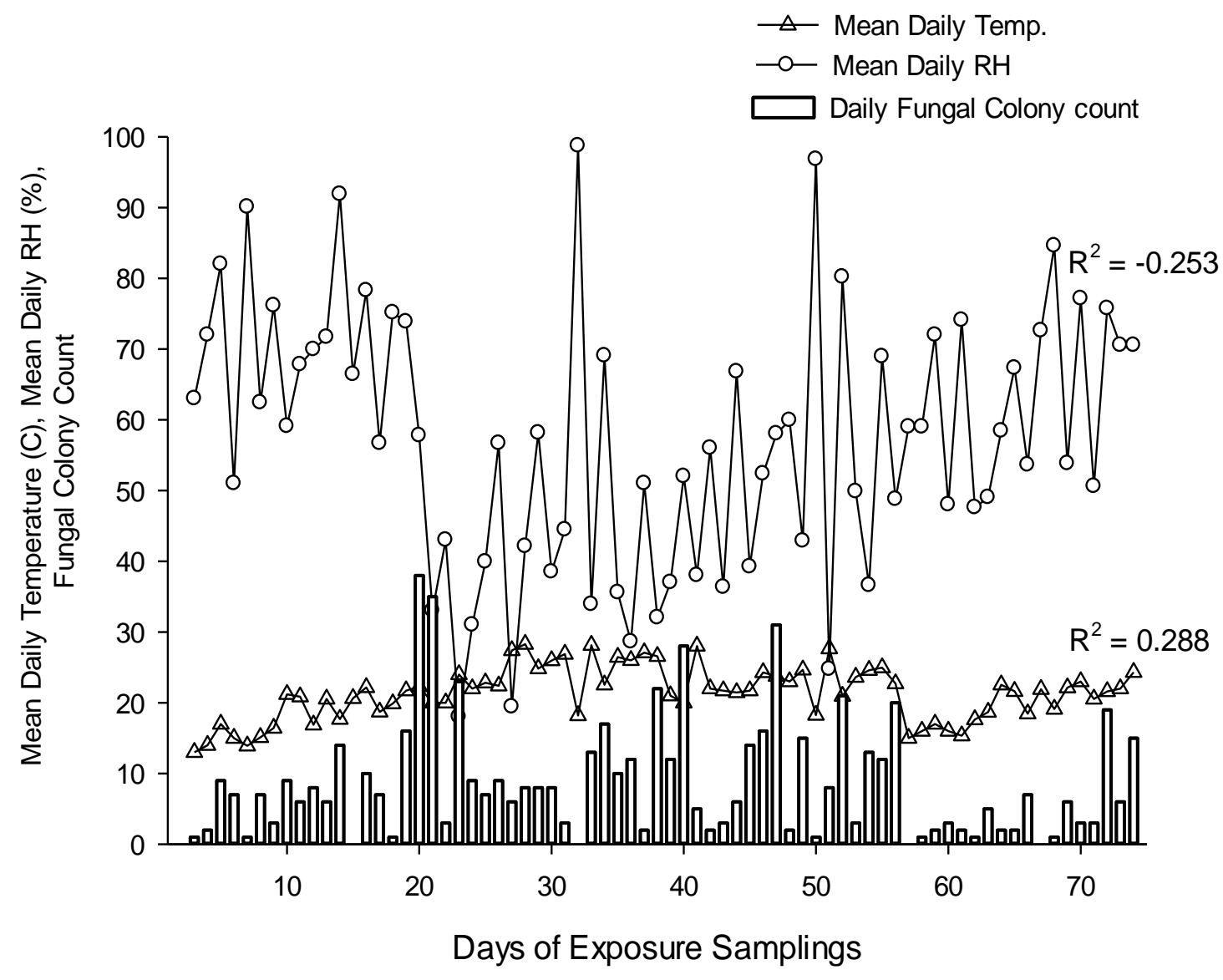

Figure 5. Variations in daily fungal colony counts in respect to changes in mean daily temperature and mean daily relative humidity $(\mathrm{RH})$. Correlation coefficient values $\left(\mathrm{R}^{2}\right)$ are significantly different between mean daily counts and each of mean daily temperature and mean daily relative humidity at $P \leq 0.05$ according to Pearson correlation coefficient. 


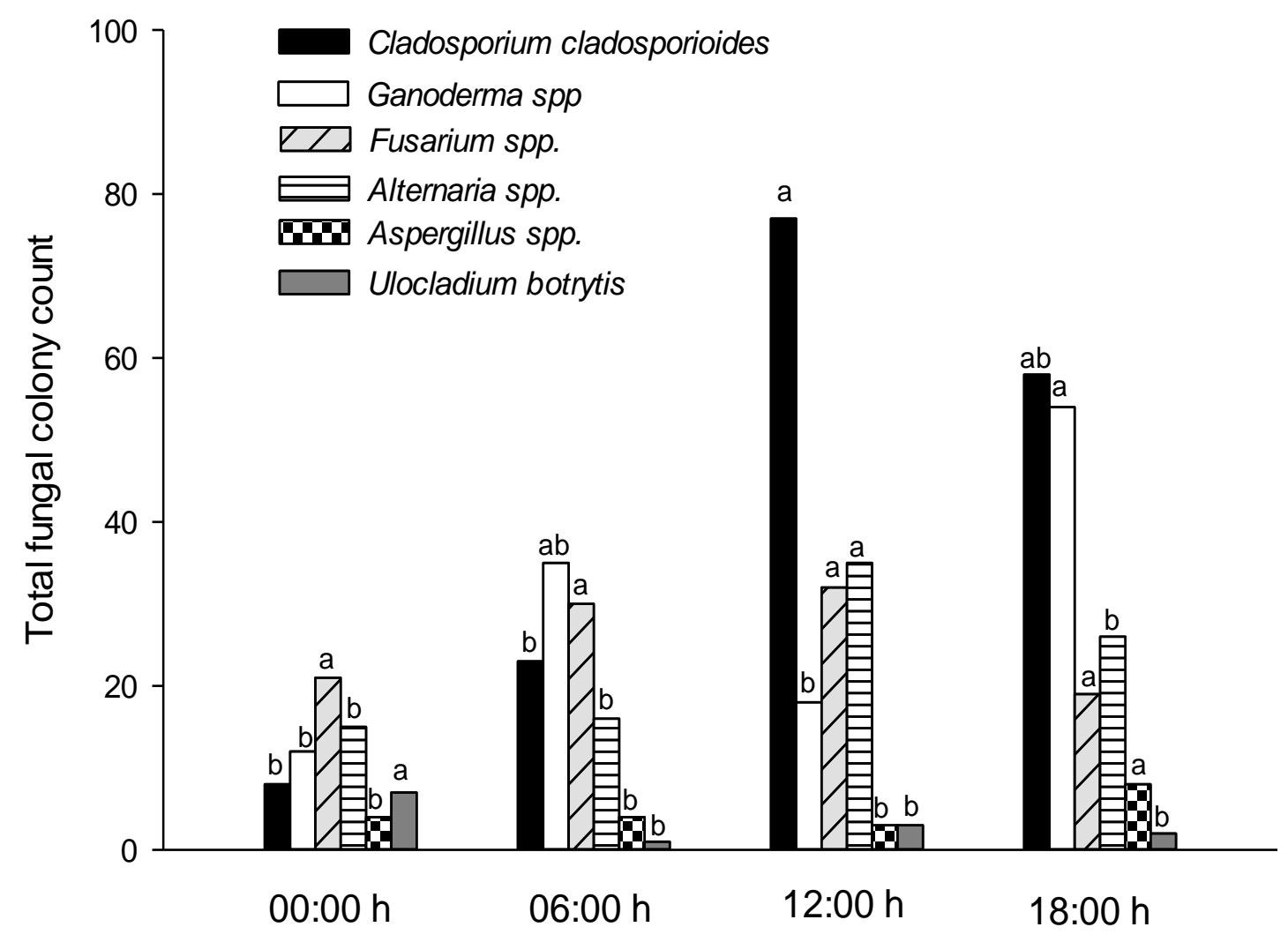

Figure 6. Diurnal variations in total fungal colony counts of the most common species in the atmosphere of Doha during the period ( $1^{\text {st }}$ of Feb - $31^{\text {st }}$ of March 2016). A total of 72 exposure samplings. Within each fungal taxa, values with common letters are not significantly different at $P \leq 0.05$ according to Tukey's test. Significant correlations were reported between mean daily temperature and each of mean daily counts of Alternaria spp. $\left(\mathrm{R}^{2}=0.316\right)$ and mean daily counts of Ganoderma spp. $\left(\mathrm{R}^{2}=0.237\right)$ at $P \leq 0.05$ according to Pearson correlation coefficient. 


\subsection{Investigating the importance of culture media on recovery of fungal diversity}

\section{and abundance}

The total number of sampling plates (exposures) with two different culture media during the study period ( $1^{\text {st }}$ of Feb - $31^{\text {st }}$ of March 2016) using gravimetric method was 27 for each different culture medium. The exposure samplings were done at the same time $(3: 00 \mathrm{pm})$ and in the same location (Qatar University Campus). Table 6 shows the total number of colonies, genera and species of mould fungi (Filamentous fungi) recovered from the two culture media. Yeast fungi were dealt with as one group. From PDA and Rose Bengal culture media, the total number of colonies retrieved was 473 and 336 colonies respectively. According to T-test at $P \leq 0.05$ there was no significant difference in total number of fungal colonies collected at each sampling event using two different culture media (Figure 7). 14 genera and 34 species were collected from PDA, while 13 genera and 25 species were recovered on Rose Bengal media (Table 6). The pair comparison of total number of fungal species collected at each sampling event using the two different media didn't show significant difference with T-test at $P \leq 0.05$ (Figure 8). The most predominant fungi genera which commonly retrieved from both PDA and Rose Bengal media were attributed to Cladosporium, Alternaria, Fusarium, Penicillium, Ganoderma, Aspergillus and Ulicladium (Figure 9). Yeast spp. were also isolated from both culture media. For Cladosporium, Aspergillus and Penicillium, higher recoveries were obtained with PDA medium than Rose Bengal medium (Figure 9). The concentration yield of Fusarium, Ganoderma and Ulicladium were higher with Rose Bengal medium than with PDA. The total recoveries of Alternaria were similar on both culture media (Figure 9). Yeast spp. 
were most often isolated with higher colony- forming unit (CFU) value from PDA medium. Mucor, Agaricales, Phoma, Stachybotrys and Rhizopus were only isolated from PDA medium, whereas Humicola, Hypomyces, Monodycts and Tritirachium were exclusively obtained with Rose Bengal medium (Table 6). 
Table 6. Total number of colonies and fungal species retrieved from the two culture media during the study period ( $1^{\text {st }}$ of Feb $-31^{\text {st }}$ of March 2016) using gravimetric method (a total of 27exposure samplings).

\begin{tabular}{|c|c|c|c|}
\hline \multirow[t]{2}{*}{$\#$} & \multirow[t]{2}{*}{ Fungal Taxa } & \multicolumn{2}{|c|}{ Total colony count } \\
\hline & & PDA medium & Rose Bengal medium \\
\hline 1 & Agaricus spp. & 1 & 0 \\
\hline 2 & Alternaria sp & 2 & 0 \\
\hline 3 & Alternaria alternate & 12 & 4 \\
\hline 4 & Alternaria brassicicola & 1 & 0 \\
\hline 5 & Alternaria chlamydospora & 6 & 26 \\
\hline 6 & Alternaria infectoria & 10 & 0 \\
\hline 7 & Alternaria phragmospora & 1 & 0 \\
\hline 8 & Alternaria tenuissima & 0 & 2 \\
\hline 9 & Aspergillus sp. & 1 & 0 \\
\hline 10 & Aspirgillus carbonaarius & 1 & 0 \\
\hline 11 & Aspergillus flavus & 8 & 11 \\
\hline 12 & Aspergillus sydowii & 4 & 0 \\
\hline 13 & Aspergillus sulphureus & 1 & 0 \\
\hline 14 & Aspergillus versicolor & 0 & 1 \\
\hline 15 & Aspergillus ustus & 4 & 1 \\
\hline 16 & Cladosporium cladosporioides & 226 & 146 \\
\hline 17 & Cladosporium herbarum & 1 & 0 \\
\hline 18 & $\begin{array}{l}\text { Cladosporium } \\
\text { Macrocarpum }\end{array}$ & 16 & 6 \\
\hline 19 & Cladosporium oxysporum & 3 & 6 \\
\hline 20 & Cladosporium sphaerosprmum & 22 & 0 \\
\hline 21 & Cladosporium tenuissimum & 2 & 0 \\
\hline 22 & Fusarium (genus) & 18 & 22 \\
\hline 23 & Fusarium dimerum & 5 & 6 \\
\hline 24 & Fusarium clamydosporum & 2 & 3 \\
\hline
\end{tabular}




\begin{tabular}{|c|c|c|c|}
\hline 25 & Fusarium oxysporum & 6 & 13 \\
\hline 26 & Ganoderma spp & 25 & 34 \\
\hline 27 & Gilmaniella humicola & 1 & 1 \\
\hline 28 & Humicola grisea & 0 & 1 \\
\hline 29 & Hypomyces chrysosperum & 0 & 1 \\
\hline 30 & Humicola sp & 0 & 1 \\
\hline 31 & Humicola insolens & 0 & 4 \\
\hline 32 & Monodycts sp. & 0 & 2 \\
\hline 33 & Mucor sp & 1 & 0 \\
\hline 34 & Penicillium (genus) & 3 & 0 \\
\hline 35 & Penicillium canescens & 1 & 1 \\
\hline 36 & Penicillium citricum & 0 & 0 \\
\hline 37 & Phoma sp & 1 & 0 \\
\hline 38 & Pithomyces & 1 & 5 \\
\hline 39 & Rhizopus stolonifer & 1 & 0 \\
\hline 40 & Stachybotrys elegans & 1 & 0 \\
\hline 41 & Tritirachium $s p$ & 0 & 1 \\
\hline 42 & Ulocladium atrum & 0 & 1 \\
\hline 43 & Ulocladium botrytis & 1 & 14 \\
\hline 44 & Ulocladium chartarum & 1 & 0 \\
\hline 45 & Yeast group & 83 & 23 \\
\hline Total nu & $\begin{array}{l}\text { folonies from the whole study } \\
\text { period }\end{array}$ & 473 & 336 \\
\hline \multicolumn{2}{|c|}{ Total number of genera recorded } & 14 & 13 \\
\hline \multicolumn{2}{|c|}{ Total number of species recorded } & 34 & 25 \\
\hline
\end{tabular}




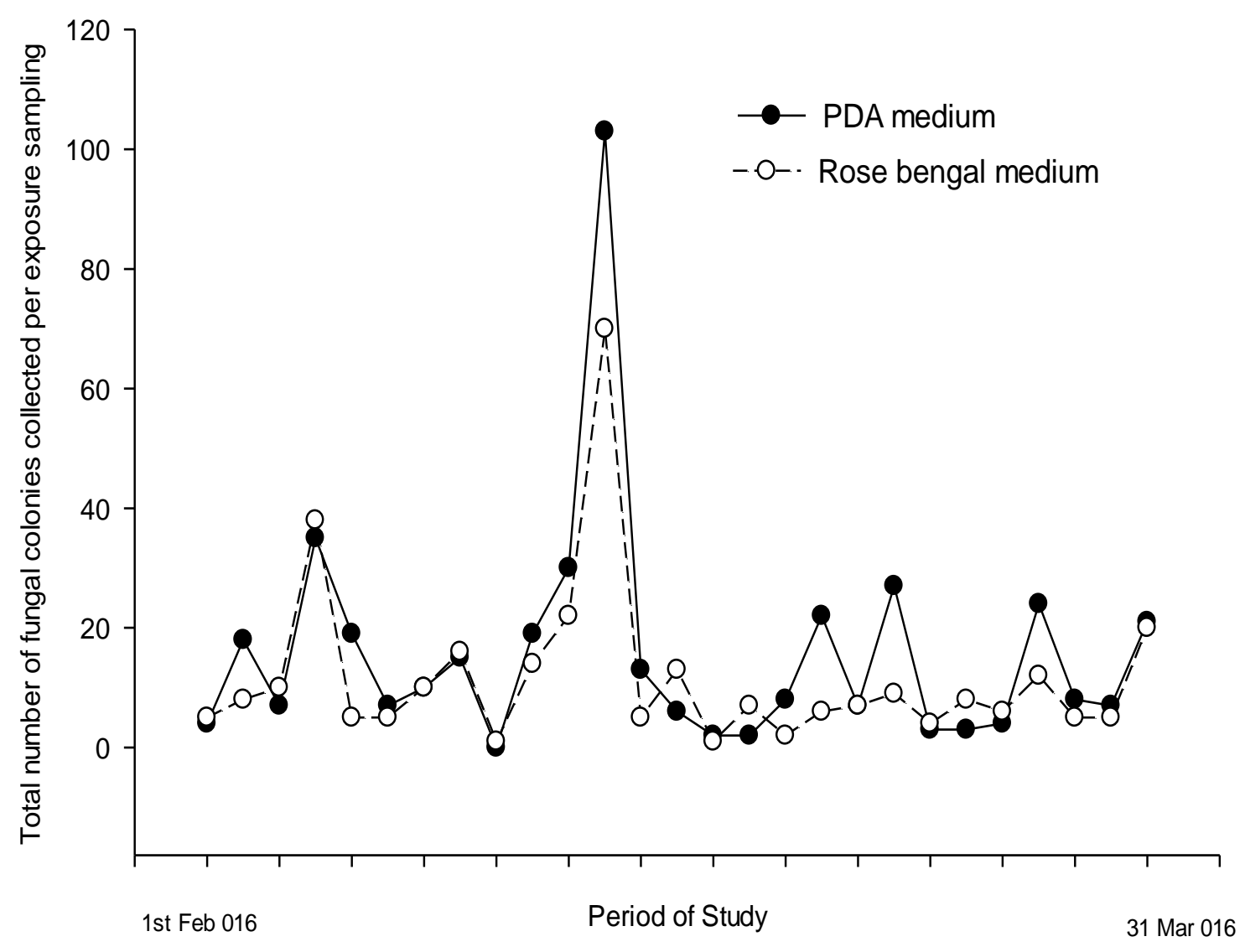

Figure 7. Total number of fungal colonies collected at each sampling event during the study period ( $1^{\mathrm{st}}$ of Feb $-31^{\mathrm{st}}$ of March 2016) in each of the two culture media used. According to T-test at $P \leq 0.05$ there was no significant difference due to type of culture media used (a total of 27exposure samplings). 


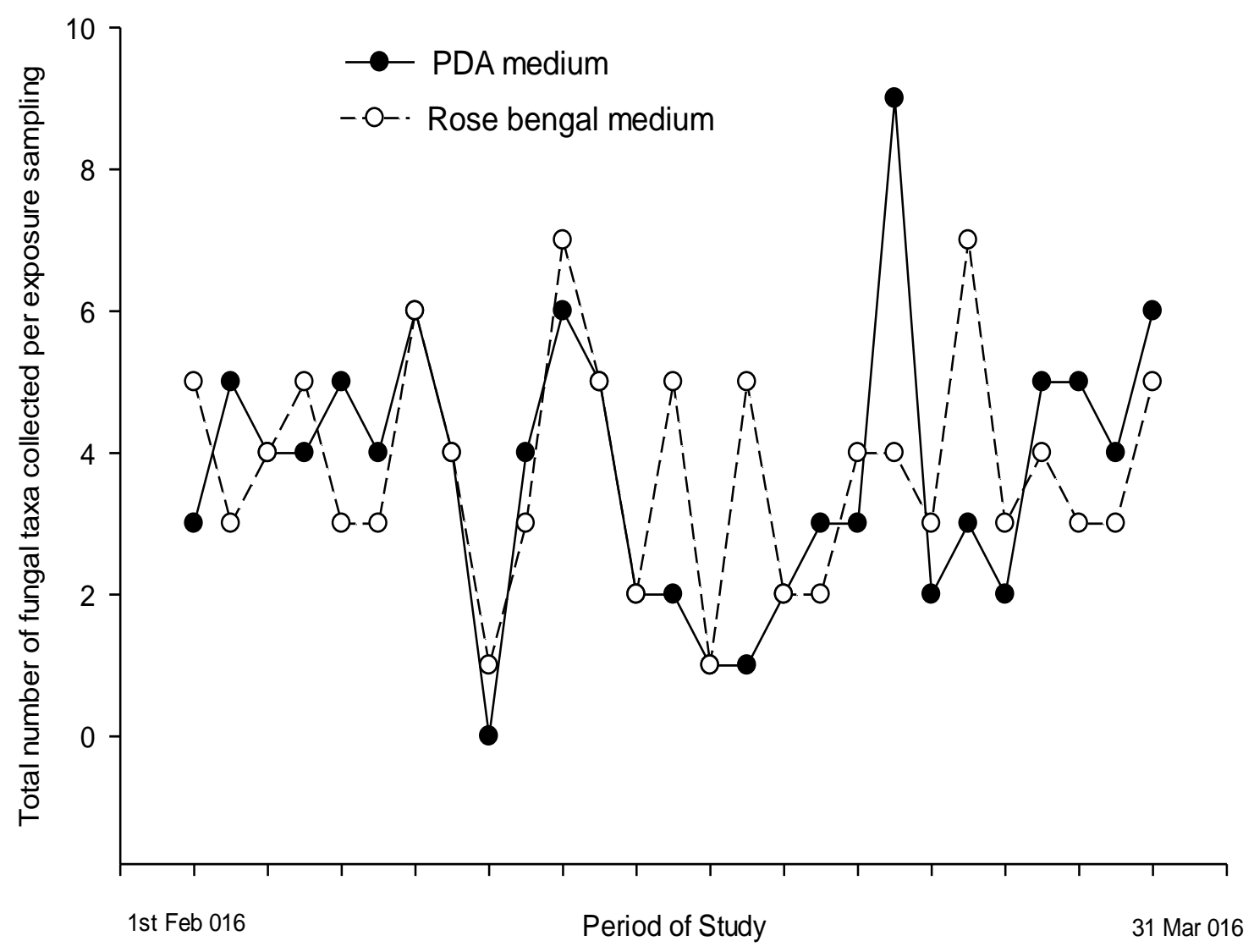

Figure 8. Total number of fungal species collected at each sampling event during the study period ( $1^{\text {st }}$ of Feb $-31^{\text {st }}$ of March 2016) in each of the two culture media used. According to T-test at $P \leq 0.05$ there was no significant difference in number of species due to type of culture media used (a total of 27exposure samplings). 


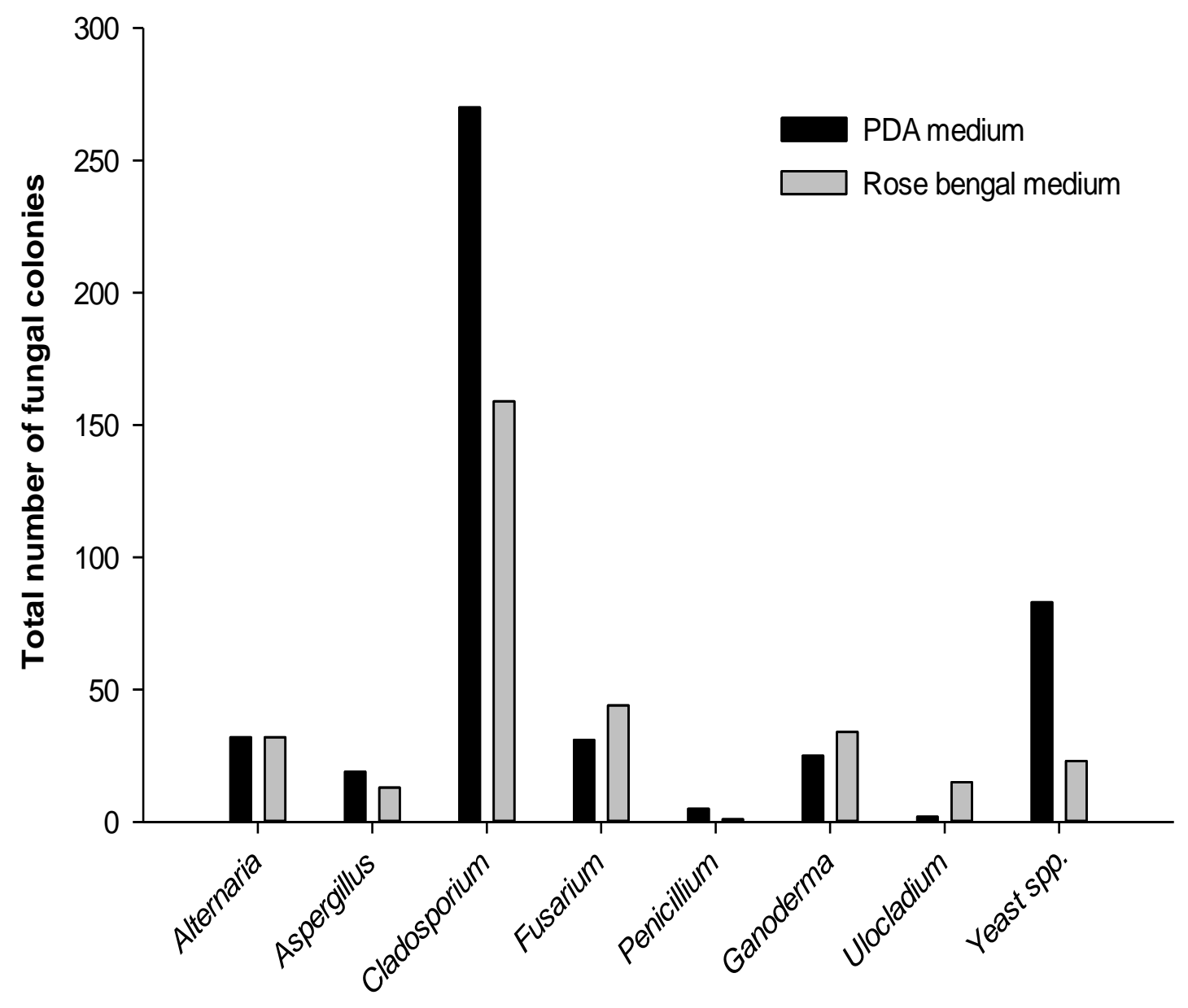

Figure 9. Total number of fungal colonies grown from the most common encountered genera during the study period ( $\left(1^{\text {st }}\right.$ of Feb - $31^{\text {st }}$ of March 2016) in each of the two culture media using gravimetric method (a total of 27 exposure samplings). 


\subsection{The impact of atmospheric status ( $\mathrm{CO} 2$ concentration) on the dynamics of airborne fungi}

Samples were collected in parallel and at the same time at Qatar University Campus and close to the Industrial area sites (around $25 \mathrm{~km}$ in distance) during the study period $\left(1^{\text {st }}\right.$ of Feb - $31^{\text {st }}$ of March 2016) using gravimetric methods. Table (7) represents the total number of colonies and fungal species obtained from the two study sites. 358 colony-forming unit (CFU), 16 fungi genera and 35 species were counted at the Industrial area site. From Qatar University Campus site, a total of 312 colonies, 12 fungal genera and 31 fungal species were collected. No significant differences were observed in the total number of colonies and fungal species between the two study sites, although daily concentration of $\mathrm{CO}_{2}$ was higher, according to average, median and range values of $\mathrm{CO}_{2}$ at the Industrial area site than at Qatar University Campus (Figure 10). The common and most abundant fungal taxa recorded at the two study sites were attributed to Cladosporium, Ganoderma, Fusarium and Alternaria. Corresponding to $\mathrm{CO}_{2}$ concentrations, the daily colony count of Cladosporium was significantly higher at Qatar University Campus than at Industrial area $(P=0.05)$ (Figure 11). Contrary to Cladosporium, the concentration of Fusarium and Alternaria were significantly higher $(P \leq 0.05)$ at Industrial area site (Figure 11$)$. The main constituents of fungal genera and their abundance rate in the atmosphere of the two study sites were widely variable between the two sites (Figure 12). Cladosporium was prominently higher in relative abundance (67\%) at the university campus constituting about two third of all fungal composition. Other fungi like Ganoderma, Fusarium, and Alternaria are also main constituents with relative abundances of $11 \%, 7 \%, 6 \%$, respectively. Other 
taxa at the University Campus had $10 \%$ abundance (Figure 12). While Cladosporium is still the main constituent of fungal taxa at the Industrial area site but its relative abundance $(29 \%)$ is very low compared to the university site (Figure 12). Interestingly, Ganoderma showed similar relative abundances $(11 \%)$ in the two sites (Figure12). The other genera of fungi Alternaria and Fusarium are considered main constituents with relative abundances of $19 \%$ and $17 \%$ respectively; however other fungal taxa are still represented by $23 \%$ (Figure 12). 
Table 7. Total number of colonies and fungal species retrieved from the two study sites during the study period ( $1^{\text {st }}$ of Feb $-31^{\text {st }}$ of March 2016) using gravimetric method (a total of 22exposure samplings). No significant correlations at $P=0.05$ were obtained neither for total colony count or number of species reported.

\begin{tabular}{|c|c|c|c|}
\hline \multirow[t]{2}{*}{$\#$} & \multirow[t]{2}{*}{ Fungal Taxa } & \multicolumn{2}{|c|}{ Total colony count } \\
\hline & & $\begin{array}{c}\text { Qatar } \\
\text { University } \\
\text { Campus }\end{array}$ & $\begin{array}{l}\text { Industri } \\
\text { al area }\end{array}$ \\
\hline 1 & Agaricales sp. & 1 & $\mathbf{0}$ \\
\hline 2 & Alternaria & 20 & 70 \\
\hline 3 & Alternaria alternate (FR.) Keissler & 12 & 43 \\
\hline 4 & Alternaria brassicicola (Schwein.) Wiltshire & 1 & 0 \\
\hline 5 & Alternaria chlamydospora Mouchacca & 1 & 21 \\
\hline 6 & Alternaria infectoria E.G. Simmons & 2 & 1 \\
\hline 7 & Alternaria phragmospora V. Emden & 4 & 3 \\
\hline 8 & Alternaria sp. & 0 & 0 \\
\hline 9 & Alternaria tenuissima (Kunze) Wilt. & 0 & 2 \\
\hline 10 & Aspergillus & 17 & 8 \\
\hline 11 & Aspergillus flavus Link & 7 & 5 \\
\hline 12 & Aspergillus sp. & 1 & 0 \\
\hline 13 & Aspergillus sulphereus (Fres.) Thom \& Church & 1 & 0 \\
\hline 14 & Aspergillus sydowii (Bainier \& Sartory) Thom \& Church & 4 & 1 \\
\hline 15 & Aspergillus carbonarius (Bainier) Thom & 0 & 2 \\
\hline 16 & Aspirgillus ustus (Bain.) Thom \& Church & 4 & 0 \\
\hline 17 & Cladosporium & 210 & 103 \\
\hline 18 & Cladosporium cladosporioides (Fres) de Vries & 173 & 83 \\
\hline 19 & Cladosporium macrocarpum Preuss & 12 & 11 \\
\hline 20 & Cladosporium oxysporum Berk. \& M.A. Curtis & 2 & 3 \\
\hline 21 & Cladosporium sphaerosprmum Penzig & 22 & 2 \\
\hline 22 & Cladosporium tenuissimum Cooke & 1 & 4 \\
\hline 23 & Cochliobolus & 0 & 1 \\
\hline 24 & Cochliobolus australiencsis (Tsuda \& Ueyama) Alcorn & 0 & 1 \\
\hline 25 & Fusarium & 22 & 62 \\
\hline 26 & Fusarium sp. & 10 & 52 \\
\hline 27 & Fusarium clamydosporum Wollenweber \& Reinking & 3 & 1 \\
\hline 28 & Fusarium dimerum Penzig & 3 & 3 \\
\hline 29 & Fusarium oxysporum Schlecht. & 6 & 6 \\
\hline 30 & Ganoderma spp. & 30 & 42 \\
\hline
\end{tabular}


Table 7. continue

\begin{tabular}{|c|c|c|c|}
\hline 31 & Humicola & 0 & 2 \\
\hline 32 & Humicola grisea Traaen & 0 & 2 \\
\hline 33 & Mucorsp & 1 & 0 \\
\hline 34 & Neurospora sp. & 0 & 32 \\
\hline 35 & Penicillium & 5 & 6 \\
\hline 36 & Penicillium sp. & 3 & 0 \\
\hline 37 & Penicillium canescens Sopp & 1 & 3 \\
\hline 38 & Penicillium citrinum Thom & 1 & 1 \\
\hline 39 & Penicillium chrysogenum Thom & 0 & 1 \\
\hline 40 & Penicillium corylophilum Dierckx & 0 & 1 \\
\hline 41 & Phoma & 1 & 5 \\
\hline 42 & Phoma glomerata (Corda) Wollenw. & 0 & 4 \\
\hline 43 & $\begin{array}{l}\text { Phoma sorghina (Saccardo) Boerema, Dorenbosch \& } \\
\text { Kesteren }\end{array}$ & 0 & 3 \\
\hline 44 & Phoma sp & 1 & 0 \\
\hline 45 & Rhizopus & 1 & 1 \\
\hline 46 & Rhizopus oryzae Went \& Prinsen-Geerligs & 0 & 1 \\
\hline 47 & Rhizopus stolonifer (Ehrenb.) Lind & 1 & 0 \\
\hline 48 & Scopulariopsis & 0 & 1 \\
\hline 49 & Scopulariopsis candida Vuillemin & 0 & 1 \\
\hline 50 & Stachybotrys & 1 & 3 \\
\hline 51 & Stachybotrys chartarum (Ehrenb.) Hughes & 1 & 0 \\
\hline 52 & Stachybotrys elegans (Pidopl.) W. Gams & 0 & 5 \\
\hline 53 & Thanatephorus & $\mathbf{0}$ & 1 \\
\hline 54 & Thanatephorus cucumeris (Frank) Donk & 0 & 1 \\
\hline 55 & Trichoderma & 0 & 1 \\
\hline 56 & Trichoderma viride Persoon & 0 & 1 \\
\hline 57 & Ulocladium & 2 & 15 \\
\hline 58 & Ulocladium botrytis Preuss & 1 & 14 \\
\hline \multirow[t]{5}{*}{59} & Ulocladium chartarum (Preuss) Simmons & 2 & 1 \\
\hline & UNKNOWN & 2 & 4 \\
\hline & $\begin{array}{l}\text { Total number of colonies from the whole study } \\
\text { period }\end{array}$ & 312 & 358 \\
\hline & Total number of genera recorded & 12 & 16 \\
\hline & Total number of species recorded & 31 & 35 \\
\hline
\end{tabular}




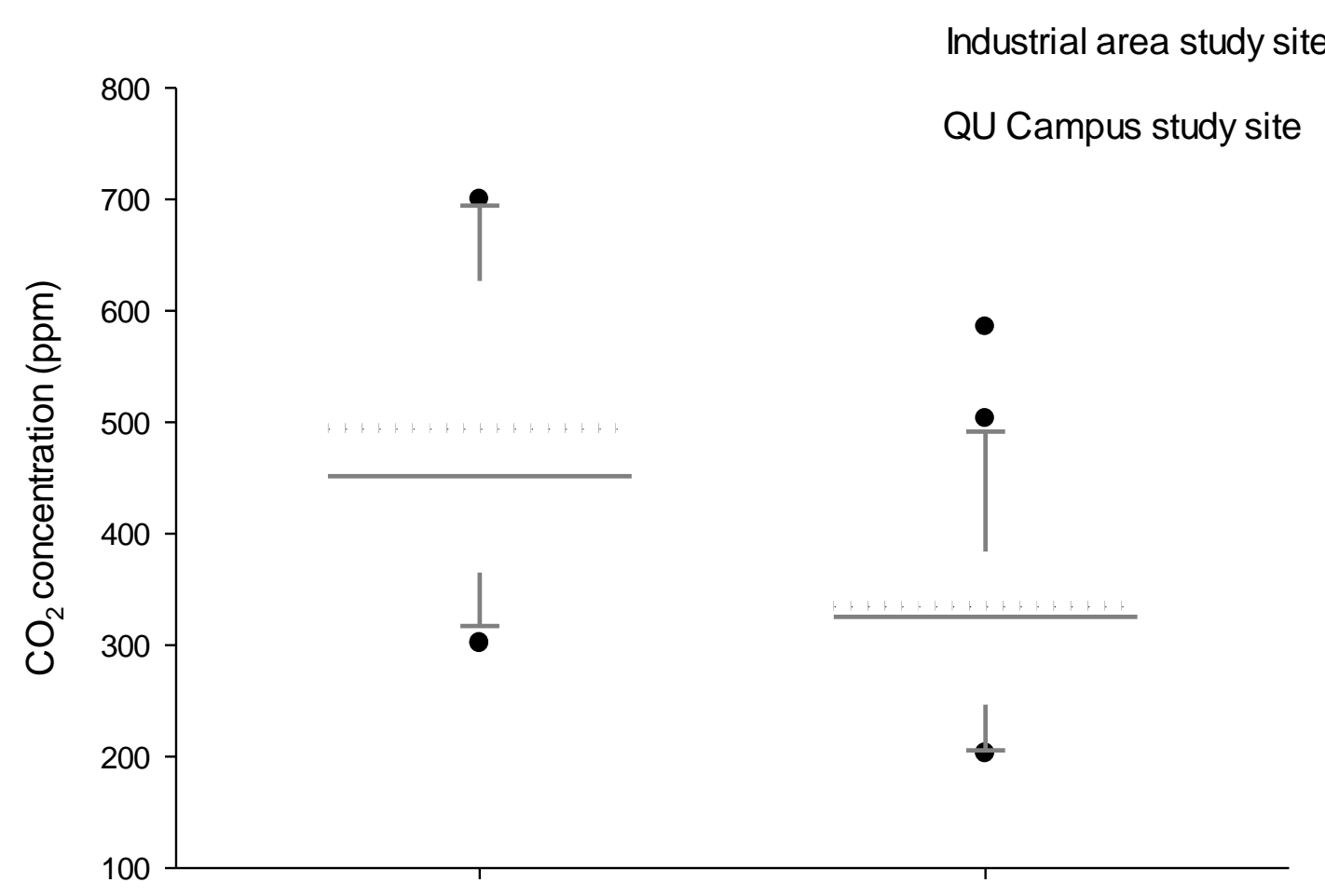

Figure 10. Box plot represents the daily concentration of $\mathrm{CO}_{2}$ recorded in each of the two study sites during the period of $\left(1^{\text {st }} \mathrm{Feb}-31\right.$ Mar 2016). The dotted lines refer to mean daily count. The blacked circles represent the outlier values. 


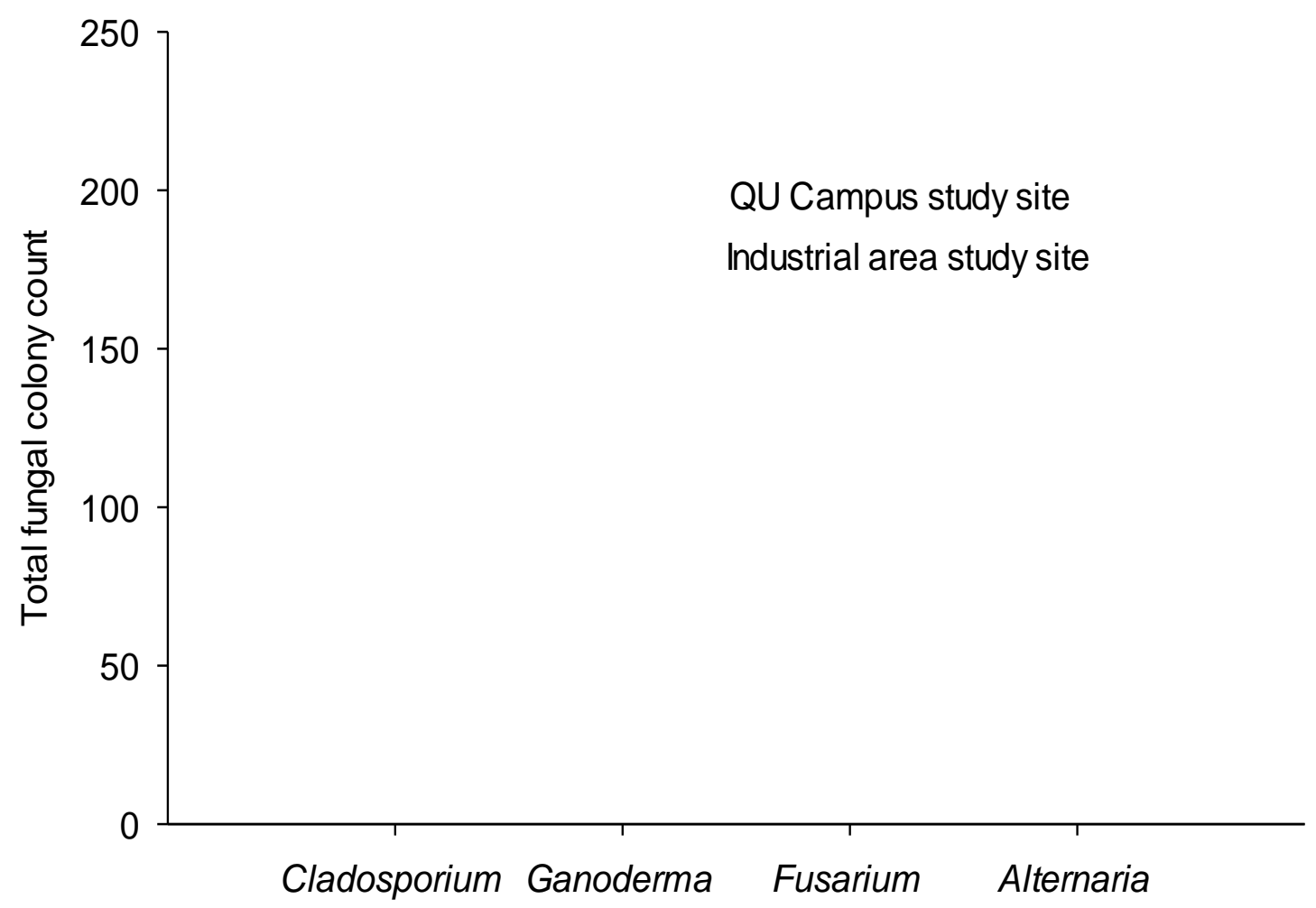

Figure 11. Fungal taxa that shown significant abundance differences between the two study sites (according to t- test of daily colony count at $P=0.05)$ during the period of $\left(1^{\text {st }}\right.$ Feb - 31 Mar 2016) with a total of 22 exposure samplings. 


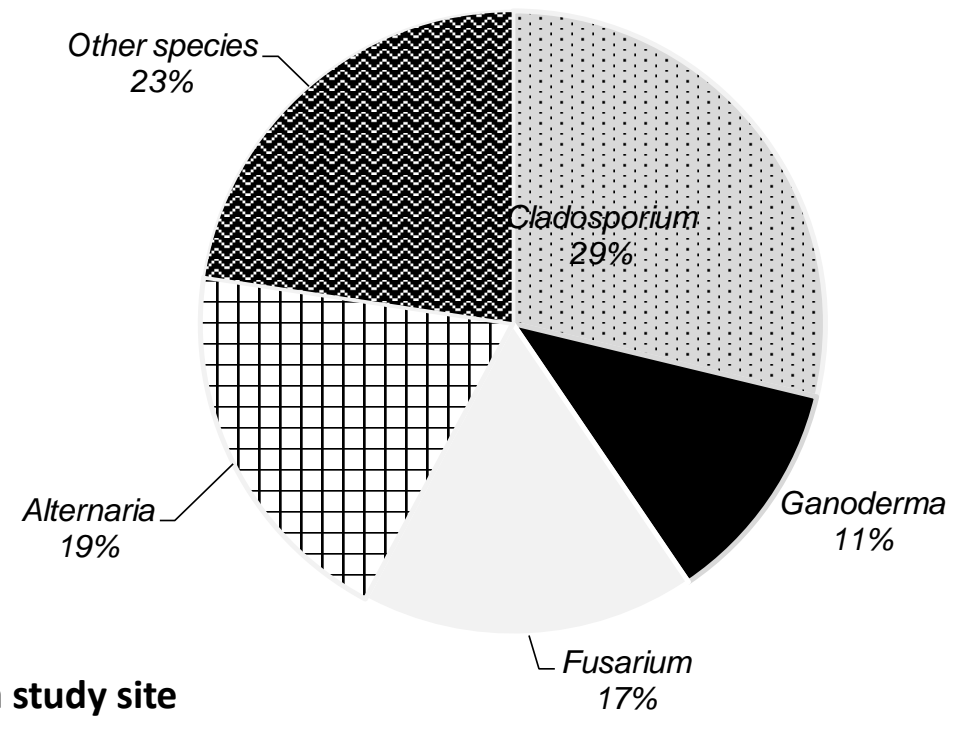

Industrial area study site

$17 \%$

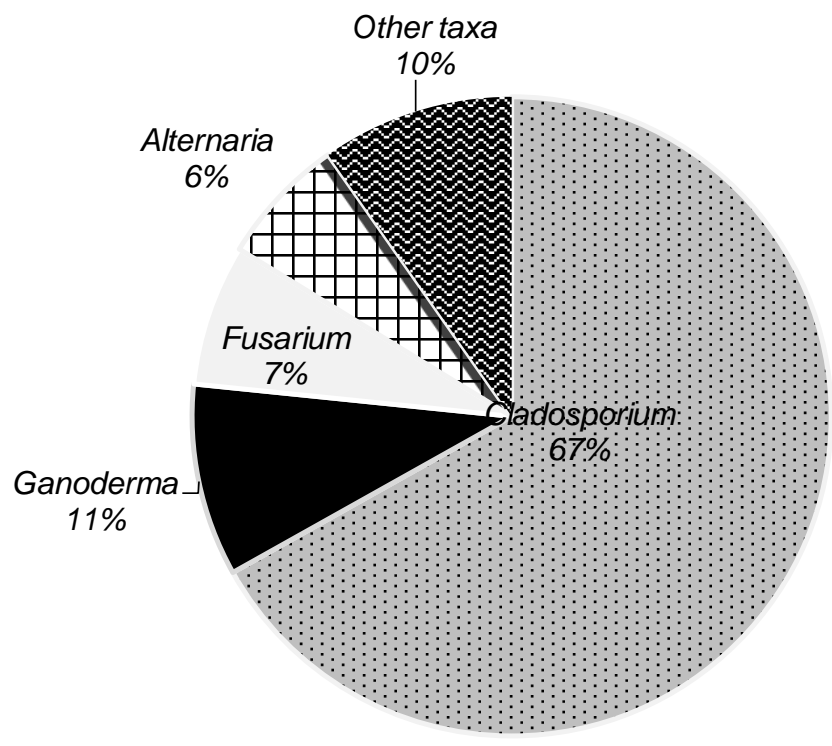

QU Campus study site

Figure 12. Pie graph to show the main constituents of fungal genera and their relative abundances in the atmosphere of the two study sites during the period of ( $1^{\text {st }} \mathrm{Feb}-31 \mathrm{Mar}$ 2016) with a total of 22 exposure samplings. 


\section{CHAPTER FIVE}

\section{DISCUSSION}

\subsection{Seasonal variations of fungal spore populations in the atmosphere of Doha}

\subsubsection{Fluctuations of abundant species}

In the present study, the dynamics of fungal airspora in the atmosphere of Doha, Qatar were investigated over one year $\left(1^{\text {st }}\right.$ of Apr 2015 - $31^{\text {st }}$ of March 2016$)$ using plate exposure method in which a total of 1197 colony counts and 21 genera assigned to 62 species were

retrieved (Table 1). A similar study has been conducted in Doha by Al-Subai (2002) during the period of March 1997-March 1998. The author used similar method (plate exposure method) to study the effect of meteorological factors on the airborne fungi population in the air of Doha; however there were major differences between the present study design and the Al-Subai's design. In the present study, one Petri dish was exposed on the roof of the Qatar University building (about $12 \mathrm{~m}$ above ground level), where at this height the composition of airborne fungal spores is more stable, for 15 minutes at 3:00 pm on each of 3 days a week (alternate days). In Al-Subai (2002), plate exposure events were assigned to 24 days monthly for 10 minutes at a level of about $1.5 \mathrm{~m}$ at 9 a.m. In Al-Subai (2002) study, $1 \%$ glucose-Czapek's agar $+0.05 \%$ yeast extract culture medium, while in this study Potato Dextrose Agar (PDA) was used as a culture medium. Both, the height level of collection and culture media used are considered variables that affected the species composition and abundance of air mycoflora (Burge et al., 1977; Herrero et al,.1996; Khattab \& Levetin, 2008 ). The above differences in the methodology of the two studies as well as the long 
time between the two studies (about 17 years) may explain the differences in the results obtained and make them not comparable. Importantly to mention that huge anthropogenic changes including urbanization, industrialization, and establishment of housing compounds, shopping centers and high-way roads were occurred in Doha within the last 15 years. Those anthropogenic changes are also expected to affect the dynamics and species composition of air-borne fungal spores. According to Al-Subai (2002), the major obtained airborne fungal genera were: Cladosporium, Alternaria and Ulocladium. From our study, Cladosporium (60.2\%), Aspergillus (10.4\%) Fusarium (9.4\%), Alternaria (8.5 \%), Ganoderma spp. (2.3\%) and Penicillium (2.0\%) (Figure 1) were the main component of the air mycoflora. Several studies demonstrated the presence of the above mentioned fungal taxa as part of the main aeromycota composition in different Middle Eastern countries (Abdel-Hafez, 1984; Al-Subai, 2002; Sen \& Asan, 2009; Abu-Dieyeh et al., 2010; Quintero et al., 2010; Shams-Ghahfarokhi et al., 2014). Our study showed that Cladosporium was the most common fungal genus among others and presented in all months with double peaks one in April and the other in February. Many authors presented Cladosporium as the main air mycoflora in different countries world-wide (In Jordan: AbuDieyeh and Barham (2014); In Japan: Takahashi 1997; in Turkey: Sen and Asan 2001; in Qatar: Al-Subai 2002; In Egypt: El-Morsy (2006). Many factors might support the abundance of Cladosporium throughout the year. Ali et al (1976) and Al-Subai (2002) demonstrated that the structural features of Cladosporium conidia such as chlamydosporelike structure make them more resistant to solar radiation and physicochemical agents; however other authors explained this phenomenon by referring to the small size, thin exine 
and smooth wall of the Cladosporium spores which help the dissemination of conidia (Shaheen, 1992; Asan et al. 2004).

Aspergillus sp. was the second predominant fungal genera and assigned for ten species (Table 1). Aspergillus represented a seasonal pattern; the highest concentration was in August and the lowest in January (Figure 3). Khan et al., (1999) demonstrated that, Aspergillus spp. were the predominant in the outdoor environment of Kuwait. Similarly, Abdel-Hafez (1984) reported that A. sydowi, A. flavus, A.niger and A. versicolor among the most common species in the air of Taif, Saudi Arabia., and Aspergillus sp. were also found to be the most abundant fungal genus in the atmosphere of Saudi Arabia (AbdelHafez, 1985). The abundance of Aspergillus sp. in the atmosphere of Doha and other Gulf regions is consistent with the findings provided by Christensen \& Tuthill (1986) who found that the tropical/subtropical habitats accommodated higher number of Aspergillus species in comparison to temperate regions. Accordingly, they concluded that Aspergillus genus is highly abundant in the tropics/subtropics especially in the saline and cultivated soils.

In the present study, Fusarium was ranked as the third among other most common airborne fungi (Figure 1). Fusarium is a cosmopolitan fungus which is well known as plant/animal pathogen (Smith, 2007). Fusariun germination can't be developed well at low water activity (Nelson et al., 1994). The dispersion of Fusarium macrocnidia was found to follow a rain or irrigation event (Fernando et al., 2000). Coincides with that Abu-Dieyeh et al. (2010) reported that Fusarium was abundant in the atmosphere of the Zarqa area, Jordan and correlated this abundance with the continuous drip irrigation of olive plantations in the study site and also the existence of many farms around the study sites. The previous 
findings may explain the abundance of Fusarium in the atmosphere of Doha since the study site, Qatar University campus, receives extensive and frequent irrigations to accommodate the need of the vegetation cover (turfgrass areas and others) and the high evaporation rate. However rainfall might interact with density of Fusarium but it's difficult to achieve any significant correlation trends since the rainfall in Qatar is very low and limited to few days of the year.

Alternaria represented the fourth most prevalent fungal taxa in the air with seven identified species (Figure 1). Alternaria represented a seasonal trend, with high colony count in May and July while the colony count declined a little and continue all over the year with almost minor fluctuation (Figure 3). Similar to Cladosporium spores, the conidia of Alternaria are of dry spore's type, dark color which tolerate the solar radiation and survive the whole year (Al-Subai, 2002). Other studies showed that the highest spore concentration of Alternaria spp. was reported in July and August, followed a wet weather (Gregory \& Hirst,1957; Grinn-Gofron \& Rapiejko, 2009). In India, when the condition is suitable for plant decomposition, after winter, the dispersal of Alternarai become the maximum (Mishra,1971).Ganoderma spp. was one of the major constituents of air mycoflora of Doha (2.4\%), but it was exclusively retrieved in February and March of the whole year (Table 1; Figure 1). In the present study, Ganoderma spp. has been identified for the first time in the atmosphere of Doha. Similar to our findings ,in Saudi Arabia, Jizan a considerable concentration of Ganoderma basidiospores was detected within the airspora (Hasnain et al., 2004). According to the later authors, airborne Ganoderma spp. was not frequently detected in many countries with similar ecological features in the Gulf region. Ganoderma 
basidiospores have ovoid or egg shape, the internal wall of spores is colored with a colour varying from golden to dark brown, the external wall is smooth and transparent where the two walls are connected by pillars (Pegler \& Young, 1973). A flattened basal apiculus is another feature of the spores (Southworth, 1974).

Ganoderma was first suggested to be associated with respiratory allergy by Gregory \& Hirst (1952). In Saudi Arabia, Jizan the concentration of Ganoderma basidiospores was significantly correlated with the high incidence of asthma in Jizan (Hasnain et al., 2004) From our study, Ganoderma basidiospores exclusively appeared in late February and March of the whole year (Table 1; Figure 1). The seasonal pattern of Ganoderma is widely varied worldwide. In Jizan region in Saudi Arabia, the seasonal trend of Ganoderma was shown from October to March with a peak in December and January when the temperature is moderate and the humidity is relatively high (Hasnain et al., 2004). In Poland, Stępalska \&Wołek (2005) found August to be the month of the highest spore incidence when the weather is warm and humid. In USA, the spores of Ganoderma were reported on more than 95\% of the days, lasting from June through October and reaching maximum concentration in late August until mid-October with a positive correlation with temperature and precipitation (Craig \& Levetin, 2000). In India, Delhi, Ganoderma had seasonal pattern from July to September (Singh et al., 1995). The presence of Ganoderma basidiospores is determined by the abundance of vegetation coverage (Cabarroi et al. 2008), and also the maximum spore concentration was reported to occur during the rainy months (Almaguer et al., 2014). From the above studies, the incidence of Ganoderma basidiospores seems to be more correlated with moderate temperature and high moisture or rainfall which may 
explain our findings about why they only reported in February (10\%) and March (90\%) as March was the month of the highest rainfall during the study period (Table 2).

\subsubsection{Fungal species fluctuation versus climatic factor}

According to our results, February was the month of greatest colony count and fungal species richness in the atmosphere of Doha and this can easily be explained due to the relatively moderate temperature and the highest reported rainfall (Figure 3). While August and September were the months of lowest fungal abundance and diversity (Figure 3). These months are characterized by relatively the highest temperature and relatively very high humidity and these conditions might interacted to not facilitate the dissemination of fungal spores from their sources (soil and plants) and/or deteriorated them especially if we also add the factor of sun radiation intensity which is also expected to be elevated during these months.

In the present study, a strong significant $(P \leq 0.01)$ positive correlation coefficient $\left(\mathrm{R}^{2}=\right.$ 0.517) were obtained between the total daily fungal counts and the total daily fungal taxa recorded which may indicate that similar interactions of weather conditions may determine the dynamics and fluctuation of both parameters.

Both daily and monthly counts of either of Cladosporium or Alternaria spores showed significant negative correlations $(P \leq 0.05)$ with daily maximum, minimum and mean temperatures. While the correlations of Cladosporium colony count with both daily or monthly relative humidity and rainfall were non-significant, the monthly rainfall data 
showed highly significant correlation $(P \leq 0.01)$ with Alternata colony counts. Highly significant $(P \leq 0.01)$ positive correlation was appeared between daily counts of Cladosporium and Alternaria and daily wind speed data (Table 2). In contrary to our results, in Poland, Grinn-Gofron \& Strzelczak, (2013) found that the concentration of air spores of Cladosporium and Alternaria were significantly and positively correlated with temperature and negatively with relative humidity, however the authors couldn't clearly rank which weather parameter is more important for the viability of those fungal spores in the air. Similarly, in Spain, Sabariego et al (2012) concluded that the mean daily count of Alternaria was significantly and positively correlated with temperature but negatively and significantly with relative humidity and rainfall and wind speed. In Turkey, both Alternaria and Cladosporium were significantly and positively correlated with temperature and humidity (Erkara et al., 2009). Our results showed similar trends with studies that have been conducted in countries with similar environment like Qatar, Hasnain et al., (2012) demonstrated that the occurrence of Alternaria spores is negatively and significantly correlated to temperature and Hameed et al., (2007) mentioned a negative insignificant correlation with relative humidity. Çolakoglu (1996) and Nourian et al. (2007) found that the concentration of Cladosporium spores increased significantly as the temperature decreased which is in support to our findings. The cumulative rainfall was positively correlated with the level of Alternaria incidence (Stennett \& Beggs, 2004), in the same regards, Gregory and Hirst (1957) noted that the dispersal of Alternaria spores was higher in August following a period of wet weather. In general raindrops accelerate the release of dry spores (Inglod, 1971) like Alternaria spores. All the above mentioned findings agreed 
with our result about the presence of a significant positive correlation between monthly data of Alternaria and rainfall.

Interestingly, the meteorological parameters didn't show an influence on the spore incidence of Aspergillus in the atmosphere of Doha (Table 1). The nature of Aspergillus spores as they are dry, relatively small make them easily and passively released by even minor wind speed or vibration (Lin \& Li 2000). Nevertheless, it seems that the inconsistency of the meteorological impacts on the dynamic of airborne fungal spores is due to the differences in the climates between different countries. Our findings agreed with Oliveira et al. (2009) who found that Aspergillus didn't display correlation with any of the meteorological parameters. In contrary to our results, Aspergillus level was positively and significantly correlated with temperature, while significantly and negatively correlation was found with relative humidity (Sen \& Asan, 2009). Aspergillus was found to be positively and significantly correlated with temperature, though negatively and significantly with relative humidity (Hameed et al., 2012).

Fusarium didn't exhibit any significant correlation with any of the weather data except for wind speed. Fernando et al. (2000) noted that similar environmental conditions are favorable for some Fusarium species to release their spores, also and even though the rain had an influence on the sporulation rate of Fusarium, it was difficult to address the impact of other factors such as soil surface temperature and wind velocity. Fusariun germination is well known to develop well in the presence of high moisture (Nelson et al., 1994) and as mentioned earlier, the abundance of Fusarium in the study site is due mainly to extensive and frequent irrigations to accommodate the need of the vegetation cover (turf grass areas 
and others) and the high evaporation rate. Total daily colony count of all encountered fungi had negative significant correlations $(P \leq 0.05)$ with any of the daily temperature parameters. A highly significant positive correlation $(P \leq 0.01)$ was also obtained between the total daily or monthly colony count and daily or monthly wind speed (Table-2 \& Figure 3) and a negative but insignificant correlation with daily mean relative humidity and rainfall. However no significant correlations were reported between total colony count and either of relative humidity or rainfall. (Figure.2). Similar to our results, Hasnain et al. (2012) found that the concentration of several fungal spore counts to be significantly and negatively correlated with temperature, though a positive and insignificant correlation was detected with relative humidity. Similarly, Nourian et al. (2007) detected a significant and negative correlation between temperature and colony count while had a positive with relative humidity. Other studies indicated contrary results as the concentration of airborne fungal spores was positively and significantly correlated with temperature (Segvić Klarić \& Pepeljnjak, 2006). Based on our statistical correlation analysis between weather data and fungal aerospors, the temperature might have the greatest influence on the dynamics of airborne fungal spores, a fact that have been highlighted by many authors, among those: (Stepalska \& Wołek, 2005; Sousa et al., 2008; Grinn-Gofron, 2010; Grinn-Gofroń, \& Bosiacka, 2015). Interestingly, the majority of retrieved fungal airospora are mesophilic (optimal temperature for growth $20-40{ }^{0} \mathrm{C}$ ) (Gravesen 1979). Our results showed that relative humidity had no significant impact on the airborne fungi of Doha which might be attributed to the adaptation of germination, growth and propagation of airborne fungi to relative humidity (Nourian et al., 2007). Another reason might be that the high temperature 
plus the sun radiation (not studied) are more limiting factors than the humidity in certain months of the year, particularly from July to September. Wind speed was found to exaggerate the number of fungal spores in the atmosphere significantly (Al-Subai, 2002; Erkara, et al., 2008; Erkara et al., 2009; Sabariego et al., 2012) which corresponding with our finding for all fungal taxa, total number of colonies and fungal species, however the impact of wind speed was related to the daily data which means that the impact of wind velocity on the fungal airospra is temporally and on daily basis rather than the accumulative effects (Figure 2). On the other hand, wind can act as a dispersal and diluting factor for spores when the wind is high and so decrease the concentration of spores significantly (Quintero et al., 2010). According to Lin \&Li, (2000), when the wind speed is less than 5 $\mathrm{m} / \mathrm{s}$, the fungal spore's concentration decreased, but when the wind velocity is more than $5 \mathrm{~m} / \mathrm{s}$ the concentration of fungal spores increased. The change in wind direction didn't exert any effect of fungal abundance or fungal diversity. McDonald \& O’Driscoll (1980) found a remarkable impact of wind direction on the count of airborne fungi. On the other hand and coinciding with our findings Al-Subai, (2002) did not find any regular correlation between wind direction and the concentration of fungal spores, which might be related to the fact that Doha is a coastal city and surrounded by the Persian Gulf.

Based on our findings, a fungal spore calendar for air-borne fungi in the atmosphere of Doha and their seasonal patterns was constructed (Figure 4). The highest density of fungal colony counts was reported in February, while the lowest was recorded in August. The highest number of fungal species was reported in February, while the lowest was obtained in August and September. This fungal spore's calendar is clinical important as it will 
provide baseline knowledge about concentrations, diversity and dynamics of airborne fungal spore in the atmosphere of Doha. These scientific knowledge are necessary to facilitate and enhance the work for allergists and thus helping them to suggest the risk of allergic sensitization for patients that are sensitive to certain allergic fungal species. Mycologists, applied ecologists and plant pathologists can get benefits from this spore calendar as well. In the present study, Cladosporium, Aspergillus, Fusarium, Alternaria, Ganoderma spp. and Penicillium represented the major fungal airospora in the atmosphere of Doha, Qatar. All these fungi are frequently associated with allergy (Wu et al., 2007; Sen \& Asan, 2009; Hasnain et al., 2012; Knutsen et al., 2012). In the Middle East and particularly in the Gulf region only few respiratory fungal studies have been attempted to assess the prevalence of allergic rhinitis, conjunctivitis, bronchial asthma, and allergic bronchopulmonary mycoses developed from the frequent exposure to allergenic spores. In Qatar, Taj-Aldeen et al. (2003) investigated the allergic fungal rhinosinusitis (AFS) cases caused by Aspergillus flavus, where they found huge quantity of allergic fungal mucin and dark crusts fully colonizing the sinuses which required a course of systemic and topical corticosteroids. The same author demonstrated that in Qatar, an observational study was carried out to estimate the size of fungal infections at public level. The data analysis revealed that, 1486 people were affected by severe asthma with fungal sensitization, 1126 patients were diagnosed with allergic bronchopulmonary and 176 individuals complained from chronic pulmonary aspergillosis (Taj-Aldeen et al., 2015). In Saudi Arabia, even though an aeromycological study was not purposely conducted as respiratory fungal study, a considered relation was found between the high prevalence of asthma in children and the 
highest concentration of Ganoderma spp. recorded among three study sites (Hasnain et al., 2004). Cladosporium, Alternaria and Aspergillus were believed to significantly causing allergic rhinitis and allergic asthma (Achatz et al., 1995).

In the present study, the spore's concentration of $A$. alternata contributed to more than the half of total Alternaria (Table 1). Bush \& Sanchez (1997) Achatz et al. (1995) considered A. alternate as one of the most significant aeroallergens. From our study, A. flavus was the predominant of the total Aspergillus (Table 1). A. fumigatus, A. niger, A. flavus and A.oryzae were frequently correlated with the respiratory allergic cases, A. falvus and due to its large spores it deposited in the upper respiratory tract and commonly cause fungal sinusitis (Hedayati et al., 2007). Cladosporium herbarum is an important and main cause of inhalant fungal allergens among other Cladosporium (Kurup et al., 2000), in this study, C. cladosporioides was the main species among Cladosporium, C. herbarum showed a minor participation to the genus Cladosporium. However, C. herbarum was more frequently associated with respiratory dysfunctions (Aukrust \& Borch, 1979; Reijula et al., 2003; Heinzerling et al., 2005). Skin prick testing (SPT) is an essential technique for diagnosing allergic sensitization such as fungal allergens which will improve the diagnostic accuracy, In Qatar there is an ongoing research about the reactivity of Skin Prick test to common aeroallergen among children with allergic respiratory diseases (Personal communication with Dr. Mohammad Ehlayel, MD, Hamad Mediacl Corporation, Qatar). 


\subsection{Diurnal variation of fungal spore populations in the atmosphere of Doha}

In the present study, the atmospheric concentrations of fungal spores under the influence of intra-diurnal fluctuations were studied during the month's period $1^{\text {st }}$ of Feb $-31^{\text {st }}$ of March 2016. Several aeromycological studies investigated the diurnal periodicity of airborne fungal spores (Sreeramulu, 1959; Helander \& Pessi, 1991; Li \& Kendrick, 1995; Al-Subai, 2002; Hameed et al., 2009; Stępalska \& Wołek, 2009; Abu-Dieyeh et al., 2010). Our findings revealed an intra-diurnal periodicity pattern of fungal spore concentrations where we found significant differences in the total colony counts and fungal diversity among different time periods (Table 3). Both parameters, total colony count and species fungal diversity were peaked significantly in the atmosphere of Doha at 18:00h and declined significantly at 00:00h (Table 3 ). A negative correlation between colony count and relative humidity while a positive correlation with temperature was noted (Figure 5). During February and March a homogeneous temperature readings were obtained that might leaded to this finding which was completely against to what we found in the relation between seasonal temperature data and total colony count of the whole year. Interestingly, a concentration gradient of fungal spores was observed which occurred in upward flux (started from 00:00 h) coordinating positively with recorded temperature and negatively with relative humidity. Our findings partially agreed with Al-Subai (2002) who studied the aeromycology of Doha during the year (1997-1998) and concluded that the highest concentration of fungal spores occurred at 12:00 when the highest temperature and lowest 
relative humidity were indicated, while the lowest concentration was recorded at 00:00h and 06:00h at reverse weather conditions. Other findings indicated that the diurnal pattern of airborne fungi is affected by solar temperature and decreased relative humidity (Joy Royes, 1987). Stępalska \& Wołek (2009) demonstrated that the highest spore's concentration was recorded at midday and afternoon due to reduction in the relative humidity. On the other hand, Fengxiang et al (1991) found that the viability of airborne fungi was higher during the nighttime than in daytime due to the darkness and high relative humidity that increase the concentration of fungal spores. However the period of study is so important to determine the diurnal periodicity of fungal spores (Abu-Dieyeh \& Barham 2014). Our study was conducted during February and March which matches the spring time in Qatar and the diurnal range of minimum humidity is still not detrimental to negatively reduce fungal spore dissemination and this may allow temperature to be the effective variable in the diurnal cycle of fungal spore dissemination. The highest similarity coefficient was obtained between 00:00h (midnight) and 06:00h (early morning), while the lowest similarity coefficient was detected between 18:00h (afternoon) and 12:00h (noon) (Table 5). The most abundant fungal taxa were Cladosporium cladosporioides, Alternaria spp., Fusarium spp., Ganoderma, Ulocladium botrytis and Aspergillus (Figure6). Cladosporium and Alternaria were found in higher concentrations at midday time (Figure6). These two fungal taxa are of clinical important due to their allergenic properties (Kurup et al. 2002). The maximum concentrations of Cladosporium and Alternaria were found to occur at the midday time (Gregory, 1973; Troutt \& Levetin, 2001; Ho et al., 2005). 
Similar to our findings, Cladosporium and Alternaria were found to have a positive correlation with temperature but a negative correlation with relative humidity (Recio et al., 2012; O’Connor et al., 2014). The spores of Cladosporium are considered dry air spores, thus the midday weather conditions when the temperature is relatively high and relative humidity decreases make it optimum for the dispersion of Cladosporium spores (Elvira, 2001). Recio et al (2012) concluded from their study that the highest correlation coefficients in term of maximum, mean and minimum temperature to be for Alternaria accordingly they recommended to predict the concentration of Alternaria spores as a function of temperature. It was demonstrated that the maximum release of Ganoderma spores occurred when the humidity increased and temperature diminished (O'Connor et al., 2014). Similarly, Calderon et al. (1995) concluded that the release of basidiospores are negatively correlated with temperature and declines at higher temperature more than $27{ }^{0} \mathrm{C}$. Coincides to what's mentioned above, in this study, we reported Ganoderma only during February and March in the atmosphere of Doha. We also found that Ganoderma significantly peaked at $18: 00 \mathrm{~h}$ where the average of main daily temperature is $23.1{ }^{\circ} \mathrm{C}$ and the average of mean daily humidity is $52.5 \%$. Even though most of the authors highlighted temperature as more detrimental in diurnal fungal cycle, we believe that a minimum degree of humidity is still needed.

Mean rainfall during the study period was the highest throughout the year, the spores of basidiomycetes are wet spores and their dispersal was mainly and directly affected by the precipitation (Lyon et al., 1984). Sufficient moisture, either during rainfall or when humidity increases is required for the spore production of Ganoderma (Ho et al., 2005; 
Stępalska \& Wołek, 2009). By the splash and “tap-and-puff”' mechanism, whereby the raindrops hit the leaves and cause the attached spore to release from their colonies into the air (Ho et al., 2005). From this study, the sporulation of Ganoderma is more conjunction with rainfall but not with increasing humidity. Aspergillus had a major peak pattern at 18:00 h (Figur.6). There is no significant diurnal periodicity of Aspergillus /Penicillium due to the nature of their spores as they are dry, relatively small and and thus they can be released passively by even minor wind speed (Lin \& Li 2000). Hameed et al (2009) observed double peaks pattern of Aspergillus 10:00 $\mathrm{h}$ and at 20:00 $\mathrm{h}$. The highest concentration of Aspergillus/Penicillium occurred at 00:00h (Ho et al., 2005). In the current study, Ulocladium botrytis peaked at midnight (00:00 h). Coincides with Al-Suwaine et al. (1999) who fund that, the concentration of Ulocladium is negatively correlated with temperature

\subsection{Investigating the importance of culture media on recovery of fungal diversity}

\section{and abundance}

The nutrients composition and water content of the culture media have been introduced as major factors that influence the growth and recovery rates of fungal spores (Ahamed \& Vermette, 2009; Domingues et al., 2000). Two different culture media were used in this study, Potato Dextrose Agar (PDA) and Czapek's/Rose-Bengal agar, to differentiate between the potentialities of fungal growth on different media. The dextrose concentration 
in PDA is double what is found in Czapek's/Rose-Bengal agars, which make it very rich with carbohydrates source. Rose Bengal (dye) and chloramphenicol (antibiotic) are main ingredients of Czapek's/Rose-Bengal agar while they are missing in PDA medium. Our results didn't reveal a significant difference in the total colony number and fungal diversity due to type of culture media (Figure 7 and 8). Hameed et al., (2007) used four culture media, Czapek Dox agar, malt extract agar, Potato dextrose agar and Sabouraud dextrose agar Petri dishes to investigate the examine the yield rate of fungal spores on different sampling media compare the response, however there was no significant difference between the total colony counts using the different culture media, which consistent to our findings. Burge et al. (1977) concluded from using eight different culture media to compare the growth pattern of fungal spores that, the total growth were similar on Sabouraud dextrose agar (SDA), Malt Extract (MALT),V8 juice (V8), and Potato dextrose agar (PDA), whereas MALT and SDA exhibited the highest occurrences of recovery rate. Selective agents such as dye are usually used to suppress the bacterial growth, among these dyes is Rose Bengal which particularly used to control the growth of spreading molds, reducing the efficiency of colony formation by yeast, reducing the diameter of the fungal colony and might inhibit the bacteria development on the culture media (Ottow, 1972; Henson, 1981; Bragulat et al., 1991). In this study, yeast spp. were most often isolated with higher colony forming unit (CFU) value from PDA medium than with Czapek's/RoseBengal agar medium (Figure 9). Also, the recovery of spreading fungi such as Rhizopus and Mucor on the Rose Bengal medium was absent (Table 6). Furthermore, the observed fungal colony diameters developed on Czapek's/Rose-Bengal agar medium were less than 
the diameter of mold colony recovered with PDA medium (data not shown). Interestingly, Ulicladium spp. was highly recovered with Czapek's/Rose-Bengal agar medium compared to its growth rate on PDA medium. Ulocladium was a highly selective fungal genera where its growth rate on cellulose-Czapek's agar was much higher than with glucose- Czapek's agar (Abdel-Hafez, 1984). In the same regard, Ulicladium spp. was the third predominant fungal genera in the atmosphere of Doha using Czapek's agar medium (Al-Subai, 2002). Even though PDA medium is the richest in carbon content, it is not always support the highest recovery pattern of all molds (Whipps \& Magan, 1987), this fact support our findings which revealed that higher recovery pattern of Cladosporium, Aspergillus and Penicillium were obtained with PDA medium, while the growth rate of Fusarium, Ganoderma and Ulicladium were higher with Czapek's/Rose-Bengal agar medium (Figure 9).

The composition of culture media makes them very selective for the development of fungal genera and thus determines the recovery and growth rates, accordingly the integration of more than one medium in aeromycological studies might yield different fungal taxa and even different colony counts, colony diameters and morphology of the same fungal genera or species. Thus, there are no perfect media for all molds. 


\subsection{The impact of atmospheric status (CO2 concentration) on the dynamics of airborne fungi}

The influence of atmospheric $\mathrm{CO}_{2}$ concentration on the composition and abundance of airborne fungi at two different areas in Qatar were examined in order to investigate the effect of urbanization and air pollution on the availability of aeromycota. The concentrations of $\mathrm{CO}_{2}$ and other air pollutants have higher levels in response to increased anthropogenic activities (Hameed et al., 2012; Chung et al., 2006). There were no significant differences in the composition and diversity of the airborne fungal population between the two study sites, though daily concentration of $\mathrm{CO}_{2}$ was higher at the Industrial area site than at Qatar University Campus (Figure 10). Coincide to our results, from Taiwan, Chung et al. (2006) and from USA, Klamer et al. (2002) demonstrated that the fungal abundance and their species richness were not significantly influenced by elevated $\mathrm{CO}_{2}$

Even though the main constituents of the airospora at the two study sites were attributed to similar fungal taxa Cladosporium, Ganoderma, Fusarium and Alternaria, their main concentrations and distribution rate in the air of the two study area were significantly varied (Figure 12). Cladosporium showed higher and significant concentration at the Qatar University site in comparison to Fusarium and Alternaria which presented at higher abundance rate at Industrial area study site, while Ganoderma had relative similar distribution rate (Figure 11). This may be explained by the fact that the elevated concentration of atmospheric $\mathrm{CO}_{2}$ rises the sporulation rate in some fungal genera (Cotty, 1987), also higher $\mathrm{CO}_{2}$ concentration might decline or altering fungal metabolism which 
subsequently either modify, stimulate or even inhibit the fungal growth pattern, spore production and other reproduction processes (Klironomos et al., 2005). Rather than the atmospheric $\mathrm{CO}_{2}$, other air pollutants such as ozone $\left(\mathrm{O}_{3}\right)$, nitrogen dioxide $\left(\mathrm{NO}_{2}\right)$, sulphur dioxide $\left(\mathrm{SO}_{2}\right)$ and particulate matter PM10 might influence the availability and biological activities of airborne fungal taxa (Hameed et al., 2012). Grinn-Gofroń et al. (2011) revealed that the concentration of Cladosporium spp. was significantly and negatively correlated with $\left(\mathrm{NO}_{2}\right)$, sulphur dioxide $\left(\mathrm{SO}_{2}\right)$ and particulate matter PM10, but positively correlated to O3. Unfortunately the above pollutants were not monitored in the current study, even though we expected to have higher levels of those pollutants at the Industrial area compared to university campus due at least to the big traffic status and this may explain why Cladosporium had higher abundance at Qatar University.

In this study, the concentartions of Alternaria spp. and Fusarium spp. were significantly higher at Industrial area site in corresponding to $\mathrm{CO}_{2}$ than at Qatar University site. Our findings were harmonized with the results of Klironomos et al. (1997) who found that the spore production levels of Fusarium spp. and Alternaria spp. were stimulated under the condition of elevated $\mathrm{CO}_{2}$ concentration. Wolf et al (2010) demonstrated that the sporulation of Alternaria alternata was significantly amplified by the impact of increasing $\mathrm{CO}_{2}$ concentration level. It was demonstrated that, Alternaria alternaria exhibited higher spore production corresponding to elevated $\mathrm{CO}_{2}$ concentration. Because increased $\mathrm{CO}_{2}$ concentration provide the plant with a higher carbon/ nitrogen ratio, pathogenic plant fungi accelerate their growth and sporulation rate (Lake\& Wade, 2009; Knutsen et al., 
2012).Interestingly, airborne fungal spores were increased by 4 -fold responding elevated CO2 concentration (Klironomos et al., 2005; Klironomos et al., 1997).

\section{CONCLUSIONS \& RECOMENDATIONS}

In conclusion, our study demonstrated the seasonal and intra-diurnal pattern of the airborne fungi in the atmosphere of Doha, Qatar in addition to that certain interacting factors were also studied. The main fungal airospora were attributed to Cladosporium, Aspergillus, Fusarium, and Alternaria. Among the meteorological parameters, temperature might be the main determinant of the fungal spore's incidence and diversity in the atmosphere of Doha. Ganoderma spp. is an allergic fungus which was determined as a major fungal constituent in the atmosphere of Doha during February and March. Ganoderma spp. was not encountered in Qatar prior to this study. A spore calendar was constructed to reflect the dynamics and fluctuations of different fungal taxa among different months of the year. This spore calendar represents an important piece of knowledge to fill the gap of data shortage about Doha atmosphere and also to provide baseline information for allergists, plant pathologists, meteorologists and other scientists. Different culture media can support the recovery of a different variety of fungal species and this may be responsible for mistaken interpretations and comparison of results among different aeromycological studies. The concentration of atmospheric $\mathrm{CO}_{2}$ at two locations showed an influence on the occurrence of certain fungal taxa, however other pollutants may also contribute to this influence. 
After completing this study and based on the results obtained, we can add the following recommendations for any further or ongoing research about aeromycology of Doha atmosphere:

- Although February and March are the best months of any fungal study in Qatar, since they matched the highest fungal density and diversity, it is recommended to study the intra-diurnal variations on the dynamics of air borne fungi in at least three different seasons to get a better idea about which intra-diurnal period is with the highest fungal spore incidence and diversity.

- It would be of interest to examine the impact of atmospheric concentration of $\mathrm{CO}_{2}$ on the incidence of fungal airospra for a period of one year. Other pollutants like Sulfer and nitrogen oxides should also be monitored and correlated with prevalent fungal species abundance and diversity.

- This study should be used to produce another study if statistical data about allergic incidence of fungi among Qatari population is available on daily and/or monthly basis

- The impact of Ganoderma as an inhalant allergen on the asthmatic patients, particularly among children, is required to be deeply investigated in such environment.

- A further collaboration research should be created between medical doctor allergists in Qatar and scientists from biological backgrounds to investigate the status of dominant allergic fungi and their dynamics not only in outdoor but also in indoor environment, especially in schools, university campuses, hospitals, kinder 
gardens and any other dwellings that have a mass of population for a certain period of time.

- A future study considering the socioeconomic and hygienic factors as parameters affecting the fluctuation of indoor fungal airspora is recommended, also the relationship between indoor and outdoor fungal flora should be clarified.

- Although fungal spore calendars are not subject to major changes within few years from the year when it's established, however it can be greatly affected if the environment around the source of fungi (soil and vegetation) due to urbanization, ecosystem changes, agriculture, soil and air pollution were changed. The global climate change is also responsible for changing in dynamics and diversity of airospora Therefore spore calendar data should be reviewed and updated each few years. 


\section{REFERENCES}

Abdel-Hafez, S. I. I. (1984). Survey of airborne fungus spores at Taif, Saudi Arabia. Mycopathologia, 88(1), 39-44.

Abdel-Hafez, S. I. I., \& Shoreit, A. A. M. (1985). Mycotoxins producing fungi and mycoflora of air-dust from Taif, Saudi Arabia. Mycopathologia, 92(2), 65-71.

Abdel-Hafez, S. I., \& El-Said, A. H. (1989). Seasonal variations of airborne fungi in Wadi Qena, Eastern Desert, Egypt. Grana, 28(3), 193-203.

Abdel-Hafez, S. I., Moubasher, A. A. H., \& Barakat, A. (1993). Seasonal variations of fungi of outdoor air and sedimented dust at Assiut region, Upper Egypt. Grana, 32(2), 115-121.

Abu-Dieyeh, M. H., \& Barham, R. (2014). Concentrations and dynamics of fungal spore populations in the air of Zarqa, Jordan, using the volumetric method. Grana, 53(2), $117-132$.

Abu-Dieyeh, M. H., Barham, R., Abu\& Vermette, P. (2009). Effect of culture medium composition on Trichoderma reesei's morphology and cellulase production. Bioresource Technology, 100(23), 5979-5987.

Achatz, G., Oberkofler, H., Lechenauer, E., Simon, B., Unger, A., Kandler, D., ... \& Breitenbach, M. (1995). Molecular cloning of major and minor allergens of Alternaria alternata and Cladosporium herbarum. Molecular Immunology, 32(3), 213-227. 
Adhikari, A., Reponen, T., Grinshpun, S. A., Martuzevicius, D., \& LeMasters, G. (2006). Correlation of ambient inhalable bioaerosols with particulate matter and ozone: a two-year study. Environmental Pollution, 140(1), 16-28.

Agarwal, M. K., Shivpuri, D. N., \& Mukerji, K. G. (1969). Studies on the allergenic fungal spores of the Delhi, India, metropolitan area: Botanical aspects (aeromycology). Journal of Allergy, 44(4), 193-203.

Agrios, G. N. (2005). Plant Pathology. 5th eds. San Diego, California: Elsevier Academic Press

Ahamed, A., Abdel-Hafez, S. I. I. (1984). Survey of airborne fungus spores at Taif, Saudi Arabia. Mycopathologia, 88(1), 39-44.

Ali, M. I., Salama, A. M., \& Ali, T. M. (1976). Possible role of solar radiation on the viability of some air fungi in Egypt. Zentralblatt für Bakteriologie, Parasitenkunde, Infektionskrankheiten und Hygiene. Zweite Naturwissenschaftliche Abteilung: Allgemeine, Landwirtschaftliche und Technische Mikrobiologie, 131(6), 529-534.

Allison, S. D., Hanson, C. A., \& Treseder, K. K. (2007). Nitrogen fertilization reduces diversity and alters community structure of active fungi in boreal ecosystems. Soil Biology and Biochemistry, 39(8), 1878-1887.

Almaguer, M., Rojas-Flores, T. I., Rodríguez-Rajo, F. J., \& Aira, M. J. (2014). Airborne basidiospores of Coprinus and Ganoderma in a Caribbean region. Aerobiologia, 30(2), 197-204. 
Al-Subai, A. A. (2002). Air-borne fungi at Doha, Qatar. Aerobiologia, 18(3-4), 175-183.

Al-Suwaine, A. S., Hasnain, S. M., \& Bahkali, A. H. (1999). Viable airborne fungi in Riyadh, Saudi Arabia. Aerobiologia, 15(2), 121-130.

Asan, A., Ilhan, S., Sen, B., Erkara, I. P., Filik, C., Cabuk, A., ... \& Tokur, S. (2004). Airborne fungi and actinomycetes concentrations in the air of Eskisehir City (Turkey). Indoor and Built Environment, 13(1), 63-74.

Asan, A., Sen, B., \& Sarica, S. (2002). Airborne fungi in urban air of Edirne city (Turkey). Biologia (Slovak Republic), 57(1), 59-68

Atkinson, R. W., Strachan, D. P., Anderson, H. R., Hajat, S., \& Emberlin, J. (2006). Temporal associations between daily counts of fungal spores and asthma exacerbations. Occupational and Environmental Medicine, 63(9), 580-590.

Aukrust, L., \& Borch, S. M. (1979). Partial purification and characterization of two Cladosporium herbarum allergens. International Archives of Allergy and Immunology, 60(1), 68-79.

Awad, A. H. A., Gibbs, S. G., Tarwater, P. M., \& Green, C. F. (2013). Coarse and fine culturable fungal air concentrations in urban and rural homes in Egypt. International Journal of Environmental Research and Public Health, 10(3), 936949. 
Aydogdu, H., \& Asan, A. (2008). Airborne fungi in child day care centers in Edirne City, Turkey. Environmental Monitoring and Assessment, 147(1-3), 423-444.

Azcón-Bieito, J., \& Talón, M. (2000). Fundamentos de fisiologia vegetal. Madrid: McGraw-Hill.

Barkai-Golan, R. (1957). A study of air borne fungi in Israel. International Journal of Biometeorology, 1(1), 83-86.

Barkai-Golan, R., \& Glazer, I. (1962). Air-borne fungi in eilat and tel-hashomer, Israel. Journal of Allergy, 33(4), 342-348.

Barnett, H. L., \& Hunter, B. B. (1999). Illustrated genera ofimperfect fungi (4th ed.). St Paul: American Phytopathological Society Press.

Batanouny, K. H. (1981). Ecology and flora of Qatar. Scientific and Applied Research Centre, Qatar University, Doha.

Booth, C. (1971). The genus Fusarium (p. 273). Kew, Surrey: Commonwealth Mycological Institute.

Bousquet, J., Khaltaev, N., Cruz, A. A., Denburg, J., Fokkens, W. J., Togias, A., ... \& Agache, I. (2008). Allergic rhinitis and its impact on asthma (ARIA) 2008*. Allergy, 63(s86), 8-160. 
Bowers, R. M., McLetchie, S., Knight, R., \& Fierer, N. (2011). Spatial variability in airborne bacterial communities across land-use types and their relationship to the bacterial communities of potential source environments. The ISME Journal, 5(4), 601-612.

Bragulat, M. R., Abarca, M. L., Bruguera, M. T., \& Cabanes, F. J. (1991). Dyes as fungal inhibitors: effect on colony diameter. Applied and Environmental Microbiology, 57(9), 2777-2780.

Brook, M. C., Al Shoukri, S., Amer, K. M., Böer, B., \& Krupp, F. (2006). Physical and environmental setting of the Arabian Peninsula and surrounding seas. Policy Perspectives for Ecosystem and Water Management in the Arabia Peninsula. UNESCO Doha and United Nations University, Hamilton, Ontario, 1-16.

Burge, H. A. (1989). Airborne allergenic fungi: classification, nomenclature, and distribution. Immunology and allergy clinics of North America, 9(2), 307-319.

Burge, H. A. (2002). An update on pollen and fungal spore aerobiology. Journal of Allergy and Clinical Immunology, 110(4), 544-552.

Burge, H. P., Solomon, W. R., \& Boise, J. R. (1977). Comparative merits of eight popular media in aerometric studies of fungi. Journal of Allergy and Clinical Immunology, 60(3), 199-203. 
Bush, R. K., \& Portnoy, J. M. (2001). The role and abatement of fungal allergens in allergic diseases. Journal of Allergy and Clinical Immunology,107(3), 430-440.

Bush, R. K., \& Sanchez, H. (1997). In vitro synthesis of Alternaria allergens and their recognition by murine monoclonal and human IgE antibodies. Annals of Allergy, Asthma \& Immunology, 78(3), 287-292.

Cabarroi, M., Maldonado, S., \& del Castillo, L. (2008). Hongos del Jardın Botanico Nacional de Cuba. I. Basidiomycota. Revista del Jardın Botanico de Cuba, 29, 161169.

Calderon, C., Lacey, J., McCartney, H. A., \& Rosas, I. (1995). Seasonal and diurnal variation of airborne basidiomycete spore concentrations in Mexico City. Grana, 34(4), 260-268.

Chandara, N.,Chanada, S. (2000). Aeromycoflora in the Central Milk Dairy of Calcutta. India. Aerobiologia, 16, 367-372.

Chatterjee, J., \& Hargreave, F. E. (1974). Atmospheric pollen and fungal spores in Hamilton in 1972 estimated by the Hirst automatic volumetric spore trap. Canadian Medical Association Journal, 110(6), 659. 
Christensen, J. H., Hewitson, B., Busuioc, A., Chen, A., Gao, X., Held, R., ... \& Dethloff, K. (2007). Regional climate projections. Climate Change, 2007: The Physical Science Basis. Contribution of Working group I to the Fourth Assessment Report of the Intergovernmental Panel on Climate Change, University Press, Cambridge, Chapter 11, 847-940.

Christensen, M., \& Tuthill, D. E. (1986). Aspergillus: an overview. In Advances in Penicillium and Aspergillus systematics (pp. 195-209). Springer US.

Chung, H., Zak, D. R., \& Lilleskov, E. A. (2006). Fungal community composition and metabolism under elevated CO2 and O3. Oecologia, 147(1), 143-154.

Colakoglu, G. (1996). Fungal spore concentrations in the atmosph at the Anatolia quarter of Istanbul, Turkey. Journal of Basic Microbiology, 36(3), 155-162.

Cotty, P.J. 1987. Modulation of sporulation of Alternnria tageticn by carbon dioxide. Mycologia, 79: 508-5 13.

Craig, R. L., \& Levetin, E. (2000). Multi-year study of Ganoderma aerobiology. Aerobiologia, 16(1), 75-81.

Crispen, K. L., Gillespie, D. N., Weiler, E. C., Noonan, C. W., Hamilton, R. F., \& Ward, T. J. (2010). A comparison of 1978 and 2006 peak pollen seasons and sampling methods in Missoula, Montana. Grana, 49(2), 128-133. 
Curlevski, N. J., Drigo, B., Cairney, J. W., \& Anderson, I. C. (2014). Influence of elevated atmospheric $\mathrm{CO}_{2}$ and water availability on soil fungal communities under Eucalyptus saligna. Soil Biology and Biochemistry, 70, 263-271.

Dales, R. E., Cakmak, S., Judek, S., Dann, T., Coates, F., Brook, J. R., \& Burnett, R. T. (2004). Influence of outdoor aeroallergens on hospitalization for asthma in Canada. Journal of Allergy and Clinical Immunology, 113(2), 303-306.

D'amato, G., \& Spieksma, F. T. M. (1995). Aerobiologic and clinical aspects of mould allergy in Europe. Allergy, 50(11), 870-877.

Daş, E., Gürakan, G. C., \& Bayındırlı, A. (2006). Effect of controlled atmosphere storage, modified atmosphere packaging and gaseous ozone treatment on the survival of Salmonella enteritidis on cherry tomatoes. Food Microbiology, 23(5), 430-438.

Deamer, W. C., \& Graham, H. W. (1947). Respiratory mold allergy-a 12 months' atmospheric survey in San Francisco. California Medicine, 66(5), 289.

Di Menna, M. E. (1955). A quantitative study of air-borne fungus spores in Dunedin, New Zealand. Transactions of the British Mycological Society, 38(2), 119-129.

Domingues, F. C., Queiroz, J. A., Cabral, J. M. S., \& Fonseca, L. P. (2000). The influence of culture conditions on mycelial structure and cellulase production by Trichoderma reesei Rut C-30. Enzyme and Microbial Technology, 26(5), 394-401. 
Domsch, K. H., Gams, W., \& Anderson, T. H. (1980). Compendium of soil fungi (p. 859). New York: Academic.

Eduard, W. (1996). Measurement methods and strategies for non-infectious microbial components in bioaerosols at the workplace. Analyst, 121(9), 1197-1201.

Elminir, H. K. (2005). Dependence of urban air pollutants on meteorology. Science of the Total Environment, 350(1), 225-237.

El-Morsy, E. S. M. (2006). Preliminary survey of indoor and outdoor airborne microfungi at coastal buildings in Egypt. Aerobiologia, 22(3), 197-210.

Elteen, K., Al-Rashidi, R., \& Shaheen, I. (2010). Seasonal variation of fungal spore populations in the atmosphere of Zarqa area, Jordan. Aerobiologia, 26(4), 263-276.

Elvira Rendueles, M. L. B. (2001). Caracterización aeropalinológica del bioaerosol atmosférico de la ciudad de Cartagena.

Erkara, I. P., Asan, A., Yilmaz, V., Pehlivan, S., \& Okten, S. S. (2008). Airborne Alternaria and Cladosporium species and relationship with meteorological conditions in Eskisehir City, Turkey. Environmental Monitoring and Assessment, 144(1-3), 3141.

Erkara, I. P., Ilhan, S., \& Oner, S. (2009). Monitoring and assessment of airborne Cladosporium link and Alternaria Nées spores in Sivrihisar (Eskisehir), Turkey. Environmental Monitoring and Assessment, 148(1-4), 477-484. 
Fang, Z., Ouyang, Z., Hu, L., Wang, X., Zheng, H., \& Lin, X. (2005). Culturable airborne fungi in outdoor environments in Beijing, China. Science of the Total Environment, $350(1), 47-58$.

Feinberg, S. M., \& Little, H. T. (1936). Studies on the relation of microorganisms to allergy: III. A year's survey of daily mold spore content of the air. Journal of Allergy, 7(2), 149-155.

Fengxiang, C., Qingxuang, H., Zhensheng, C., Lingyin, M., \& Shigang, Y. (1991). Factors of influence on microbial pollution in the atmosphere over Beijing area. Aerobiologia, 7(2), 136-143.

Fernando, W. G., Miller, J. D., Seaman, W. L., Seifert, K., \& Paulitz, T. C. (2000). Daily and seasonal dynamics of airborne spores of Fusarium graminearum and other Fusarium species sampled over wheat plots. Canadian Journal of Botany, 78(4), 497-505.

Frey, D., \& Durie, E. B. (1962). Estimation of air-borne fungus spores; a comparison of slide and culture methods. Mycopathologia et Mycologia Applicata, 16(4), 295303.

Gao, M., Jia, R., Qiu, T., Han, M., Song, Y., \& Wang, X. (2015). Seasonal size distribution of airborne culturable bacteria and fungi and preliminary estimation of their deposition in human lungs during non-haze and haze days. Atmospheric Environment, 118, 203-210. 
Gillespie, V. L., Clark, C. S., Bjornson, H. S., Samuels, S. J., \& Holland, J. W. (1981). A comparison of two-stage and six-stage Andersen impactors for viable aerosols. The American Industrial Hygiene Association Journal, 42(12), 858-864.

Gravesen, S. (1979). Fungi as a cause of allergic disease. Allergy, 34(3), 135-154.

Green, B. J., Mitakakis, T. Z., \& Tovey, E. R. (2003). Allergen detection from 11 fungal species before and after germination. Journal of Allergy and Clinical Immunology, 111(2), 285-289.

Green, B. J., Sercombe, J. K., \& Tovey, E. R. (2005). Fungal fragments and undocumented conidia function as new aeroallergen sources. Journal of Allergy and Clinical Immunology, 115(5), 1043-1048.

Gregory, P. H. (1973). The air spora near the earth's surface. The Microbiology of the Atmosphere 2nd Edition. Leonard Hill. Aylesbury, UK.

Gregory, P. H., \& Hirst, J. M. (1952). Possible role of basidiospores as air-borne allergens. Nature, 170,414.

Gregory, P. H., \& Hirst, J. M. (1957). The summer air-spora at Rothamsted in 1952. Microbiology, 17(1), 135-152.

Grinn-Gofron, A. (2010). The occurrence of Ganoderma spores in the air and its relationships with meteorological factors. Acta Agrobotanica, 63(1). 
Grinn-Gofron, A., \& Bosiacka, B. (2015). Effects of meteorological factors on the composition of selected fungal spores in the air. Aerobiologia, 31(1), 63-72.

Grinn-Gofroń, A., \& Rapiejko, P. (2009). Occurrence of Cladosporium spp. and Alternaria spp. spores in Western, Northern and Central-Eastern Poland in 2004-2006 and relation to some meteorological factors. Atmospheric Research, 93(4), 747-758.

Grinn-Gofroń, A., \& Strzelczak, A. (2013). Changes in concentration of Alternaria and Cladosporium spores during summer storms. International Journal of Biometeorology, 57(5), 759-768.

Grinn-Gofroń, A., Strzelczak, A., \& Wolski, T. (2011). The relationships between air pollutants, meteorological parameters and concentration of airborne fungal spores. Environmental Pollution, 159(2), 602-608.

Halwagy, M. H. (1989). Seasonal airspora at three sites in Kuwait 1977-1982. Mycological Research, 93(2), 208-213.

Hameed, A. A., Khoder, M. I., \& Emad, A. A. (2007). Fertile fungal spores collected on different faced surfaces in the atmosphere of Giza, Egypt. Aerobiologia, 23(1), 4757.

Hameed, A. A., Khoder, M. I., Ibrahim, Y. H., Saeed, Y., Osman, M. E., \& Ghanem, S. (2012). Study on some factors affecting survivability of airborne fungi. Science of the Total Environment, 414, 696-700. 
Hameed, A. A., Khoder, M. I., Yuosra, S., Osman, A. M., \& Ghanem, S. (2009). Diurnal distribution of airborne bacteria and fungi in the atmosphere of Helwan area, Egypt. Science of the Total Environment, 407(24), 6217-6222.

Harrison RM, Perry R. (1986).Handbook of air pollution analysis 2nd ed. London, N.Y: Chapman and Hall.

Harrison, J., Pickering, C. A. C., Faragher, E. B., Austwick, P. K. C., Little, S. A., \& Lawton, L. (1992). An investigation of the relationship between microbial and particulate indoor air pollution and the sick building syndrome. Respiratory Medicine, 86(3), 225-235.

Hasnain, S. M., Akhter, T., \& Waqar, M. A. (2012). Airborne and allergenic fungal spores of the Karachi environment and their correlation with meteorological factors. Journal of Environmental Monitoring, 14(3), 1006-1013.

Hasnain, S. M., Al-Frayh, A., Gad-el-Rab, M. O., \& Al-Sedairy, S. (1998). Airborne Alternaria spores: potential allergic sensitizers in Saudi Arabia. Annals of Saudi Medicine, 18, 497-501.

Hasnain, S. M., Al-Frayh, A., Khatija, F., \& Al-Sedairy, S. (2004). Airborne Ganoderma basidiospores in a country with desert environment. Grana, 43(2), 111-115.

Hasnain, S. M., Fatima, K., Al-Frayh, A., \& Al-Sedairy, S. T. (2005). One-year pollen and spore calendars of Saudi Arabia Al-Khobar, Abha and Hofuf. Aerobiologia, 21(34), 241-247. 
Hedayati, M. T., Pasqualotto, A. C., Warn, P. A., Bowyer, P., \& Denning, D. W. (2007). Aspergillus flavus: human pathogen, allergen and mycotoxin producer. Microbiology, 153(6), 1677-1692.

Heinzerling, L., Frew, A. J., Bindslev-Jensen, C., Bonini, S., Bousquet, J., Bresciani, M., ... \& Haahtela, T. (2005). Standard skin prick testing and sensitization to inhalant allergens across Europe-a survey from the GA2LEN network. Allergy, 60(10), $1287-1300$.

Helander, M. L., \& Pessi, A. M. (1991). Circadian periodicity of airborne pollen and spores; significance of sampling height. Aerobiologia, 7(2), 129-135.

Henson, O. E. (1981). Dichloran as an inhibitor of mold spreading in fungal plating media: effects on colony diameter and enumeration. Applied and Environmental Microbiology, 42(4), 656-660.

Heo, K. J., Kim, H. B., \& Lee, B. U. (2014). Concentration of environmental fungal and bacterial bioaerosols during the monsoon season. Journal of Aerosol Science, 77, $31-37$.

Herrero, B., Fombella-Blanco, M. A., Fernández-González, D., \& Valencia-Barrera, R. M. (1996). Aerobiological study of fungal spores from Palencia (Spain). Aerobiologia, 12(1), 27-35.

Hirst, J. (1952). An automatic volumetric spore trap. Annals of Applied Biology,39(2), 257265. 
Ho, H. M., Rao, C. Y., Hsu, H. H., Chiu, Y. H., Liu, C. M., \& Chao, H. J. (2005). Characteristics and determinants of ambient fungal spores in Hualien, Taiwan. Atmospheric Environment, 39(32), 5839-5850.

Horner, W. E., Helbling, A., Salvaggio, J. E., \& Lehrer, S. B. (1995). Fungal allergens. Clinical Microbiology Reviews, 8(2), 161-179.

\section{http://www.mdps.gov.qa/ar/Pages/default.aspx}

Ibanez,V., Rojas, G., Roure, J.(2001). Airborne fungi monitoring in Santiago, Chile. Aerobiologia, 17, 137-142.

Ingold, C. T. (1971). Fungal spores. Their liberation and dispersal (p 302). Oxford.

Jaakkola, J. J., Hwang, B. F., \& Jaakkola, M. S. (2010). Home dampness and molds as determinants of allergic rhinitis in childhood: a 6-year, population-based cohort study. American Journal of Epidemiology, 172(4), 451-459.

Jensen, P. A., Todd, W. F., Davis, G. N., \& Scarpino, P. V. (1992). Evaluation of eight bioaerosol samplers challenged with aerosols of free bacteria. The American Industrial Hygiene Association Journal, 53(10), 660-667.

Jones, A. M., \& Harrison, R. M. (2004). The effects of meteorological factors on atmospheric bioaerosol concentrations-a review. Science of the Total Environment, 326(1), 151-180. 
Jothish, P. S., \& Nayar, T. S. (2004). Airborne fungal spores in a sawmill environment in Palakkad District, Kerala, India. Aerobiologia, 20(1), 75-81.

Joy Royes, V. I. (1987). Some components of the air spora in Jamaica and their possible medical application. Grana, 26(2), 151-157.

Katial, R. K., Zhang, Y., Jones, R. H., \& Dyer, P. D. (1997). Atmospheric mold spore counts in relation to meteorological parameters. International Journal of Biometeorology, 41(1), 17-22.

Khan, Z. U., Khan, M. A. Y., Chandy, R., \& Sharma, P. N. (1999). Aspergillus and other moulds in the air of Kuwait. Mycopathologia, 146(1), 25-32.

Khattab, A., \& Levetin, E. (2008). Effect of sampling height on the concentration of airborne fungal spores. Annals of Allergy, Asthma \& Immunology, 101(5), 529-534.

Klamer, M., Roberts, M. S., Levine, L. H., Drake, B. G., \& Garland, J. L. (2002). Influence of elevated $\mathrm{CO}_{2}$ on the fungal community in a coastal scrub oak forest soil investigated with terminal-restriction fragment length polymorphism analysis. Applied and Environmental Microbiology, 68(9), 4370-4376.

Klironomos, J. N., Allen, M. F., Rillig, M. C., Piotrowski, J., Makvandi-Nejad, S., Wolfe, B. E., \& Powell, J. R. (2005). Abrupt rise in atmospheric CO2 overestimates community response in a model plant-soil system. Nature, 433(7026), 621-624. 
Klironomos, J. N., Rillig, M. C., Allen, M. F., Zak, D. R., Pregitzer, K. S., \& Kubiske, M. E. (1997). Increased levels of airborne fungal spores in response to Populus tremuloides grown under elevated atmospheric $\mathrm{CO}_{2}$. Canadian Journal of Botany, 75(10), 1670-1673.

Knutsen, A. P., Bush, R. K., Demain, J. G., Denning, D. W., Dixit, A., Fairs, A., ... \& Moss, R. B. (2012). Fungi and allergic lower respiratory tract diseases. Journal of Allergy and Clinical Immunology, 129(2), 280-291.

Koppelman, G. H. (2007). Gene-environment interaction in allergic disease: More questions, more answers. Journal of Allergy and Clinical Immunology,120(6), 1266-1268.

Kozakiewicz, Z. (1989). Aspergillus species on stored products.Mycological Papers No. 161(pp. 188). Kew, Surrey:Commonwealth Mycological Institute.

Kummer, V., \& Thiel, W. R. (2008). Bioaerosols-sources and control measures. International Journal of Hygiene and Environmental Health, 211(3), 299-307.

Kurup, V. P. (1989). Hypersensitivity pneumonitis due to sensitization with thermophilic actinomycetes. Immunology and Allergy Clinics of North America,9(2), 285-306.

Kurup, V.P., \& Fink, J. N. (1993). Fungal infection and immunity responses.Plenum Press, New York, (s), 393-404. 
Kurup, V. P., Shen, H. D., \& Banerjee, B. (2000). Respiratory fungal allergy. Microbes and Infection, 2(9), 1101-1110.

Kurup, V. P., Shen, H. D., \& Vijay, H. (2002). Immunobiology of fungal allergens. International Archives of Allergy and Immunology, 129(3), 181-188.

Lacey, J. (1981). The aerobiology of conidial fungi. Biology of conidial fungi, 1, 373-416.

Lacey, M. E., \& West, J. S. (2007). The air spora: a manual for catching and identifying airborne biological particles. Springer Science \& Business Media.

Lake, J. A., \& Wade, R. N. (2009). Plant-pathogen interactions and elevated CO2: morphological changes in favour of pathogens. Journal of Experimental Botany, 60(11), 3123-3131.

Li, D. W., \& Kendrick, B. (1995). A year-round outdoor aeromycological study in Waterloo, Ontario, Canada. Grana, 34(3), 199-207.

Lin, W. H., \& Li, C. S. (2000). Associations of fungal aerosols, air pollutants, and meteorological factors. Aerosol Science \& Technology, 32(4), 359-368.

Lyon, F. L., Kramer, C. L., \& Eversmeyer, M. G. (1984). Variation of airspora in the atmosphere due to weather conditions. Grana, 23(3), 177-181.

Ma, J., \& van Weele, M. (2000). Effect of stratospheric ozone depletion on the net production of ozone in polluted rural areas. Chemosphere-Global Change Science, 2(1), 23-37. 
Marenco, A., Gouget, H., Nédélec, P., \& Karcher, F. (1994). Evidence of a long-term increase in tropospheric ozone from Pic du Midi data series: Consequences: Positive radiative forcing. Journal of Geophysical Research: Atmospheres (19842012), 99(D8), 16617-16632.

Masoli, M., Fabian, D., Holt, S., \& Beasley, R. (2004). The global burden of asthma: executive summary of the GINA Dissemination Committee report.Allergy, 59(5), $469-478$.

Matthias-Maser, S., Jaenicke, R. (1995). The size distribution of primary biological aerosol particles with radii $>0.2 \mathrm{~mm}$ in an urban/rural influenced region. Atmospheric Research 39, 279-286.

Matthias-Maser, S., Obolkin, V., Khodzer, T., \& Jaenicke, R. (1998). Seasonal variation of primary biological aerosol particles in the remote continental region of lake baikal/Sibiria. Journal of Aerosol Science, 29, S545-S546.

McDonald, M. S., \& O'driscoll, B. J. (1980). Aerobiological studies based in Galway. A comparison of pollen and spore counts over two seasons of widely differing weather conditions. Clinical \& Experimental Allergy, 10(2), 211-215.

McQuilken, M. A. R. K., Budge, S. P., \& Whipps, J. M. (1997). Effects of culture media and environmental factors on conidial germination, pycnidial production and hyphal extension of Coniothyrium minitans. Mycological Research, 101(01), 1117. 
Mishra, R. R. (1971). Aeromycology of Gorakhpur III. Seasonal variation in air fungal spora. Mycopathologia et mycologia applicata, 45(3-4), 301-310.

Mitakakis, T. Z., \& Guest, D. I. (2001). A fungal spore calendar for the atmosphere of Melbourne, Australia, for the year 1993. Aerobiologia, 17(2), 171-176.

Mitakakis, T. Z., Barnes, C., \& Tovey, E. R. (2001). Spore germination increases allergen release from Alternaria. Journal of Allergy and Clinical Immunology, 107(2), 388390.

Mitakakis, T. Z., O'meara, T. J., \& Tovey, E. R. (2003). The effect of sunlight on allergen release from spores of the fungus Alternaria. Grana, 42(1), 43-46.

Mohamed, D. J., \& Martiny, J. B. (2011). Patterns of fungal diversity and composition along a salinity gradient. The ISME Journal, 5(3), 379-388.

Mohammad, M. J., Hamad, S. R., \& Malkawi, H. I. (2003). Population of arbuscular mycorrhizal fungi in semi-arid environment of Jordan as influenced by biotic and abiotic factors. Journal of Arid Environments, 53(3), 409-417.

Mohammadi, P., \& Krumbein, W. E. (2008). Biodeterioration of ancient stone materials from the Persepolis monuments (Iran). Aerobiologia, 24(1), 27-33.

Moubasher, A. H. (1993). Soil fungi in Qatar and other Arab countries (p. 566). Doha. University of Qatar, Center of Scientific and Applied Research. 
Moustafa, A. F. (1975). Osmophilous fungi in the salt marshes of Kuwait. Canadian Journal of Microbiology, 21(10), 1573-1580.

Moustafa, A. F., \& Kamel, S. M. (1976). A study of fungal spore poupulations in the atmosphere of Kuwait. Mycopathologia, 59(1), 29-35.

Nelson, P. E., Dignani, M. C., \& Anaissie, E. J. (1994). Taxonomy, biology, and clinical aspects of Fusarium species. Clinical Microbiology Reviews, 7(4), 479-504.

Nesa, D., Lortholary, J., Bouakline, A., Bordes, M., Chandenier, J., Derouin, F., \& Gangneux, J. P. (2001). Comparative performance of impactor air samplers for quantification of fungal contamination. Journal of Hospital Infection, 47(2), 149155.

Nieguitsila, A., Arné, P., Durand, B., Deville, M., Benoît-Valiergue, H., Chermette, R., ... \& Guillot, J. (2011). Relative efficiencies of two air sampling methods and three culture conditions for the assessment of airborne culturable fungi in a poultry farmhouse in France. Environmental Research, 111(2), 248-253.

Norton, J., Majid, S. A., Allan, D., \& Al Safran, M. (2009). An illustrated checklist of the flora of Qatar. Gosport: Browndown Publications.

Nourian, A. A., Badali, H., Khodaverdi, M., Hamzehei, H., \& Mohseni, S. (2007). Airborne mycoflora of Zanjan-Iran. International Journal of Agriculture \& Biology, 9(4), 628-630. 
O’Connor, D. J., Sadyś, M., Skjøth, C. A., Healy, D. A., Kennedy, R., \& Sodeau, J. R. (2014). Atmospheric concentrations of Alternaria, Cladosporium, Ganoderma and Didymella spores monitored in Cork (Ireland) and Worcester (England) during the summer of 2010. Aerobiologia, 30(4), 397-411.

O'Gorman, C. M., \& Fuller, H. T. (2008). Prevalence of culturable airborne spores of selected allergenic and pathogenic fungi in outdoor air. Atmospheric Environment, 42(18), 4355-4368.

O'Brien, H. E., Parrent, J. L., Jackson, J. A., Moncalvo, J. M., \& Vilgalys, R. (2005). Fungal community analysis by large-scale sequencing of environmental samples. Applied and Environmental Microbiology, 71(9), 5544-5550.

Oliveira, M., Ribeiro, H., Delgado, J. L., \& Abreu, I. (2009). The effects of meteorological factors on airborne fungal spore concentration in two areas differing in urbanisation level. International Journal of Biometeorology, 53(1), 61-73.

Ormstad, H., Johansen, B. V., \& Gaarder, P. I. (1998). Airborne house dust particles and diesel exhaust particles as allergen carriers. Clinical and Experimental allergy, 28(6), 702-708.

Ottow, J. C. G. (1972). Rose Bengal as a selective aid in the isolation of fungi and actinomycetes from natural sources. Mycologia, 304-315.

Pakpour, S., Li, D. W., \& Klironomos, J. (2015). Relationships of fungal spore concentrations in the air and meteorological factors. Fungal Ecology, 13, 130-134. 
Pegler, D. N., \& Young, T. W. K. (1973). Basidiospore form in the British species of Ganoderma karst. Kew Bulletin, 351-364.

Pepeljnjak, S., \& Šegvić, M. (2003). Occurrence of fungi in air and on plants in vegetation of different climatic regions in Croatia. Aerobiologia, 19(1), 11-19.

Pieckenstain, F. L., Gárriz, A., Chornomaz, E. M., Sánchez, D. H., \& Ruiz, O. A. (2001). The effect of polyamine biosynthesis inhibition on growth and differentiation of the phytopathogenic fungus Sclerotinia sclerotiorum. Antonie Van Leeuwenhoek, 80(3-4), 245-253.

Pitt, J. I., \& Hocking, A. D. (1997). Fungi and food spoilage (2nd ed.). Cambridge: Blackie Academic and Professional,University Press.

Polymenakou, P. N. (2012). Atmosphere: a source of pathogenic or beneficial microbes. Atmosphere, 3(1), 87-102.

Quintero, E., Rivera-Mariani, F., \& Bolaños-Rosero, B. (2010). Analysis of environmental factors and their effects on fungal spores in the atmosphere of a tropical urban area (San Juan, Puerto Rico). Aerobiologia, 26(2), 113-124.

Recio, M., del Mar Trigo, M., Docampo, S., Melgar, M., García-Sánchez, J., Bootello, L., \& Cabezudo, B. (2012). Analysis of the predicting variables for daily and weekly fluctuations of two airborne fungal spores: Alternaria and Cladosporium. International journal of biometeorology, 56(6), 983-991. 
Reijula, K., Leino, M., Mussalo-Rauhamaa, H., Nikulin, M., Alenius, H., Mikkola, J. ... \& Haahtela, T. (2003). IgE-mediated allergy to fungal allergens in Finland with special reference to Alternaria alternata and Cladosporium herbarum. Annals of Allergy, Asthma \& Immunology, 91(3), 280-287.

Ren, P., Jankun, T. M., Belanger, K., Bracken, M. B., \& Leaderer, B. P. (2001). The relation between fungal propagules in indoor air and home characteristics. Allergy, 56(5), 419-424.

Reponen, T. (2011). Methodologies for Assessing Bioaerosol Exposures.Encyclopedia of Environmental Health, 722-730.

Reyes, E. S., de la Cruz, D. R., Merino, E. S., \& Sánchez, J. S. (2009). Meteorological and agricultural effects on airborne Alternaria and Cladosporium spores and clinical aspects in Valladolid [Spain]. Annals of Agricultural and Environmental Medicine, 16(1), 53-61.

Richards, M. (1956). A census of mould spores in the air over Britain in 1952.Transactions of the British Mycological Society, 39(4), 431-441.

Richer, R. (2009). Conservation in Qatar: impacts of increasing industrialization (p. 27). CIRS, Centre for International and Regional Studies.Georgetown University School of Foreign Service in Qatar. 
Rossi, V., Bugiani, R., Giosué, S., \& Natali, P. (2005). Patterns of airborne conidia of Stemphylium vesicarium, the causal agent of brown spot disease of pears, in relation to weather conditions. Aerobiologia, 21(3-4), 203-216.

Rousk, J., \& Baath, E. (2011). Growth of saprotrophic fungi and bacteria in soil. FEMS Microbiology Ecology, 78(1), 17-30.

Sabariego, S., Bouso, V., \& Perez-Badia, R. (2012). Comparative study of airborne Alternaria conidia levels in two cities in Castilla-La Mancha (central Spain), and correlations with weather-related variables. Annals of Agricultural and Environmental Medicine, 19(2).

Rossi, V., Bugiani, R., Giosué, S., \& Natali, P. (2005). Patterns of airborne conidia of Stemphylium vesicarium, the causal agent of brown spot disease of pears, in relation to weather conditions. Aerobiologia, 21(3-4), 203-216.

Sabariego, S., De La Guardia, C. D., \& Alba, F. (2000). The effect of meteorological factors on the daily variation of airborne fungal spores in Granada (southern Spain). International Journal of Biometeorology, 44(1), 1-5.

Sabariego, S., Díez, A., \& Gutiérrez, M. (2007). Monitoring of airborne fungi in Madrid (Spain). Acta Botanica Croatica, 66(2), 117-126. 
Şakiyan, N., \& İnceoglu, Ö. (2003). Atmospheric concentrations of Cladosporium Link and Alternaria Nees spores in Ankara and the effects of meteorological factors. Turkish Journal of Botany, 27(2), 77-81.

Samson, R. A., Hoekstra, E. S., Frisvad, J. C., \& Filtenborg, O. (2002). Introduction to food- and aierborne fungi.Utrecht: Centraalbureau voor Schimmelcultures.

Segvić Klarić, M., \& Pepeljnjak, S. (2006). A year-round aeromycological study in Zagreb area, Croatia. Ann Agric Environ Med, 13(1), 55-64.

Sen, B., \& Asan, A. (2001). Airborne fungi in vegetable growing areas of Edirne, Turkey. Aerobiologia, 17(1), 69-75.

Sen, B., \& Asan, A. (2009). Fungal flora in indoor and outdoor air of different residential houses in Tekirdag City (Turkey): seasonal distribution and relationship with climatic factors. Environmental Monitoring and Assessment, 151(1-4), 209-219.

Shaheen, I. A. (1992). Aeromycology of Amman area, Jordan. Grana, 31(3), 223-228.

Shams-Ghahfarokhi, M., Aghaei-Gharehbolagh, S., Aslani, N., \& Razzaghi-Abyaneh, M. (2014). Investigation on distribution of airborne fungi in outdoor environment in Tehran, Iran. Journal of Environmental Health Science and Engineering, 12(1), 1.

Sharpe, R. A., Bearman, N., Thornton, C. R., Husk, K., \& Osborne, N. J. (2015). Indoor fungal diversity and asthma: a meta-analysis and systematic review of risk factors. Journal of Allergy and Clinical Immunology, 135(1), 110-122. 
Shelton, B. G., Kirkland, K. H., Flanders, W. D., \& Morris, G. K. (2002). Profiles of airborne fungi in buildings and outdoor environments in the United States. Applied and Environmental Microbiology, 68(4), 1743-1753.

Singh, A. B., Gupta, S. K., Pereira, B. M. J., \& Prakash, D. (1995). Sensitization to Ganoderma lucidum in patients with respiratory allergy in India. Clinical \& Experimental Allergy, 25(5), 440-447.

Smith, S. N. (2007). An overview of ecological and habitat aspects in the genus Fusarium with special emphasis on the soil-borne pathogenic forms. Plant Pathol Bull, 16, $97-120$.

Sousa, S. I. V., Martins, F. G., Pereira, M. C., Alvim-Ferraz, M. C. M., Ribeiro, H., Oliveira, M., \& Abreu, I. (2008). Influence of atmospheric ozone, PM 10 and meteorological factors on the concentration of airborne pollen and fungal spores. Atmospheric Environment, 42(32), 7452-7464.

Southworth, D. (1973). Introduction to the biology of airborne fungal spores. Annals of Allergy, 32(1), 1-22.

Sreeramulu, T. (1959). The diurnal and seasonal periodicity of spores of certain plant pathogens in the air. Transactions of the British Mycological Society, 42(2), 177184.

Stanley, R. L., \& Pollen, H. F. (1974). Biology, chemistry and Management. 
Stein, S. W. (1999). Size distribution measurements of metered dose inhalers using Andersen Mark II cascade impactors. International Journal of Pharmaceutics, $186(1), 43-52$.

Stennett, P. J., \& Beggs, P. J. (2004). Alternaria spores in the atmosphere of Sydney, Australia, and relationships with meteorological factors. International Journal of Biometeorology, 49(2), 98-105.

Stępalska, D., \& Wołek, J. (2005). Variation in fungal spore concentrations of selected taxa associated. Aerobiologia, 21(1), 43-52.

Stępalska, D., \& Wołek, J. (2009). Intradiurnal periodicity of fungal spore concentrations (Alternaria, Botrytis, Cladosporium, Didymella, Ganoderma) in Cracow, Poland. Aerobiologia, 25(4), 333-340.

Syed, A., \& Abdulla, S. M. S. (2002). Assessing Desert vegetation cover using remotely sensed data: A case study from the State of Qatar.

Taj-Aldeen, S. J., Chandra, P., \& Denning, D. W. (2015). Burden of fungal infections in Qatar. Mycoses, 58(S5), 51-57.

Taj-Aldeen, S. J., Hilal, A. A., \& Chong-Lopez, A. (2003). Allergic Aspergillus flavus rhinosinusitis: a case report from Qatar. European archives of oto-rhinolaryngology, 260(6), 331-335. 
Takahashi, T. (1997). Airborne fungal colony-forming units in outdoor and indoor environments in Yokohama, Japan. Mycopathologia, 139(1), 23-33.

Taylor EJ, editor. (1988) .Dorland medical dictionary. Philidelphia: W.B. Saunders Co.

Troutt, C., \& Levetin, E. (2001). Correlation of spring spore concentrations and meteorological conditions in Tulsa, Oklahoma. International Journal of Biometeorology, 45(2), 64-74.

Turner, P. D. (1966). The fungal air spora of Hong Kong as determined by the agar plate method. Transactions of the British Mycological Society, 49(2), 255-267.

Van Der Heijden, M. G., Bardgett, R. D., \& Van Straalen, N. M. (2008). The unseen majority: soil microbes as drivers of plant diversity and productivity in terrestrial ecosystems. Ecology letters, 11(3), 296-310.

Vermani, M., Vijayan, V. K., Menon, B., Kausar, M. A., \& Agarwal, M. K. (2011). Physico-chemical and clinico-immunologic studies on the allergenic significance of Aspergillus tamarii, a common airborne fungus. Immunobiology, 216(3), 393401.

Vijay, H. M., Burton, M., Young, N. M., Copeland, D. F., \& Corlett, M. (1991). Allergenic components of isolates of Cladosporium herbarum. Grana, 30(1), 161-165. 
Waisel, Y., Ganor, E., Glikman, M., Epstein, V., \& Brenner, S. (1997). Airborne fungal spores in the coastal plain of Israel: A preliminary survey. Aerobiologia, 13(4), 281-287.

Wang, W., Ma, X., Ma, Y., Mao, L., Wu, F., Ma, X. ... \& Feng, H. (2010). Seasonal dynamics of airborne fungi in different caves of the Mogao Grottoes, Dunhuang, China. International Biodeterioration \& Biodegradation, 64(6), 461-466.

Whangchai, K., Saengnil, K., \& Uthaibutra, J. (2006). Effect of ozone in combination with some organic acids on the control of postharvest decay and pericarp browning of longan fruit. Crop Protection, 25(8), 821-825.

Whipps, J. M., \& Magan, N. (1987). Effects of nutrient status and water potential of media on fungal growth and antagonist-pathogen interactions1. Eppo Bulletin, 17(4), 581591.

Wolf, J., O'Neill, N. R., Rogers, C. A., Muilenberg, M. L., \& Ziska, L. H. (2010). Elevated atmospheric carbon dioxide concentrations amplify Alternaria alternata sporulation and total antigen production. Environmental Health Perspectives, $118(9), 1223$.

Won, W. D., \& Ross, H. (1969). Reaction of airborne Rhizobium meliloti to some environmental factors. Applied Microbiology, 18(4), 555-557.

World Health Organization. (2000). Air quality guidelines for Europe. 
Wu, P. C., Su, H. J. J., \& Ho, H. M. (2000). A comparison of sampling media for environmental viable fungi collected in a hospital environment. Environmental Research, 82(3), 253-257.

Wu, Y. H., Chan, C. C., Rao, C. Y., Lee, C. T., Hsu, H. H., Chiu, Y. H., \& Chao, H. J. (2007). Characteristics, determinants, and spatial variations of ambient fungal levels in the subtropical Taipei metropolis. Atmospheric Environment, 41(12), 2500-2509.

Yuste, J. C., Peñuelas, J., Estiarte, M., GARCIA-MAS, J., Mattana, S., Ogaya, R. ... \& Sardans, J. (2011). Drought-resistant fungi control soil organic matter decomposition and its response to temperature. Global Change Biology, 17(3), $1475-1486$.

Zak, D. R., Holmes, W. E., White, D. C., Peacock, A. D., \& Tilman, D. (2003). Plant diversity, soil microbial communities, and ecosystem function: are there any links. Ecology, 84(8), 2042-2050. 
Appendix A: Samples of pictures for selected fungal colonies on Potato Dextrose Agar (PDA) medium.

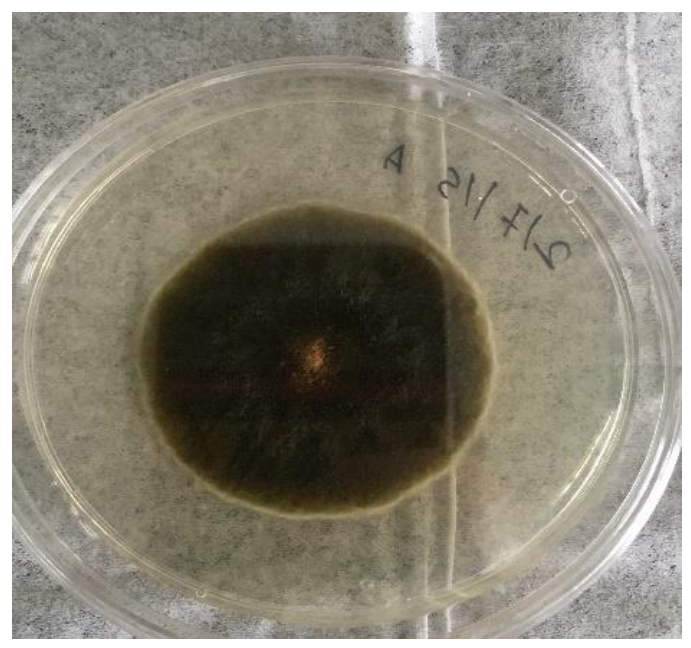

A

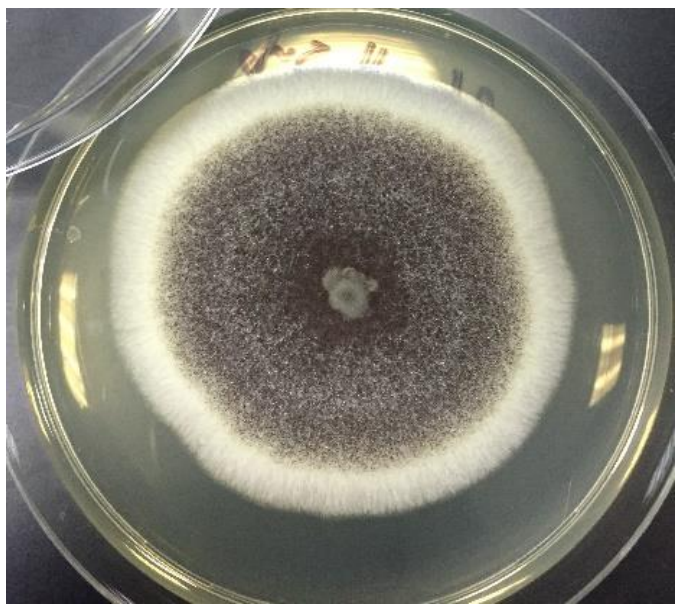

$\mathrm{D}$

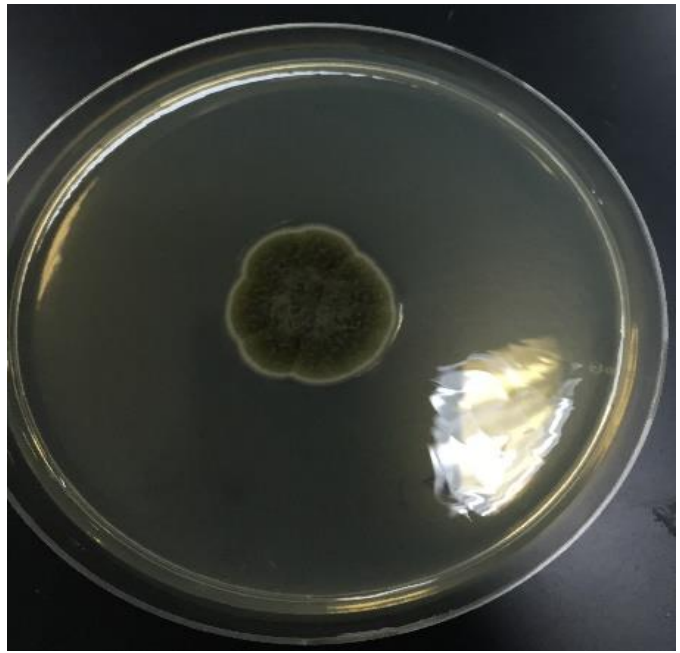

B 3

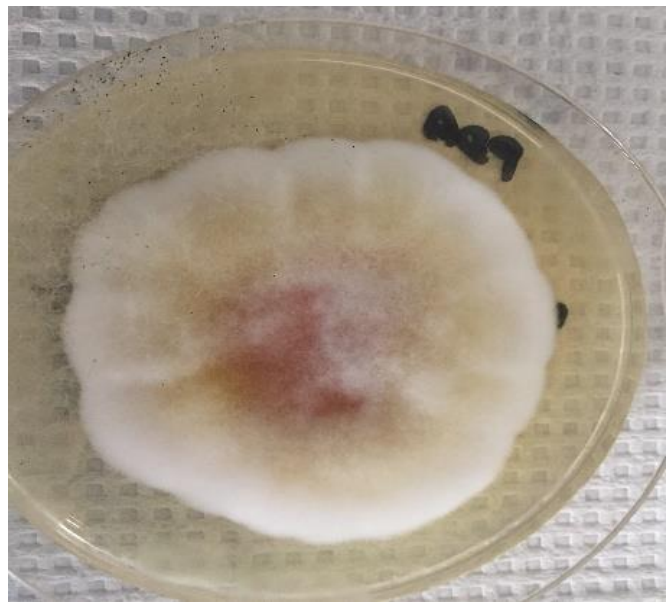

$\mathrm{F}$ 


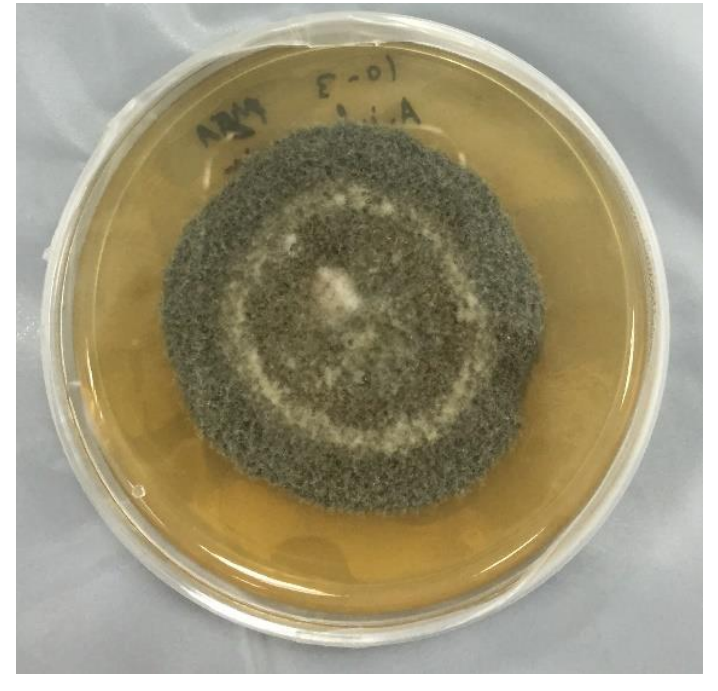

E

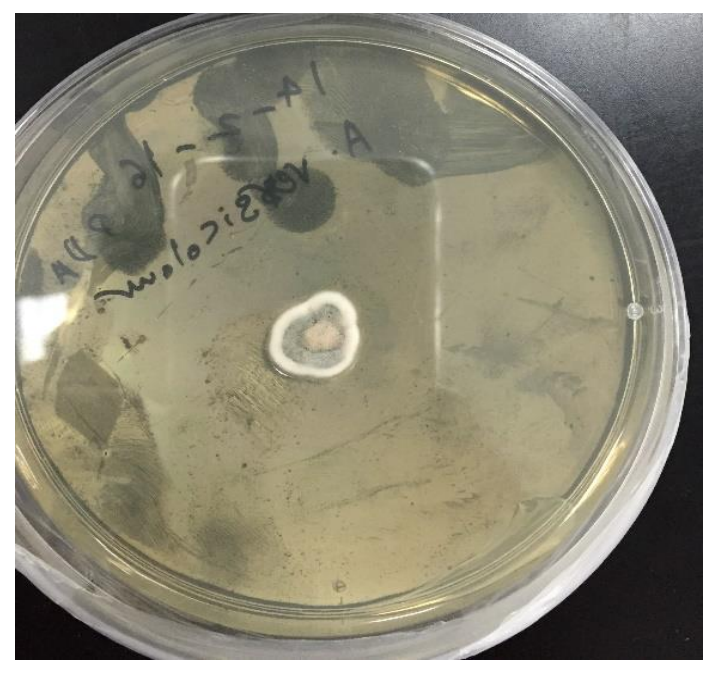

G

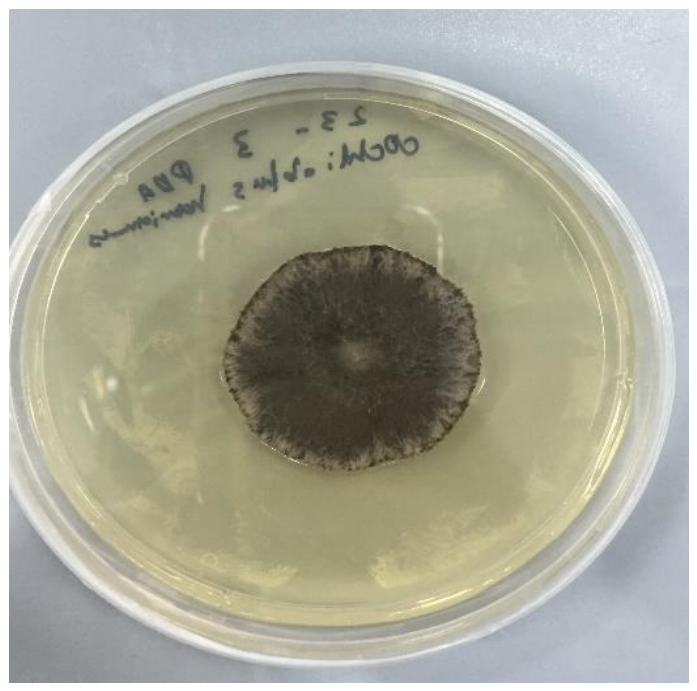

F
A. Alternaric.
ate
B. Cladosporium cladosporioides
C. Aspergillus carbonarius
D. Fusarium oxysporum
E. Alternaria infectoria
F. Cochliobolus hawaiiensis
G. Aspergillus versicolor 
Appendix B: Samples of pictures for selected fungal spores on slides which photographed under light microscope using the $40 \mathrm{X}$ objective lens.
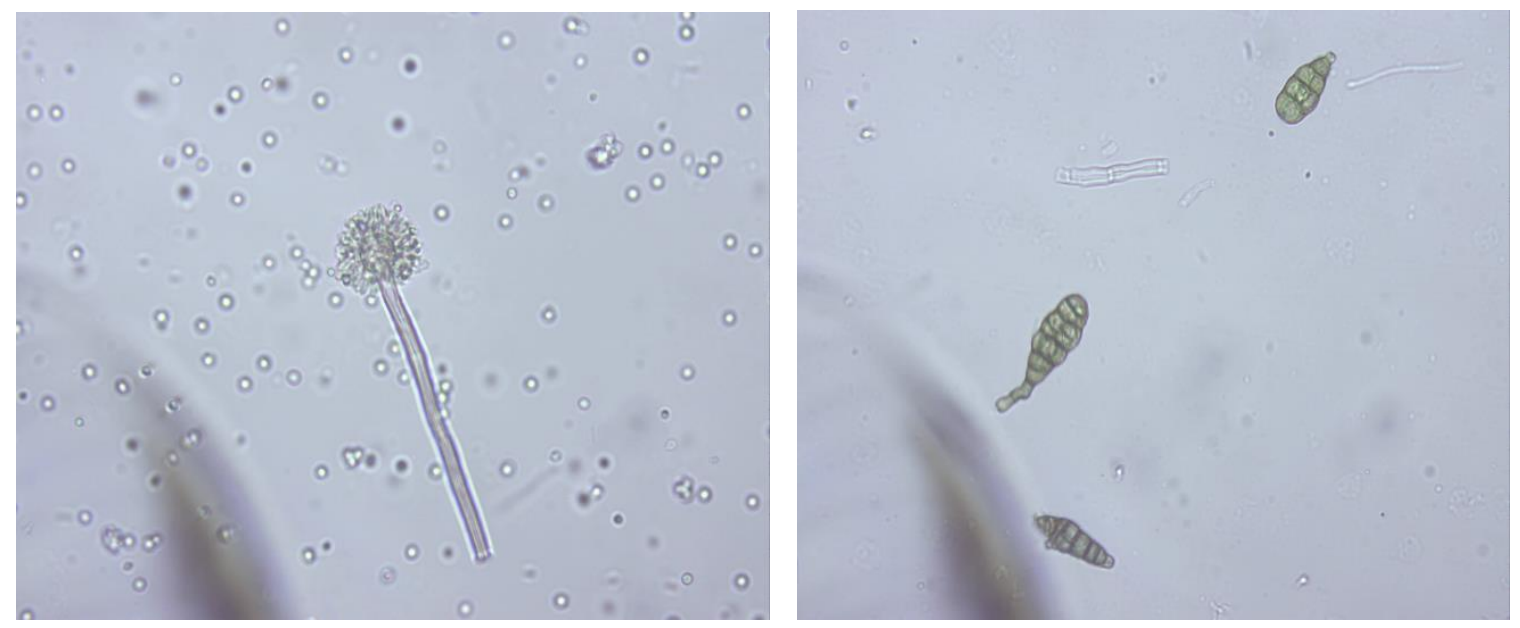

A

B
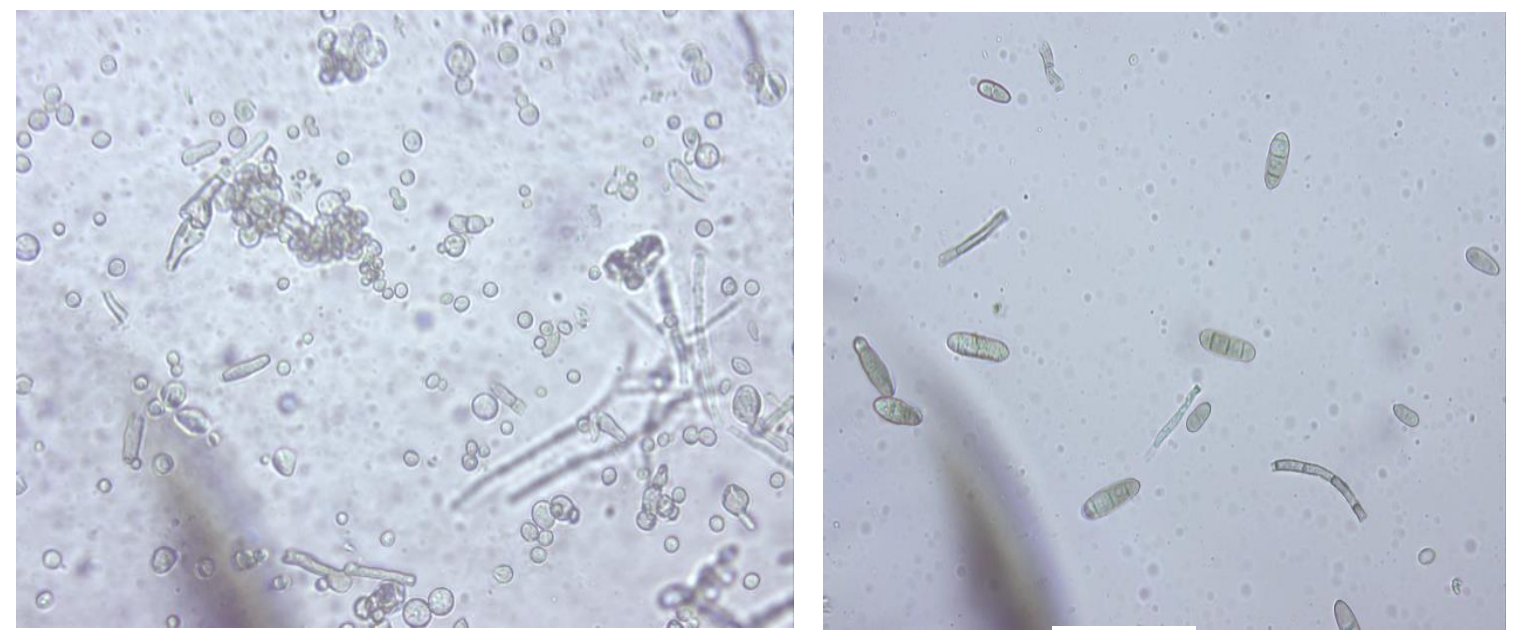

C

D 


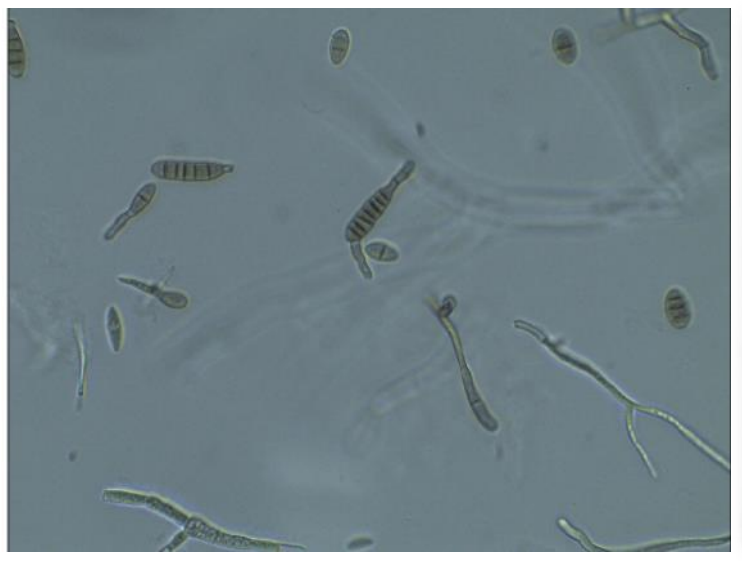

E

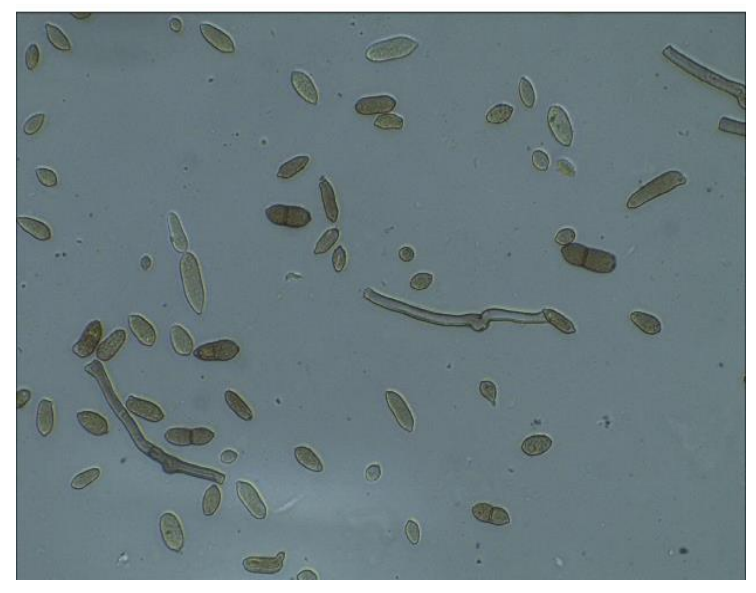

G

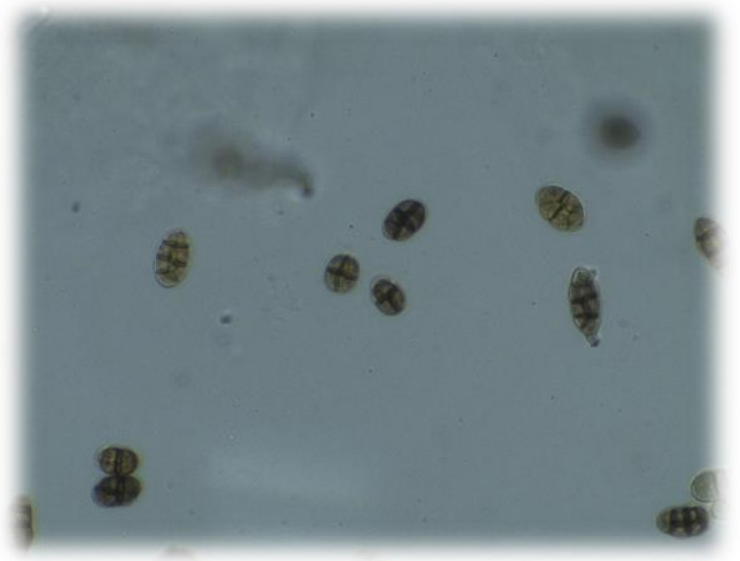

F

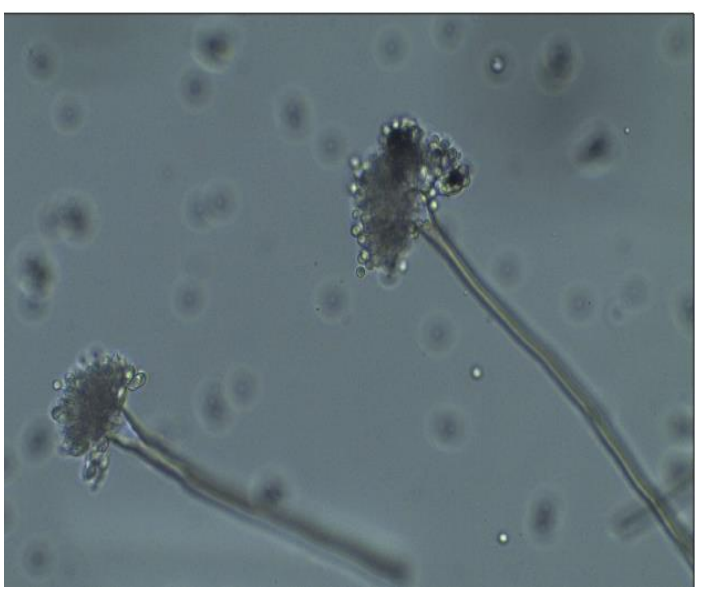

$\mathrm{H}$
A. Aspergillus versicolor
B. Alternaria alternate
C. Cladosporium cladosporioides
D. Cochliobolus hawaiiensis
E. Alternaria infectoria
F. Ulocladium botrytis
G. Ganoderma spp.
H. Aspergillus flavus 